\title{
Design and Synthesis of Antiviral Iminoribitol $C$-Nucleosides
}

\section{By \\ Li Ye}

A thesis submitted to the Victoria University of Wellington in fulfilment of the requirements for the degree of Master in Drug Discovery and Development

Victoria University of Wellington 


\section{Abstract}

Infections caused by RNA viruses, such as Ebola and Zika, continue to exist worldwide as significant public health problems. In response to the urgent need for safer and more efficacious treatment options to treat infections caused by RNA viruses, the pharmaceutical and biotechnology industries have devoted significant efforts over the last two decades to discovering and developing new antiviral agents. One such antiviral, Sofosbuvir ${ }^{\circledR}$, was approved by the US Federal Drug Administration (FDA) in 2014 and has revolutionized the treatment of Hepatitis-C. Sofosbuvir ${ }^{\circledR}$ was the second largest selling drug in the world in 2016 and in just twenty-one months Gilead reported sales worth \$26.6 billion USD.

The strategy of using nucleoside analogues to inhibit viral RNA dependent RNA polymerase (RdRp) has been pursued since the 1970s, and exemplified by the discovery and development of ribavirin. The natural substrates of RNA polymerases are nucleoside triphosphates and often the efficacy of nucleoside analogues as antivirals are dependent on their ability to be converted by the host or virus to mono-, di-, and ultimately tri-phosphate analogues which block the active site of RNA polymerase as an analogue of the substrate causing chain termination. Recently Biocryst Pharmaceuticals (Biocryst) described the anti-viral properties of Immucillin-A (Galidesivir), an iminoribitol based nucleoside analogue, which was found to have broad spectrum antiviral activity especially against RNA viruses including Ebola.

Researchers at the Ferrier Research Institute (Ferrier) have synthesized an analogue of Immucillin-A, 8-aza-Immucillin-A (AIA) which shows comparable activity to ImmucillinA, in anti-viral screens against Ebola, and this antiviral activity forms part of a US patent application. The Ferrier is keen to further exemplify this compound class through the synthesis of analogues of both Immucillin-A and AIA as well as improve the overall synthesis of the lead compound AIA.

Included as part of this study is the synthesis of pro-drugs of these iminoribitol based nucleoside analogues. Prodrugs are metabolized inside the body and are often 
converted to the corresponding pharmacologically active form. In general, prodrug strategies have improved the bioavailability and efficacy of many drugs. In particular, prodrugs strategies involving nucleoside analogue antivirals, which target RNA polymerase, have been particularly effective as they ensure conversion to the monophosphate in vivo. Conversion to the 5'-monophosphate form of a nucleoside analogue is the rate limiting step to the inhibition of the RNA polymerase - prior to its conversion to the triphosphate analogue. The prodrug is effectively a protected monophosphate, and is then readily converted to monophosphate by the host and then onto the di- and tri-phosphate by kinases in both the host and virus. ProTide prodrugs, such as Sofosbuvir ${ }^{\circledR}$ provide a verified strategy for improving anti-viral activity and hence our desire to synthesize pro-drugs of all our iminoribitol based nucleoside analogues.

This research thesis also involved repeating the known synthesis of the Immucillins, in particular, Immucillin-H (Forodesine), which requires in excess of 20 linear synthetic steps to make. The linear synthetic route to Immucillin- $\mathrm{H}$ was used instead of the more convenient convergent method developed by the Ferrier as several key synthetic intermediates in this progress were utilized in the attempted synthesis of some of the planned nucleoside analogues of AIA.

As part of this work the candidate learned aspects of scaling up chemical reactions and the critical analysis of both reaction hazards and reagent compatibilities at scale. Where possible and given the number of synthetic steps involved the candidate was also interested in improving the yields of the building blocks involved in the synthesis of the Immucillins with limited success.

Key words: Iminoribitol, Immucillins, prodrug, ProTides. 


\section{Acknowledgements}

I would like to thank Gary Evans and Peter Tyler, who supervised the project, and for the privilege of being able to work in Ferrier Research Institute.

I also wish to thank Keith Clinch, Lawrence Harries, Jennifer Mason, Yinrong Lu, Herbert Wong, Ralf Schwoerer and Farah Lamiable-Oulaidi for their instruction in experimental chemistry and data analysis.

Finally, I would like to thank the MDDD program director Simon Hinkley for this opportunity.

\section{Declaration and Copyright}

The Copyright of this thesis resides with the author. No quotation from it should be published without prior consent and information derived from it should be acknowledged.

The work in this thesis was completed by the author at Victoria university of Wellington, New Zealand. It has not been submitted, in part or in whole, for any higher degree at this or any other University. 


\section{Contents}

DESIGN AND SYNTHESIS OF ANTIVIRAL IMINORIBITOL C-NUCLEOSIDES .....................1

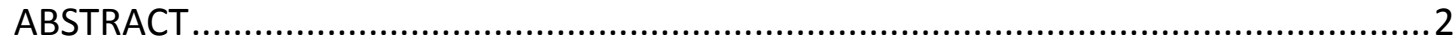

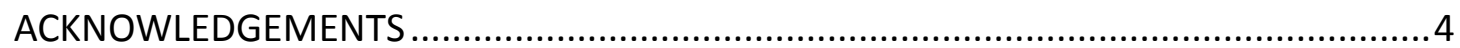

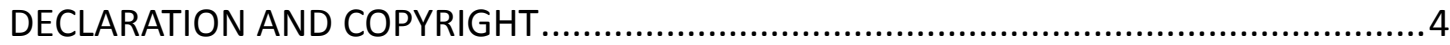

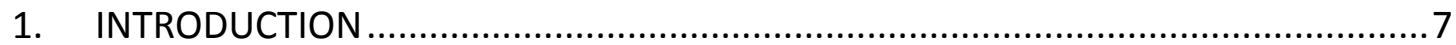

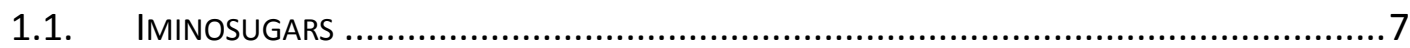

1.2. NUCLEOSIDE AND NUCLEOTIDE ANALOGUES AS ANTIVIRAL AGENTS..............................10

1.3. IMINOSUGAR BASED NUCLEOSIDES AND NUCLEOTIDES ANALOGUES ...........................11

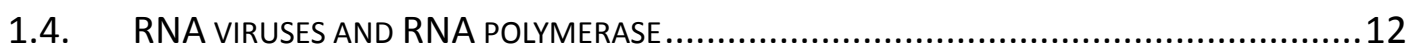

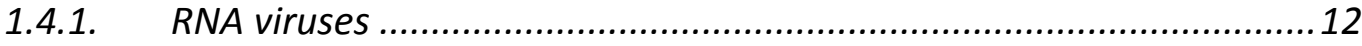

1.4.2. RNA virus replication and inhibition ............................................... 13

1.4.2.1. RNA virus Replication ...........................................................13

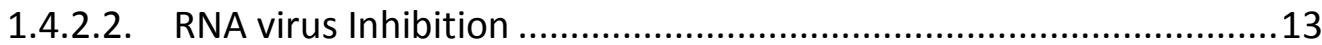

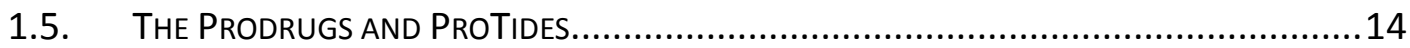

1.5.1. Examples of nucleoside prodrugs INX-08189..................................17

1.5.2. Examples of nucleoside prodrugs: Sofosbuvir ${ }^{\oplus}$ (Sovaldi ${ }^{\oplus}$ )....................18

1.5.3. Examples of nucleoside prodrugs: GS-5734 ...................................19

1.5.4. Examples of nucleoside prodrugs: GS-7340 (Tenofovir alafenamide)..19

1.5.5. Examples of nucleoside prodrugs: NUC-1031 (gemcitabine)..............20

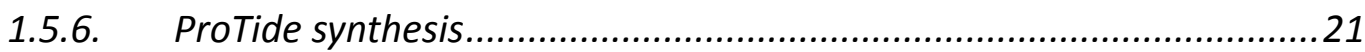

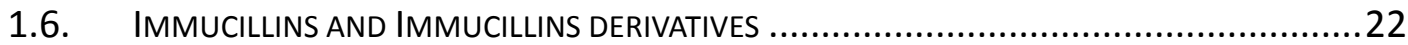

1.6.1. Immucillin-H (BCX1777 or Forodesine) ..........................................23

1.6.2. Immucillin-A (BCX4430 or Galidesivir) ...........................................24

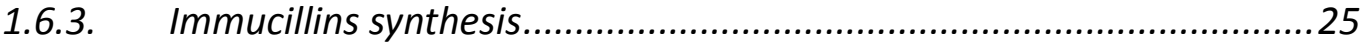

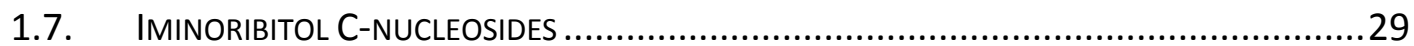

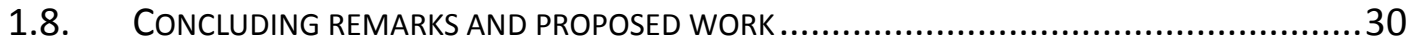




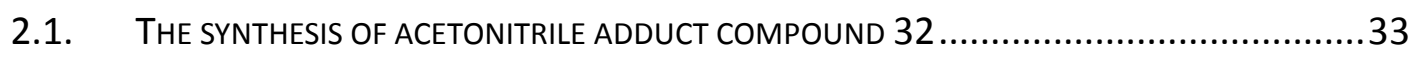

2.2. THE ATTEMPTED SYNTHESIS OF ISOTHIAZOLE-C-NUCLEOSIDES 33, 34.......................36

2.3. THE SYNTHESIS OF IMMUCILLIN-H COMPOUND 24 ............................................40

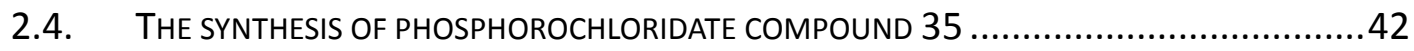

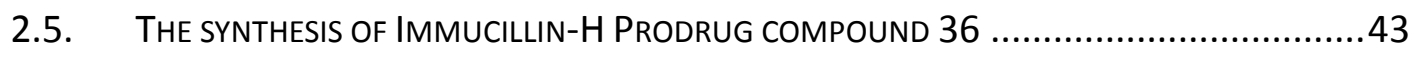

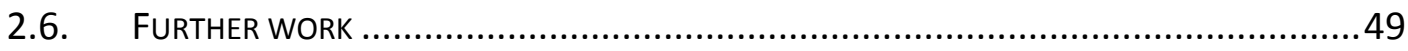

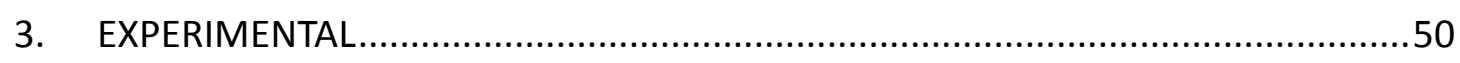

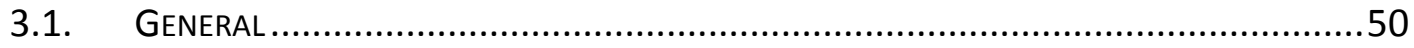

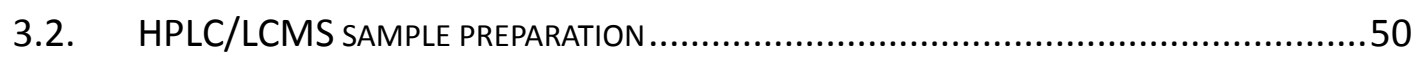

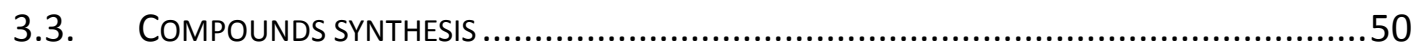

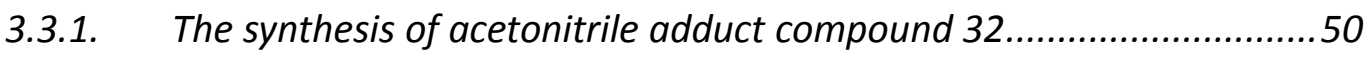

3.3.2. The attempted synthesis of isothiazole-N-nucleosides $33,34 \ldots \ldots . . . . .56$

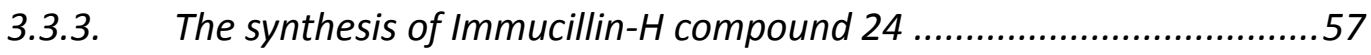

3.3.4. The synthesis of phosphorochloridate compound 35 .......................60

3.3.5. The synthesis of Immucillin-H Prodrug compound 36........................61

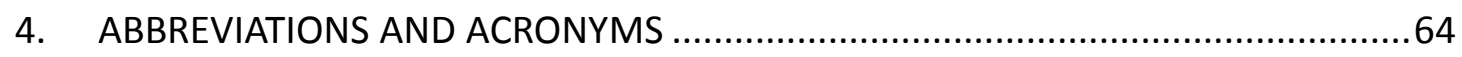

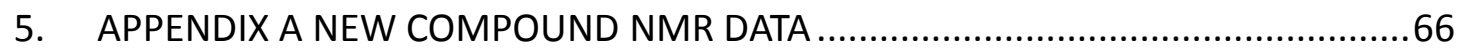

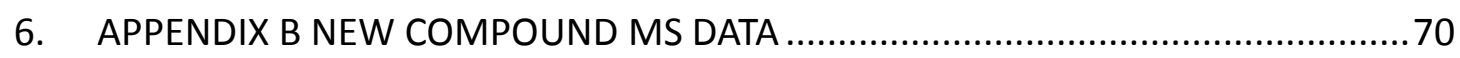

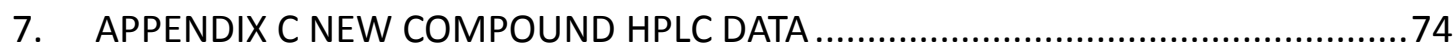

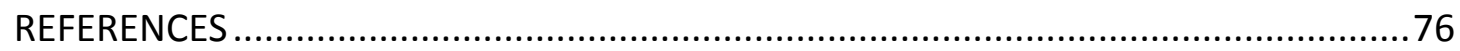




\section{Introduction}

\subsection{Iminosugars}

Iminosugars are sugar analogues where the endocyclic oxygen is replaced by nitrogen. This simple but significant substitution affords iminosugars with remarkable biological properties and provides chemists with many synthetic challenges. Therefore from both academic and pharmaceutical industry perspectives, iminosugars are an attractive class of molecules ${ }^{1}$. Our group in particular has been interested in the biological activities of these compounds where the ribose ring oxygen has been replaced by nitrogen, affording an iminosugar called an iminoribitol (Figure 1.1).

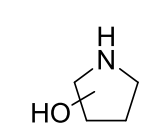<smiles>OC1CCNCC1</smiles><smiles>C1CCNCC1</smiles><smiles>OCC1NCC(O)C1O</smiles>

Pyrrolidine Piperidine Azepane Iminoribitol

Figure 1.1

The earliest therapeutic use of an iminosugar can be dated back to ancient times when the traditional Chinese phytomedicines, based upon the mulberry (Morus alba) whose leaves and roots were later found to contain significant quantities of iminosugar deoxynojirimycin (DNJ), were used as remedy (Figure 1.2). ${ }^{1}$ While in Europe the first medication that was produced on an industrial scale is thought to be Haarlem oil which was used as whitener of the skin and for the treatment of diabetes in $17^{\text {th }}$ century. A major component of Haarlem oil is also an extract of Morus alba leaves and hence contains DNJ. ${ }^{1}$ Structural elucidation of DNJ did not occur for another two hundred years and was preceded by its chemical synthesis. ${ }^{2-4}$<smiles>OCC1NCC(O)C(O)C1O</smiles>

deoxynojirimycin (DNJ)

Figure 1.2 
Iminosugar research has been growing rapidly since several groups of academics began to synthesize derivatives of sugars involving substitution of the ring oxygen with nitrogen, sulfur and phosphorus. ${ }^{5}$ Coincidently, the first synthesis of DNJ and the first isolation of nojirimycin from natural source, the bacteria Streptomyces, were published together in 1967 (Figure 1.3). ${ }^{3}$ Nojirimycin showed promise as a potential antibiotic agent. ${ }^{2}$ Meanwhile in 1976 DNJ was isolated by scientists working at Bayer AG from another natural source and showed it had promising biological activity acting as an $\alpha$-glucosidase inhibitor. ${ }^{2,5}$ This discovery turned out to be the beginning of a period of significant growth in iminosugar research and led to the synthesis of many iminosugar based analogues of carbohydrates. ${ }^{6}$ However, difficulty in developing synthetic approaches to iminosugars coupled with challenges around the isolation of iminosugars from natural sources meant that that there was little impact from this research during the 1980 s. $^{1}$

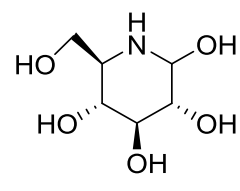

Nojirimycin

Figure 1.3

Nevertheless, since the 1990s, particularly after 2000, the tide in iminosugar research has turned. This change can be attributed to two important aspects. The first aspect is the development of innovative synthetic methodologies and strategies which allow the successful synthesis of rationally designed iminosugars even for extended seven membered ring systems (Figure 1.4). ${ }^{7}$ The second aspect, which seems more important, is the bioactivity of these compounds coupled with the progress in the fields of biology and glycobiology. It has been demonstrated that iminosugars and their derivatives are inhibitors of a series of enzymes which are considered to be druggable targets and therefore offer promise as drugs for the treatment of variety of diseases. For example, glycosyltransferases which are enzymes that control the formation of glycosidic linkages in nature, together with nucleoside processing enzymes, glycogen phosphorylases, sugar nucleotide mutases and 
metalloproteinases, are all potential biological targets and all of which are important in a range of natural processes. ${ }^{8}$

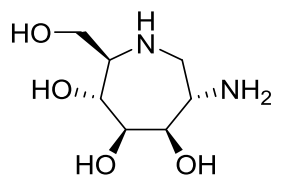

azepane iminosugar

Figure 1.4

One outstanding achievement was the understanding that the folding state of abnormal glycosidases could be positively influenced by reversible competitive inhibitors. Therefore, glycosidase inhibitors could be used to prevent their destruction during the quality control process in the endoplasmic reticulum (ER). This new principle, known as chemical chaperone therapy, has been studied with a DNJ analogue for use in the treatment of Fabry disease and in 2003 the first ER therapy was approved by the FDA. ${ }^{9-10}$

Another remarkable example of the therapeutic potential of iminosugars is the rational design of a series of powerful inhibitors, transition state analogues, of nucleoside processing enzymes through transition state analysis. The making and breaking of chemical bonds during every reaction in chemistry and biology passes through a transition state, which can be thought of as the moment at which a bond decides if it will break or reform. Transition state analogues mimic the structure of the enzyme substrate/product at the transition state leading to bioactive compounds that bind incredibly tightly to the target enzyme. A series of iminosugar $C$-nucleosides have been designed by Vern Schramm and his collaborators at the Ferrier to be transitionstate analogues and inhibit their target enzymes in the pico- to femto-molar range. ${ }^{11-}$ 12

Due to the wide range of enzymes inhibited by iminosugars, this class of carbohydrate mimic has made a significant impact on many different diseases, for instance diabetes, viral diseases, lysosomal diseases and cystic fibrosis etc. ${ }^{13}$ Furthermore, iminosugarbased drugs such as Glyset ${ }^{\mathrm{TM}}$ and Zavesca ${ }^{\mathrm{TM}}$ have progressed all the way to the market (Figure 1.5). ${ }^{1}$ 
<smiles>OCCN1CC(O)C(O)[C@H](O)C1CO</smiles>

Glyset $^{\mathrm{TM}}$<smiles>CCCCN1CC(O)C(O)[C@H](O)C1CO</smiles>

Zavesca $^{\mathrm{TM}}$

Figure 1.5

\subsection{Nucleoside and nucleotide analogues as antiviral agents}

Nucleotides consist of a nucleoside and at least one phosphate group. Nucleotides are the subunits, or building blocks of the nucleic acids DNA and RNA which comprise the genetic material of all living organisms including viruses (Figure 1.6).

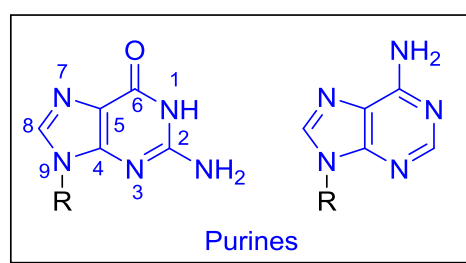

Purines

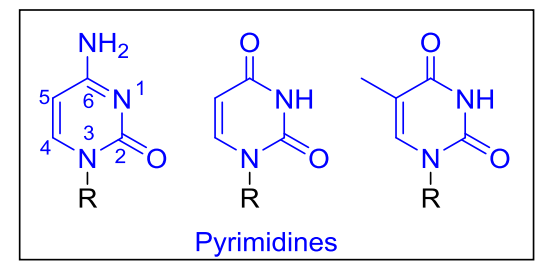

Base

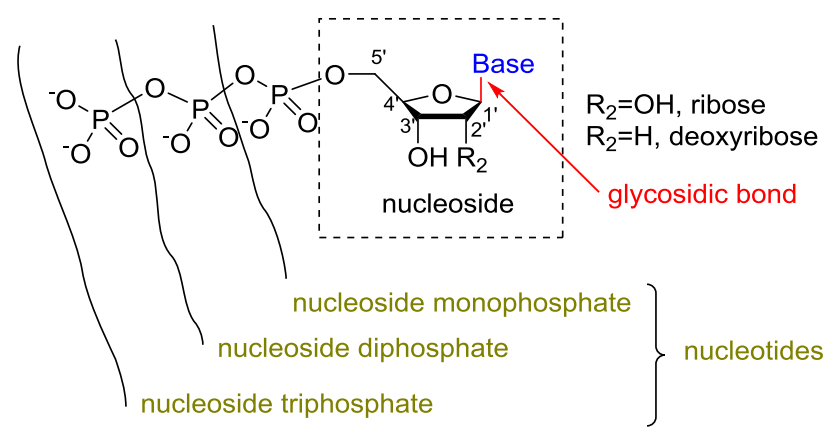

Figure 1.6

Nucleoside and nucleotide analogues are chemically modified compounds that have been designed to mimic their counterparts in physiology. The study of using nucleosides or nucleotides analogues as potential antiviral drugs began as early in the 1970s. ${ }^{14}$ Nowadays they account for more than half the drugs used against viral infections. ${ }^{15}$ Moreover, nucleoside and nucleotide analogues have become an important component of the treatment of certain cancers. During the last decade, 
several drugs of this compound class have been approved by the FDA as both antiviral and anticancer drugs demonstrating the potential of these compounds. ${ }^{16}$

Currently, over 25 approved nucleoside and nucleotide analogues are used as antiviral agents for the treatment of HIV and hepatitis etc. ${ }^{16}$ MK0608 is one example of this class of drugs (Figure 1.7) and is an analogue of adenosine that exhibits potent binding ability to Hepatitis C virus (HCV) NS5B protein active site. It is believed that the carbon at the C7-position greatly improves its specificity and reduces deamination by adenosine deaminases. ${ }^{17}$

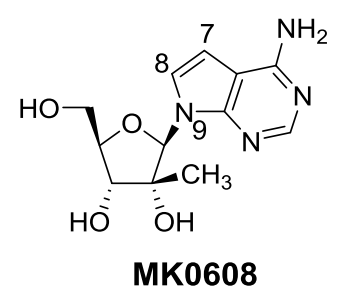

Figure 1.7

\subsection{Iminosugar based nucleosides and nucleotides analogues}

Iminosugar based nucleosides and nucleotides analogues are comprised of members that possess generic structural features. One common feature is a $C$-glycosidic bond and the nitrogen in the ring system (instead of oxygen), therefore they are iminosugar based nucleoside analogues (Figure 1.8). Compared to numerous literatures reports on nucleoside analogues, in general, very little attention has been paid to these iminosugar based compounds. In fact, few compounds were reported before 2000 even though there had been flourishing growth in the field of iminosugars and nucleoside analogues, separately. ${ }^{18}$ Recently the discovery of bioactivity of the iminoribitol- $C$-nucleosides, known colloquially as the "Immucillins", has triggered a new round of assessment concerning the value of iminosugar based nucleosides and nucleotides as potential therapeutics and in particular as antivirals. ${ }^{19}$ 


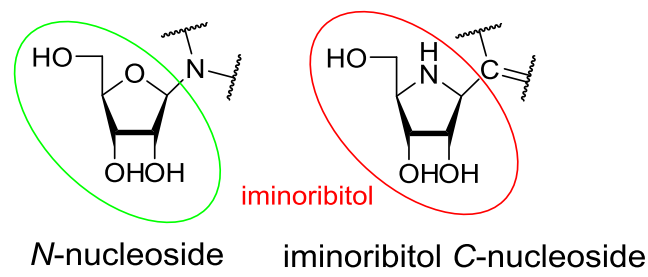

Figure 1.8

\subsection{RNA viruses and RNA polymerase}

\subsubsection{RNA viruses}

An RNA virus is a virus that has RNA as its genetic material. RNA viruses remain a constant threat to global health, with new infections from Human Immunodeficiency Virus (HIV), Hepatitis B (HBV) and HCV killing more than 3 million people annually. ${ }^{20}$ $\mathrm{HCV}$ is an RNA virus from Flaviviridae family that affects approximately 200 million people around the world. The flavivirus that cause Dengue fever infects up to 100 million people each year, leading to 20,000 deaths per year. ${ }^{21}$ Recently, outbreaks of hemorrhagic fever caused by the Ebola virus (EBOV) and birth defects caused by Zika virus (ZIKV) have again reminded us how vulnerable our society is to viral infections. The recent EBOV outbreak began around the end of 2013 and reached a peak in 2014. The transmittance of EBOV viral infections occurred across borders and oceans by infected travelers. After more than two years, in June 2016, the World Health Organization (WHO) finally announced the end of the latest outbreak of EBOV in Africa. ${ }^{22}$ EBOV has claimed the lives of thousands of people within the last three years, yet while the epidemic is currently under control, there remains no effective vaccine or small molecule drug treatment available..$^{23}$ 


\subsubsection{RNA virus replication and inhibition}

\subsubsection{RNA virus Replication}

Even though large amounts of money and effort have been invested in the development of new antiviral drugs, health problems caused by RNA viruses remain serious. The replication of RNA viruses relies on RNA-dependent RNA polymerase (RdRp) and this protein is a validated druggable target. As the primary biological targets in the battle against viral infections, the structural biology and biochemistry of RdRps from a variety of viruses including HCV, EBOV, and ZIKV have been extensively studied. ${ }^{15}$

RdRps synthesize RNA using RNA precursors together with other related proteins encoded by the virus or host. Compared to DNA replication, the RNA replication directed by RdRps usually exhibits a high error frequency due to low fidelity and a lack of repair mechanisms. This lack of fidelity means that once nucleoside analogues are phosphorylated to their 5'-triphosphates, by a combination of host and viral kinases, they then inhibit the viral RNA polymerase through obligate or non-obligate RNA chain termination. RdRps usually have high overall sequence homology across a variety of viruses so broad spectrum antiviral activity for some nucleoside analogues is observed. As stated above, more and more information on the structure and function of a variety of viral RdRps are becoming available. Therefore, as viruses become resistant to existing antivirals coupled with the emergence of new viral threats to the world due to climate change, this information offers biologists and chemists opportunities to rationally design inhibitors of RdRps and discover new antiviral drug leads. ${ }^{15}$

\subsubsection{RNA virus Inhibition}

It was found that the incorporation of nucleoside and nucleotide analogues into RNA would result in either the termination of chain elongation, the accumulation of mutations or apoptosis. Generally, the absence of the 3'-hydroxyl group on the ribose 
moiety of nucleoside and nucleotide analogues impeded the formation of $3^{\prime}, 5^{\prime}$ phosphodiester bonds between the analogues and the incoming $5^{\prime}$-nucleoside triphosphates, leading to an early termination of the growing viral RNA chain. However, chain termination was also found with compounds which possessed the 3'-hydroxyl group which needed further investigation. ${ }^{16}$

Therefore, nucleoside and nucleotide analogues need to compete with physiological nucleotides during the initiation and extension of DNA and RNA chains mediated by cellular or viral polymerases. The success in incorporation of the analogues depends on the affinity of polymerases to nucleotides. Due to the weaker specificity for nucleotides, viral RNA polymerases (compared to DNA polymerases) are therefore more likely to incorporate analogues. ${ }^{16}$ Additionally, chain termination could also occur during RdRps synthesis in viruses that have reverse transcription steps. ${ }^{24}$

The natural substrate of RdRps are RNA triphosphates, thus nucleoside and nucleotide analogues must be converted to their corresponding triphosphates to incorporate into RNA to inhibit viral replication. To achieve this, we rely on the kinases of both the host and virus, and prodrug strategies which were developed by medicinal chemists. The outcome of all this research is that a number of nucleoside analogue inhibitors of viral RdRps have been discovered. ${ }^{15}$

\subsection{The Prodrugs and ProTides}

A "prodrug" is a compound which is metabolized into a pharmacologically active drug in the body. The corresponding prodrug is administered to improve absorption, distribution, metabolism and excretion. Prodrug strategies have been used to enhance the clinical efficacy of various drug molecules. ${ }^{25}$

The idea of employing nucleoside analogues as potential antiviral agents has been pursued since the 1960s. As stated above the bioactivity of these analogues relies on the formation of corresponding nucleoside di- or tri- phosphates. This usually is achieved by a stepwise addition of phosphate assisted by cellular kinases. ${ }^{26}$ Nucleoside di- or tri- phosphates themselves cannot be used as drugs due to their poor stability 
and high polarity which makes it difficult for them to cross the cell membranes. On the other hand, the activation process of nucleoside analogues is often held back in the first phosphorylation step. Therefore, to circumvent this rate limiting step and increase bioavailability, these drugs are often prepared as prodrugs in a stable monophosphate form. ${ }^{27}$ Additionally, to deliver the drugs intracellularly, these prodrugs are designed to be capable of crossing the biological membranes thereby successfully reaching target tissues.

Currently a few prodrug strategies are available to deliver these prodrugs intracellularly based on the development of monophosphorylation methods and protecting groups. In the first instance we intended to explore the application of the aryloxyphosphoramidate protides strategy to the immucillins. ${ }^{28}$ Chris McGuigan's "ProTide" technology is one of the most applied phosphate prodrug approaches used by researchers and industry. It has emerged as a practical strategy in the discovery of nucleotide therapeutics. The idea of ProTide is masking the nucleoside phosphate or phosphonate groups with (i) an aryl motif and (ii) an amino acid ester (Scheme 1.1). Structurally these prodrugs contain one phosphorus atom bearing an aryloxy and an amino acid alkyl ester group. Their mode of action (MOA) includes a stepwise process of ester hydrolysis of the amino acid moiety, spontaneous cyclization, hydrolysis and the action of an intracellular phosphoramidase to free the nucleoside monophosphate. ${ }^{29}$ During the development of the ProTide technology, one oxygen of 5'-O-monophosphate groups of therapeutic nucleosides was substituted by simple dialkyl and haloalkyl groups. Nevertheless, biological activity was not improved. After a few attempts at optimizing the substituents McGuigan and co-workers found that Lalanine was a superior amino acid in the alkyloxy phosphoramidates. Meanwhile diaryl phosphates were also found to be highly active. Therefore, a combination of amino acid ester (particularly L-alanine), an aryl group and nucleosides analogues generated the potent aryloxy tri-ester phosphoramidates. The mechanism of revealing the nucleoside monophosphate from the ProTide protecting groups is considered to initially occur through the action of two enzymes, namely an esterase and 
phosphoramidase (Scheme 1.1).

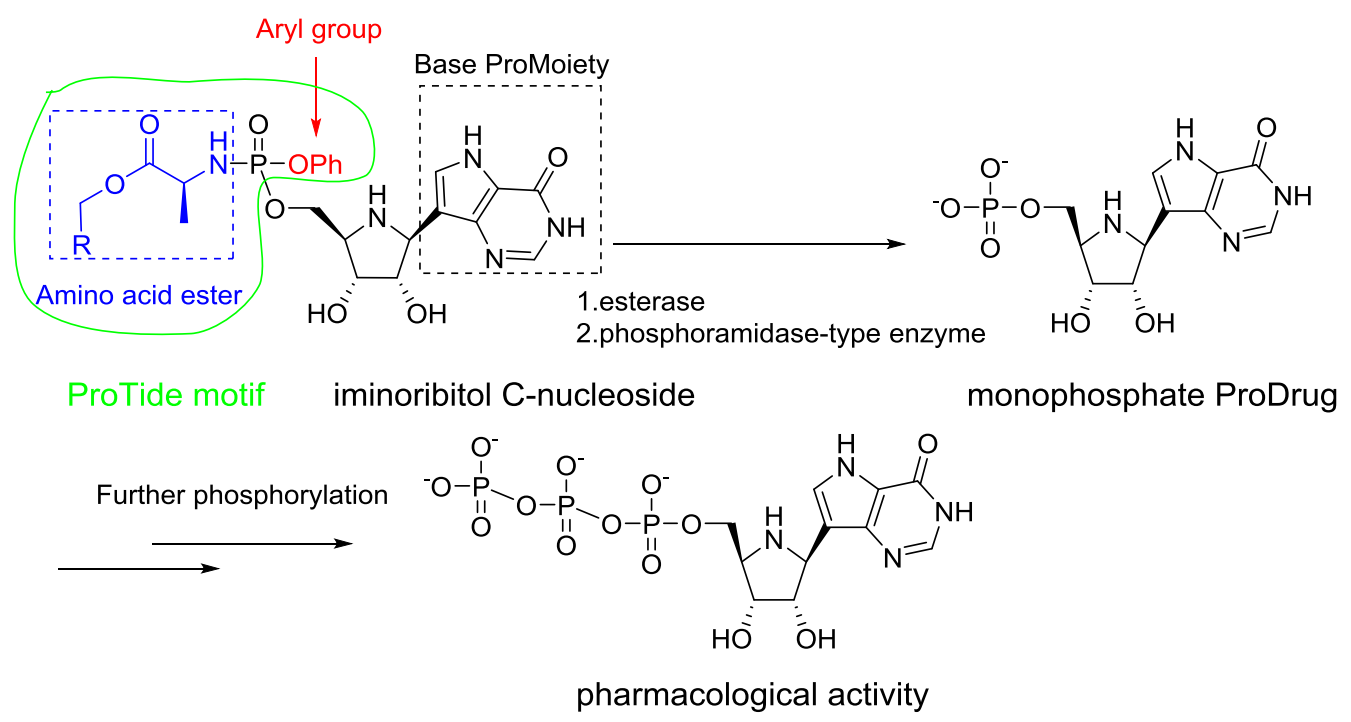

Scheme 1.1

The nucleoside monophosphate is then promptly converted to the active di- and then tri- phosphate which mimics the natural substrate of the viral RdRp (Scheme 1.1). ${ }^{27}$ To sum up, these phosphate moieties have been chosen because:

- Firstly, they are easy to prepare and mature methods are accessible. (Generally speaking, there are three different methods which can be used to prepare them. Coupling the nucleoside with a phosphorochloridate reagent could be the primary option ${ }^{30-31}$ while other methods developed by Li et $a^{32}$ and Nillroth et $a^{33}$ are also under consideration).

- Secondly, they can increase or reveal the bioactivity of nucleosides analogues ${ }^{27}$.

- Thirdly, the proof-of-principle demonstration of Sofosbuvir ${ }^{\circledR}$ in humans has opened the door for the development of a series of aryloxyphosphoramidate prodrugs. ${ }^{27}$ (for instance, GS-7340 and GS-9131 which are both prodrugs for the treatment of HIV and are now in phase III and phase II separately ${ }^{34}$. Thymectacin for colon cancer treatment is now in phase $\mathrm{I} / \mathrm{II}^{35}$. These kinds of prodrugs have promising bioactivity with a great chance of being suitable agents).

- Finally, as they can be conveniently prepared by chemical synthesis, they are also suitable for biological evaluation in vitro. ${ }^{36}$

One potential disadvantage of this type of phosphate moiety is that apart from the Page 16 of 83 
variable yields involved in their synthesis, the phosphorus atom provides chiral centre which results in a mixture of diastereomers usually being formed. Furthermore, these diastereomers are often inseparable by flash chromatography. This can be a serious problem as the diastereomers may have different biological activities. This, however, can be mitigated by (a) diastereoselective approach through asymmetric synthesis using chiral auxiliary designed by Román et $a^{37}$ (b) HPLC or selective crystallization to separate the products, neither of which were investigated as part of this thesis. ${ }^{27}$

\subsubsection{Examples of nucleoside prodrugs INX-08189}

INX-08189 was designed and synthesized by the McGuigan research group (Figure 1.9). It exhibits $10 \mathrm{nM}$ potency in the HCV genotype $1 \mathrm{~b}$ subgenomic replicon which is 500 times more potent than the parent nucleoside. It should be noted that the potency of the lead compound INX-08189 was proportional to the intracellular 2'-C-methyl guanosine triphosphate levels in primary human hepatocytes. ${ }^{38}$ This result echoes the mechanism illustrated in Scheme 1.1. Additionally, the separated diastereomers of INX-08189 were similar in terms of biological activity in the replicon assay and enzyme processing. INX-08189 has passed the investigational new drug application stage and progressed onto clinical trials for the treatment of chronic HCV infections. ${ }^{38}$ Due to the outstanding pharmacokinetic and pharmacodynamic profiles coupled with successful early clinical outcomes, INX-08189 was acquired by Bristol-Myers Squibb (BMS). Unfortunately, cardiotoxicity issues arose in phase 3 clinical trials and the clinical studies were suspended. ${ }^{39}$ It can be seen that the ProTide technique is critical in accelerating the development of nucleoside therapeutics in general. As a matter of interest at the initial development stage, it is not always necessary to isolate each diastereomer and they can be progressed together as mixture. 


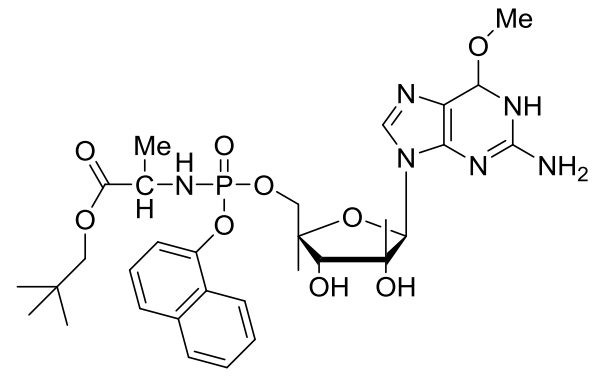

INX-08189

Figure 1.9

\subsubsection{Examples of nucleoside prodrugs: Sofosbuvir ${ }^{\circledR}$ (Sovaldi ${ }^{\circledR}$ )}

Another outstanding example of a drug utilizing the ProTide strategy is antiviral agent Sofosbuvir ${ }^{\circledast}$. The previous "standard of care" treatment regime for HCV lasted up to one year and involved the combined administration of interferon and ribavirin. Ribavirin is a nucleoside analogue resembling adenosine or guanosine which blocks HCV RdRp and halts viral replication of HCV or RNA viruses in general (Figure 1.10). However over time, problems have arisen such as poor efficacy against certain HCV genotypes, long periods of time required for treatment, and serious side effects. Consequently, new therapies for the treatment of HCV had been sought by doctors especially for those patients who cannot endure current therapeutic regimes. ${ }^{15}$ Sofosbuvir ${ }^{\circledR}$ has revolutionized $\mathrm{HCV}$ treatment only requiring a relatively short treatment period of 8-12 weeks, against all HCV genotypes and with few adverse side effect. Furthermore, it has exhibited low resistance development during treatment. ${ }^{40}$ From the point of view of a medicinal chemist, it is a uracil derivative and thus in terms of its mechanism, it is consistent with Sofosbuvir ${ }^{\circledR}$ being a RdRp inhibitor (Figure 1.10). ${ }^{14}$ In 2013, Sofosbuvir ${ }^{\circledR}$ was approved by the FDA as a component of combination antiviral treatment regimen in the treatment for chronic HCV infection and after just twenty-one months Gilead reported sales worth \$26.6 billion USD. ${ }^{41-42}$ 


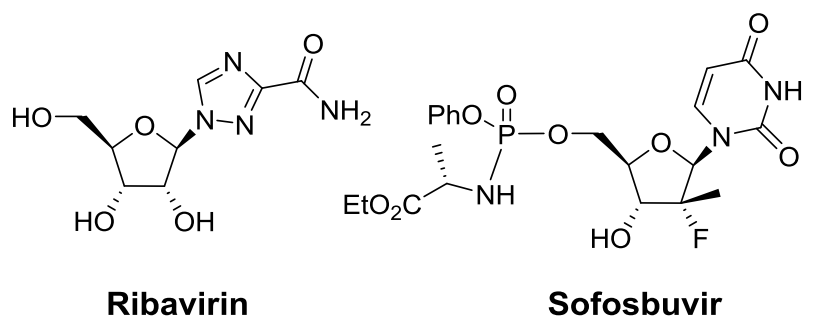

Figure 1.10

\subsubsection{Examples of nucleoside prodrugs: GS-5734}

GS-5734 is a C-nucleoside ProTide which is currently undergoing phase 1 clinical trials for the treatment of EBOV (Figure 1.11). It exhibits antiviral activity against EBOV and other filoviruses in cell-based assays. It was observed that the pharmacologically active nucleoside triphosphate was formed in multiple human cell types when incubated with GS-5743 in vitro. Moreover, intravenous administration of GS-5734 in nonhuman primate models resulted in outstanding suppression of EBOV replication and protected $100 \%$ of EBOV-infected animals against lethal diseases. This ProTide based prodrug also showed potential as an inhibitor of broad spectrum pathogenic RNA viruses including filoviruses during the initial assay. ${ }^{43}$

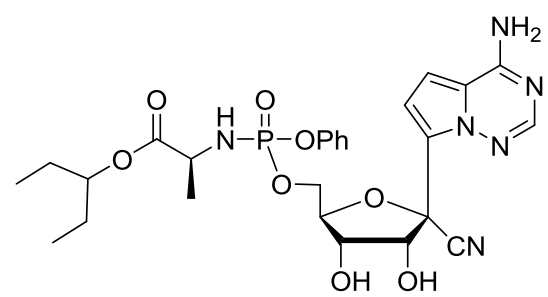

GS-5734

Figure 1.11

\subsubsection{Examples of nucleoside prodrugs: GS-7340 (Tenofovir alafenamide)}

GS-7340 (trade name Vemlidy) is a ProTide prodrug analogue of tenofovir disoproxil which is an orally available prodrug of tenofovir (Figure 1.12). and is an acyclic nucleoside analogue of adenosine. Tenofovir disoproxil is a medication used in the 
treatment of chronic HBV infections and the prevention of HIV. GS-7340 exhibits improved anti-HIV activity than tenofovir disoproxil. Remarkably, compared to tenofovir and tenofovir disoproxil, GS-7340 generated up to 30-fold higher levels of tenofovir and its phosphorylated metabolites in vivo. GS-7340 is more potent than the FDA approved tenofovir disoproxil (trade name Viread) and in the phase III clinical studies, it exhibited better therapeutic effects, lower doses requirement and fewer incidences of side effects. It was approved for the treatment of HIV-1 infection by the US FDA in 2015 (in combination with other agents). It should be noted that the (L)alaninyl analog (GS 7340) was 1,000-fold more active than the (D)-alaninyl analog. Moreover, the spatial configuration at the phosphorous is also critical to the anti-viral activity and metabolic stability. ${ }^{44}$

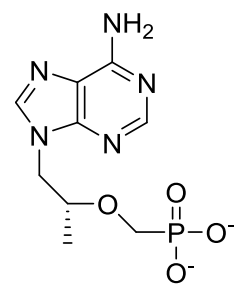

Tenofovir

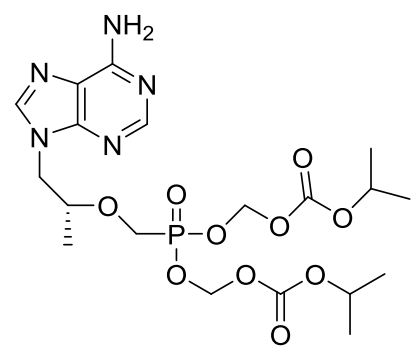

Tenofovir disoproxil

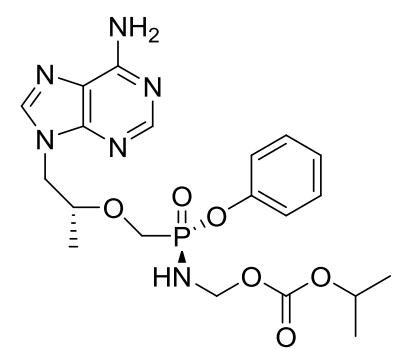

GS-7340

Figure 1.12

\subsubsection{Examples of nucleoside prodrugs: NUC-1031 (gemcitabine)}

Gemcitabine is a nucleoside analogue used in cancer treatment (Figure 1.13). It has become the standard care for the treatment of pancreatic cancers after FDA approval in 1996. However, its efficacy is limited due to cancer cell resistance. It was found that the phosphoramidate motif can protect it from many key cancer resistance mechanisms. Thus, a series of gemcitabine phosphoramidate prodrugs have been synthesized and tested including NUC-1031. Currently NUC-1031 is being developed by NuCana Biomed Ltd. (Gemzar ${ }^{\mathrm{TM}}$ ) and has progressed to phase I/II clinical trials. This 
compound circumvents resistance mechanisms and exhibits great efficacy against a broad range of cancers. Meanwhile NUC-1031 is well tolerated by patients. The current clinical studies are promising. ${ }^{45}$

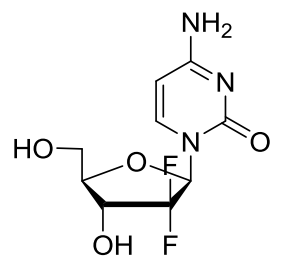

Gemcitabine

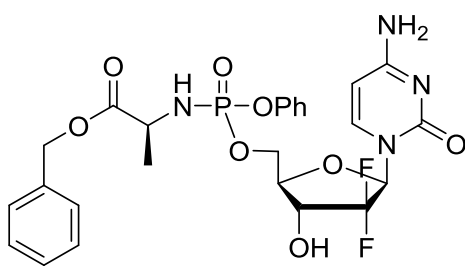

NUC-1031

Figure 1.13

\subsubsection{ProTide synthesis}

The synthesis of Protides is largely based on phosphorochloridate chemistry which generally require (i) a regioselectively protected nucleoside or nucleoside analogue $\mathbf{2}$, in our case an iminoribitol-C-nucleosides such as 8-aza-Immucillin-A, and (ii) an aryl aminoacyl phosphorochloridate $\mathbf{1}$ such as ethyl (chloro(phenoxy)phosphoryl)-Lalaninate (Figure 1.14).

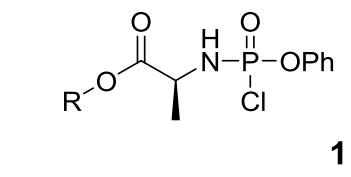

Aryl aminoacyl phosphorochloridate

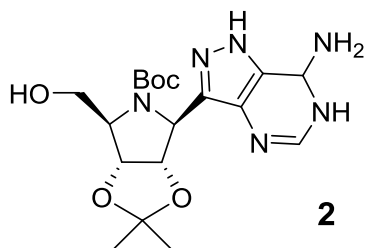

Regioselectively protected nucleoside analogues

Figure 1.14

The chlorophosphamidate 1 is the key reagent in ProTide synthesis. It can be prepared using two reagents (i) an amino acid ester $\mathbf{5}$ and (ii) an aryl phosphorodichloridate 6 which is usually commercially available (Scheme 1.2). 


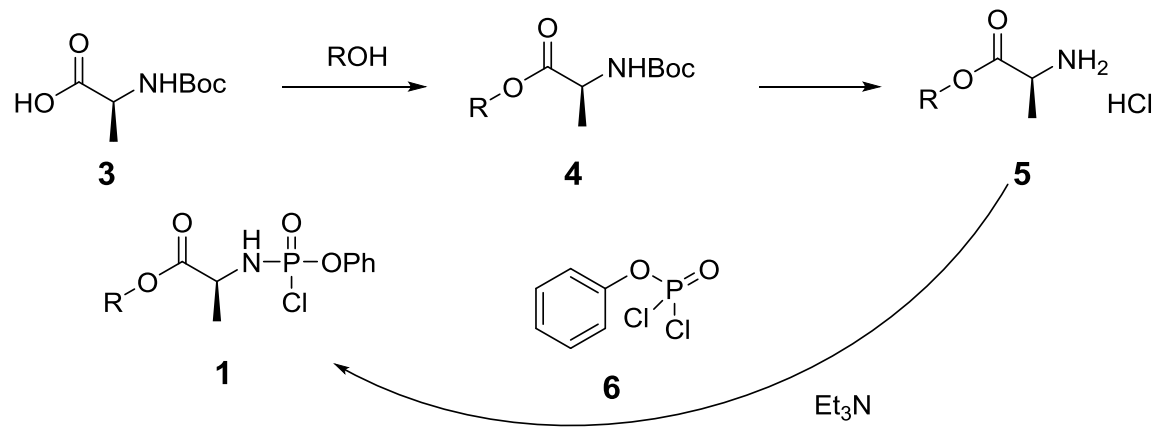

Scheme 1.2

Where amino acid ester $\mathbf{5}$ is not commercially available, it can be made by esterification using an appropriate amino acid via the methods described by Greene et $a{ }^{4}{ }^{46}$

Amino acid ester 1 (aryl aminoacyl phosphorochloridates) can be obtained by reaction of 5 and 6 in the presence of $E t_{3} N$ as illustrated in Scheme 1.2. The phosphorus is a chiral centre because of the 4 different substituents on it that results in a pair of diastereomers in about 1:1 ratio although the ratio may vary. Generally, amino acid ester 1 synthesis would be completed within a few hours and could be used immediately after a quick purification by silica gel flash chromatography. ProTides bearing the L-alanine residue are usually superior and the R group (ester moiety) can be altered between (i) branched groups such as isopropyl, neopentyl and 3methylpentane (ii) cyclic groups such as cyclopentyl (iii) aromatic groups such as benzyl..$^{45}$

The chlorophosphoramidate reagent $\mathbf{1}$ is reacted with $\mathbf{2}$ in the presence of either an amine base ( $\mathrm{N}$-methylimidazole method) or organometallic reagents (tertButylmagnesium chloride method) in either dry THF or DCM under argon. ${ }^{45,47}$

\subsection{Immucillins and Immucillins derivatives}

Immucillin-H (Forodesine) and Immucillin-A (Galidesivir) are both in human clinical trials and are potent inhibitors of purine nucleoside phosphorylase (PNP) and RdRp, respectively. ${ }^{48-49}$ Therefore, Immucillin-A has been found to exhibit potent broad 
spectrum antiviral activity against a range of RNA viruses including Marburg virus (MARV), EBOV, and ZIKV. ${ }^{50-51}$ Other compounds that have similar structures to Immucillin-A have been claimed to have antiviral activity and therefore might be potentially used as antiviral agents, including Immucillin-H. ${ }^{52}$ To-date, however, no data indicating any antiviral activity for these compounds has Been revealed. Small changes in structure can dramatically affect the antiviral activity of nucleoside and nucleotide analogues. Therefore coupling with the need for new antiviral drugs, these compounds and others that are structurally similar to Immucillin-A and Immucillin-H are worth further investigation as potential antivirals.

\subsubsection{Immucillin-H (BCX1777 or Forodesine)}

Immucillin-H (also known as BCX1777 and Forodesine) is an iminoribitol-C-nucleoside that is an effective inhibitor of purine nucleoside phosphorylase (PNP) and nucleoside hydrolase enzymes (Figure 1.15). ${ }^{53}$ Mutation of the genes responsible for the expression of PNP leads to a loss of T-cell function, therefore inhibition of PNP might be useful in combatting many diseases where the malfunction of a T-cell response results in a disease state, as in T-cell leukaemias and lymphomas, psoriasis and arthritis. ${ }^{54}$ Immucillin-H was first synthesized in 1998 by Tyler et al via a 23-step linear synthesis. ${ }^{55}$ Immucillin-H was licensed to Biocryst by the Albert Einstein College of Medicine and what is now the Ferrier Research Institute. Immucillin-H has progressed to clinical trials for the treatment of certain types of leukaemia and lymphoma under the tradename Forodesine and will be approved for use for the treatment of peripheral T-Cell lymphoma in Japan later in $2017 .^{56-57}$

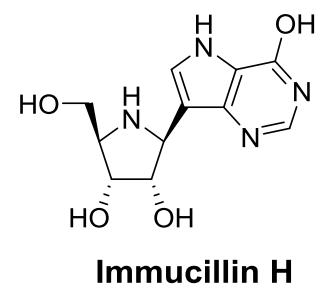

Figure 1.15 


\subsubsection{Immucillin-A (BCX4430 or Galidesivir)}

With EBOV having been identified as a high-priority target by the WHO. Research funded by the US National Institute for Allergy and Infectious Diseases (NIAID) has screened many compounds (mainly small molecules) against EBOV. However only a few of those candidate compounds have shown potential as therapeutics. ${ }^{58}$ Remarkably, among these candidates an iminoribitol C-nucleoside analogue BCX4430 (Figure 1.16), also known as Immucillin-A or Galidesivir, showed broad spectrum antiviral activity against a range of viruses including EBOV and ZIKV. ${ }^{59-60}$

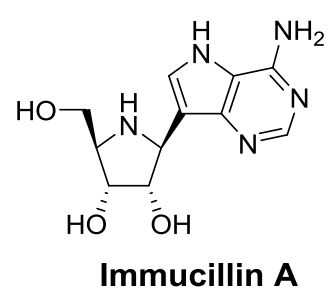

Figure 1.16

Immucillin-A was originally synthesized as an inhibitor of nucleoside hydrolase enzymes which are critical to the function of many protozoa. ${ }^{48-49}$ However, due to the promiscuity of RNA polymerases, it has proven to be a useful lead compound for the design of further iminoribitol based inhibitors of RdRp which is described as part of this thesis (vide infra). The first synthesis of Immucillin-A was by Tyler et al via a 23step linear synthesis and it was licensed to Biocryst in $2013 .{ }^{61}$

Immucillin-A showed activity against MARV, ZIKV and EBOV in non-human primate models. Prompted by BioCryst and the US Army Medical Research Institute of Infectious Disease, Immucillin-A was progressed, as potential treatment for EBOV, and has successfully completed Phase I human clinical trials showing it was well tolerated and safe. ${ }^{62}$ The antiviral activity of Immucillin-A was reported by Nature in 2014 and indicated that, as an adenosine analogue, Immucillin-A was metabolized into its $5^{\prime}$ triphosphate form at which point it became an active metabolite for incorporation by RNA polymerase. Following pyrophosphate cleavage, Immucillin-A monophosphate form was incorporated into viral RNA strands effectively inhibiting Hepatitis C RNA 
polymerase by non-obligate RNA chain termination, thus reducing the replication of the RNA virus. Moreover, the Nature publication also confirmed that the nucleotide form of this drug had a very high selectivity for viral RNA polymerases and was not incorporated into human RNA and DNA. 59

The recent research of Immucillin-A against ZIKV in cell culture and mouse model demonstrated the efficacy of Immucillin-A in a lethal ZIKV infection, protecting the mouse from ZIKV-associated mortality. ${ }^{63}$

Consequently, analogues of Immucillin-A are potentially valuable lead compounds for the discovery of new broad spectrum, non-toxic antivirals. Recently, the Ferrier Research Institute has begun writing a patent application describing the structure and associated antiviral activity of AIA, an analogue of Immucillin-A, where the carbon at 8-position has been replaced by a nitrogen (Figure 1.17). AIA exhibited potent antiviral activity against EBOV and Marburg virus (MARV) in screening by the US NIAID (unpublished). Based on this result the Ferrier will look to exemplify patent claims for a variety of other analogues of Immucillin-A. The proposed target inhibitors may be useful for treating a broad range of RNA viruses including flavivirus, EBOV, ZIKV, influenza, HCV, HBV and severe acute respiratory syndrome (SARS) etc and will further exemplify the Ferrier Research Institute patent application.

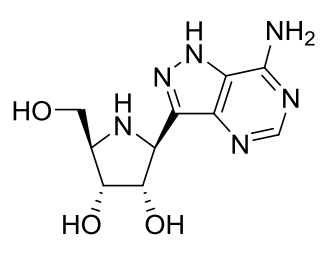

\section{8-aza-Immucillin A}

Figure 1.17

It was also planned to prepare the prodrug of each iminoribitol-C-nucleoside analogues, Immucillin-H, A and G.

\subsubsection{Immucillins synthesis}

As a key starting material for the preparation of the Immucillins, the iminoribitol moiety 14 was originally synthesized using a method developed in part by Fleet et al Page 25 of 83 
and adapted by Horenstein and Schramm from the readily available sugar lactone Dgulonolactone 7 (Scheme 1.3). ${ }^{64-65}$ Gulonolactone 7 was firstly treated with acetone and dimethoxypropane to afford the fully protected lactone 8 which can be reduced to the diol 9 in excellent yield (96\%). Esterification of the diol afforded the mesylate ester 10. Subsequent treatment of $\mathbf{1 0}$ with benzylamine underwent a cyclization to give the protected hexose analogue $\mathbf{1 1}$. Hydrolysis of $\mathbf{1 1}$ with $80 \%$ aqueous acetic acid resulted in selective hydrolysis of the acetonide to give the diol $\mathbf{1 2}$. Periodate oxidiation followed by reduction of the resulting aldehyde $\left(\mathrm{NaBH}_{4}\right)$ afforded the iminoribitol derivative (13) in good yield (71\%).

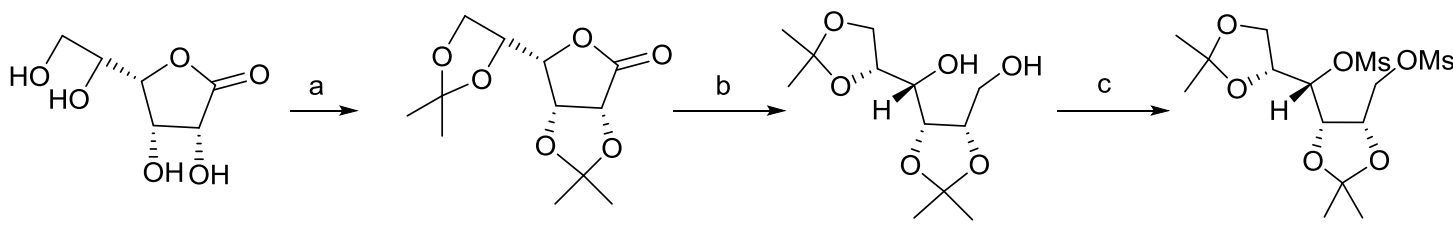

7

8

9

10

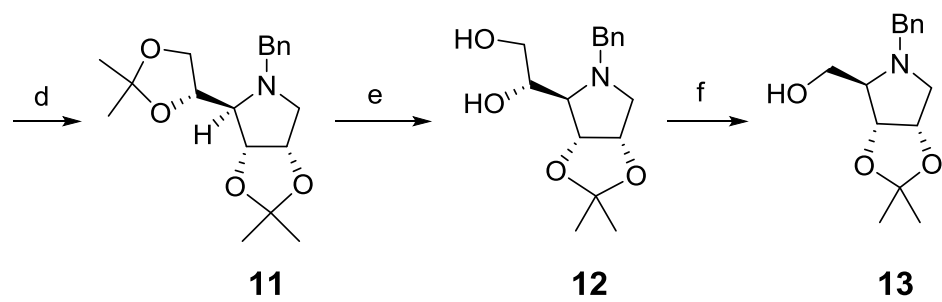

Scheme 1.3 Reagents: (a) Acetone, 2,2-dimethoxypropane (b) $\mathrm{NaBH}_{4}$ (c) $\mathrm{MsCl}$ (d) Benzylamine (e) $\mathrm{CH}_{3} \mathrm{COOH}(f) \mathrm{IO}_{4}, \mathrm{NaBH}_{4}$

Conversion of $N$-benzyl iminoribitol 13 to its protected version 14 proceeded in $92 \%$ overall yield by protection of the 5-hydroxyl as its TBS ether, followed by removal of the $\mathrm{N}$-benzyl protecting group by catalytic hydrogenation. In order to functionalize the iminosugars, the protected iminoribitol 14 was then treated with $\mathrm{N}$-chlorosuccinimide in pentane, followed by a reaction with the sterically hindered base lithium tetramethylpiperadine which afforded the imine $\mathbf{1 6}$ as an electrophile that could be immediately treated with a variety of nucleophilic organolithium. For example addition of phenylmagnesium bromide to the imine $\mathbf{1 6}$ stereoselectively established the $C$-glycoside bond affording the phenyl iminoribitol 17 (Scheme 1.4) ${ }^{66}$ 


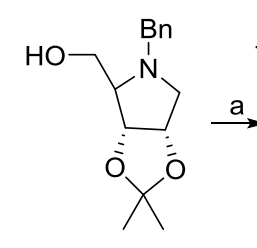

13

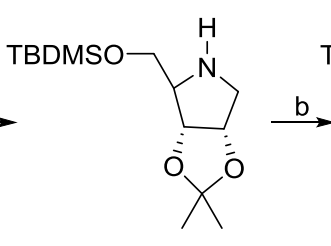

14

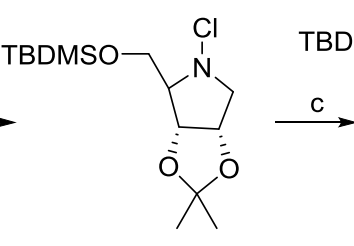

15

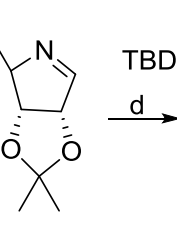

16

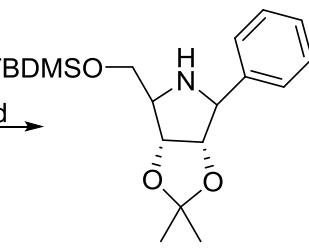

17

Scheme 1.4 Reagents: (a) TBDMSCl, Et $3 \mathrm{~N}, \mathrm{DCM}$, then $\mathrm{Pd} / \mathrm{C}, \mathrm{H}_{2}$, EtOH (b) $\mathrm{N}$-chlorosuccinimide, pentane, $30 \mathrm{~min}$ (c) Lithium tetramethyl piperidide, $\mathrm{THF},-78^{\circ} \mathrm{C}, 30 \mathrm{~min}$ (d) $\mathrm{PhMgBr}, \mathrm{Et}_{2} \mathrm{O},-78^{\circ} \mathrm{C}, 30$ $\min$.

Immucillin-H was the first Immucillin synthesized and extensively studied from this family of compounds. The first synthesis was a linear synthesis involved 23 steps and will be discussed below (vide infra, Scheme 2.1, Scheme 2.10). ${ }^{53}$

In order to provide kilogram quantities of Immucillin-H for pre-clinical and clinical studies an improved convergent strategy was developed and is illustrated in Scheme 1.6. ${ }^{67}$ Iminoribitol 14 was transformed into imine $\mathbf{1 6}$ via a $\mathrm{N}$-chloro intermediate as reported for the linear strategy. Meanwhile, the 9-deaza purine moiety was synthesized starting from 9-deazahypoxanthine $\mathbf{1 8}$ which could be converted to the 6 chloro derivative 19 , followed by protection of the pyrrole nitrogen, displacement of the 6-chloro group with methoxide, and bromination with NBS to afford the bromo 20. ${ }^{67}$ After the lithium-halogen exchange of 20 , it was added to imine 16 stereoselectively forming the $C$-glycoside bond. Finally, global deprotection furnished Immucillin- $\mathrm{H}$, isolated as $\mathrm{HCl}$ salt $\mathbf{2 4} .^{23}$ These additions of organometallic species to the imine could be a general approach to Immucillins. ${ }^{53}$ 


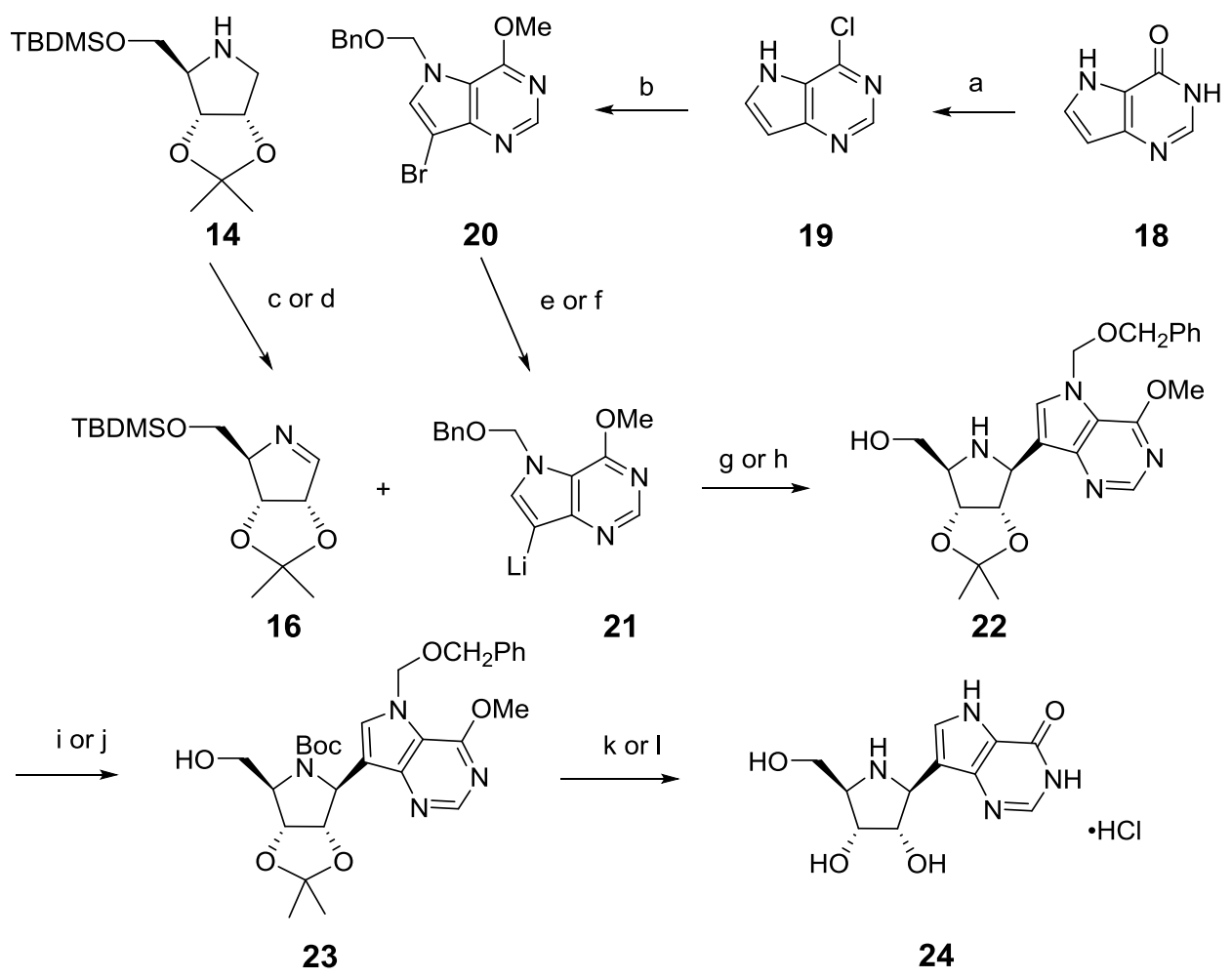

Scheme 1.5

Scheme 1.6 Reagents and conditions (a) $\mathrm{POCl}_{3}$ (b) $\mathrm{BnOCH}_{2} \mathrm{Cl}, \mathrm{NaH}, \mathrm{THF}, 0^{\circ} \mathrm{C}$ to $\mathrm{rt}, 1 \mathrm{~h}$, then $\mathrm{MeOH}$, $\mathrm{NaH}, \mathrm{rt}, 1 \mathrm{~h}$ then NBS. (c) NCS, pentane, then LTMP, THF (d*) NCS, PhMe, then KOH, Bu4NBr (e) ${ }^{n} \mathrm{BuLi}$, Et $2 \mathrm{O}$, anisole, $-70^{\circ} \mathrm{C}\left(\mathrm{f}^{*}\right) \mathrm{n}$-Hexyl-Li, $-15^{\circ} \mathrm{C}, \mathrm{MtBE}(\mathrm{g})$ anisole, $-70^{\circ} \mathrm{C}(\mathrm{h} *)$ toluene, $-15^{\circ} \mathrm{C}(\mathrm{i})(\mathrm{Boc}){ }_{2} \mathrm{O}, \mathrm{DCM}$, $\mathrm{rt}, 1 \mathrm{~h}\left(\mathrm{j}^{*}\right)(\mathrm{Boc})_{2} \mathrm{O} / \mathrm{MtBE},-15^{\circ} \mathrm{C}$, Heptane $(\mathrm{k}) \mathrm{H}$, $\mathrm{Pd} / \mathrm{C}, \mathrm{EtOH}, 18 \mathrm{~h}$, then $\mathrm{HCl}, \mathrm{MeOH}, 1.5 \mathrm{~h}$. (I*) $^{*}$ (cat) $\mathrm{HCl}$, EtOH. *Conditions improved by BioCryst.

The synthesis of Immucillin-H was further modified by BioCryst (Scheme 1.6). ${ }^{68}$ The new route has a number of clear advantages. Firstly, the coupling reaction was carried out at a warmer $-15^{\circ} \mathrm{C}$ instead of the $-70^{\circ} \mathrm{C}$ condition reported in previous literature. Secondly, it circumvented the hydrogenation step which involved dangerous high pressure conditions. Moreover, it accelerated the overall process. The removal of the benzyloxymethyl (BOM) ethers protecting group is acid catalyzed hydrogenation. Surprisingly under the conditions of (cat.) $\mathrm{HCl}$ and $\mathrm{EtOH}$, it was possible to give the Immucillin- $\mathrm{H} \mathrm{HCl}$ in greater yield than previous method and it was purified without difficulty.

Immucillin-H could also be used to make Immucillin-A (Scheme 1.7). Immucillin-H (24) 
was treated with di-tert-butyldicarbonate followed by acetic anhydride to furnish 26 . The protected version of Immucillin-H $\mathbf{2 6}$ was chlorinated to afford the intermediate 27 where the 6-chloro group was sequentially substituted by an azide group and then hydrogenated to yield the amine 29. Deacetylation of 29 yielded the $\mathrm{HCl}$ salt of Immucillin-A (30). ${ }^{23}$

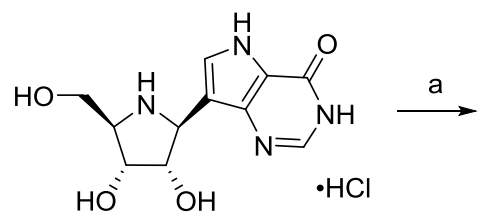

24

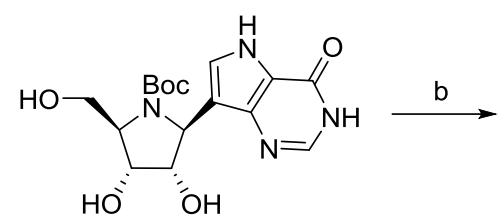

25

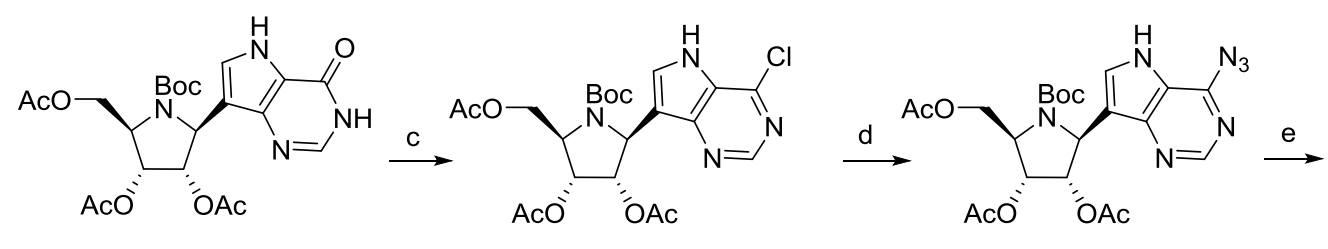

26

27

28

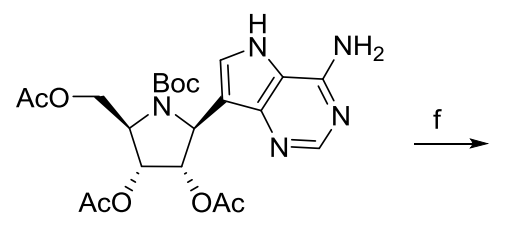

29

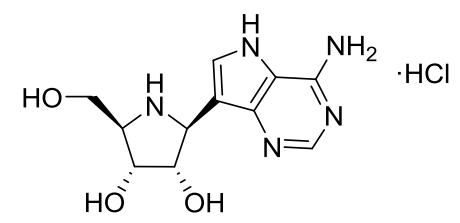

30

Scheme 1.7 Reagents and conditions (a) $\mathrm{Boc}_{2} \mathrm{O}, \mathrm{Et}_{3} \mathrm{~N}, \mathrm{MeOH}, \mathrm{H}_{2} \mathrm{O}$, rt (b) $\mathrm{Ac}_{2} \mathrm{O}$, pyridine, DMAP, $14 \mathrm{~h}$, $0^{\circ} \mathrm{C}$ to rt (c) $\mathrm{POCl}_{3}, \mathrm{PhNMe}_{2}, \mathrm{BnNEt}_{3} \mathrm{Cl}, \mathrm{MeCN}, 80^{\circ} \mathrm{C}, 10 \mathrm{~min}$ (d) $\mathrm{NaN}_{3}, \mathrm{DMF}, 80^{\circ} \mathrm{C}, 10 \mathrm{~h}$ (e) $\mathrm{H}_{2}, \mathrm{Pd}(\mathrm{OH})_{2}$, $\mathrm{MeOH}, 9$ atm, 15-18 h (f) NaOMe, MeOH, rt, 8 h, then (aq.) HCl, rt, 30 min.

\subsection{Iminoribitol $C$-nucleosides}

Some of the natural $C$-nucleosides, for instance formycin and formycin B, displayed antiviral and antitumor activities. Therefore, in the search of new therapeutics drugs, a number of these nucleosides with fused ring systems were synthesized. These compounds covered a wide range of nucleoside and nucleotide analogues including thiazole $C$-nucleosides ${ }^{69}$, isothiazole $C$-nucleosides ${ }^{65,70}$ and maleimide $C$-nucleosides ${ }^{71}$ etc. (Scheme 1.8) 
<smiles>Nc1ncnc2c(C3O[C@H](CO)[C@@H](O)[C@H]3O)n[nH]c12</smiles>

Formycin<smiles>O=c1[nH]cnc2c(C3O[C@H](CO)[C@@H](O)[C@H]3O)n[nH]c12</smiles>

Formycin B<smiles>O=c1[nH]cnc2c([C@@H]3O[C@H](CO)[C@@H](O)[C@H]3O)nsc12</smiles><smiles>Nc1nc2c([C@@H]3O[C@H](CO)[C@@H](O)[C@H]3O)nsc2c(=O)[nH]1</smiles>

isothiazole $C$-nucleosides

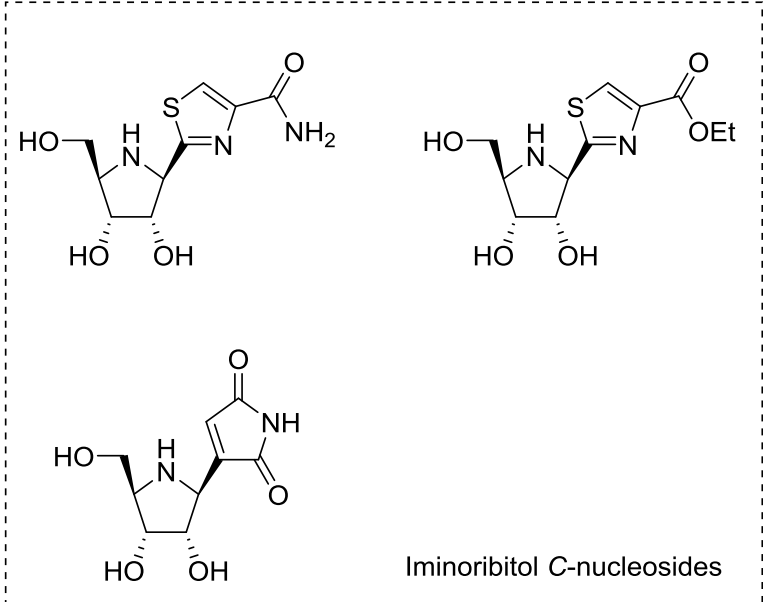

thiazole $C$-nucleosides

maleimide $C$-nucleosides

\section{Scheme 1.8}

Our aim is to make the iminoribitol isothiazole- $C$-nucleosides 33 and 34 (Figure 1.19) as neither compound had been claimed in the recent Biocryst patent providing us with freedom to operate if these compounds proved to be potent antivirals and we then wanted to commercialize them.

\subsection{Concluding remarks and proposed work}

Therefore, the compounds to be synthesized in this thesis are designed to inhibit RdRp activity via non-obligate RNA chain termination which is a mechanism requiring anabolism of the parent compounds to their triphosphate derivatives to afford mimics of the natural substrate. To facilitate this anabolic process prodrugs of our target compounds will be synthesized using the ProTide technology developed by McGuigan and will be valuable in terms of our antiviral screening program. 
Overall, the aims of this thesis are to (1) repeat known synthetic methods and investigate ways to improve these methods in terms of purification and yields. (2) synthesize Immucillin prodrugs for antiviral screening and (3) investigate the synthesis of new analogues of 8-aza-Immucillin-A such as iminoribitol isothiazole-C-nucleosides. Therefore, the proposed works are:

a) The synthesis of building block $\mathbf{3 2}$ which can be used to make Immucillin- $\mathrm{H}, \mathrm{A}$ or G, 7-thio-8-aza-Immucillin-H, A or G (Figure 1.18). ${ }^{72}$

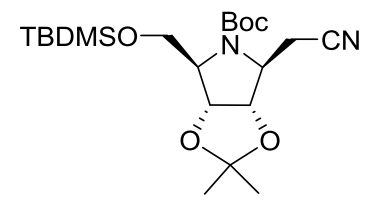

32

Figure 1.18

b) The synthesis of analogues of 8-aza-Immucillin-A and related prodrug. Based on the structure of immucillin-A and the structurally related compound 8-azaimmucillin-A we have designed a series of analogues which we aim to synthesize and these will be screened as antiviral agents (Figure 1.19). ${ }^{65,} 70$

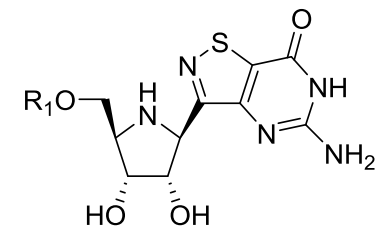

33

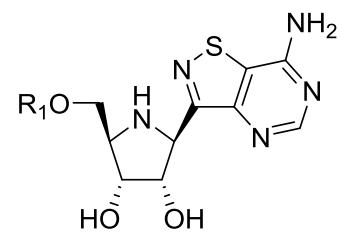

34

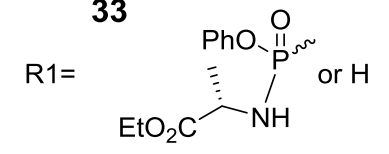

Figure 1.19

c) The synthesis of building block $\mathbf{3 5}$ which can be used to make ProTides (Figure 1.20).<smiles>CCC(CC)COC(=O)C(C)NP(=O)(Cl)Oc1ccccc1</smiles>

35

Figure 1.20

d) The synthesis of Immucillin-H (Figure 1.21)..$^{53}$ 


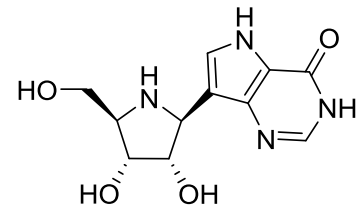

24

Figure 1.21

e) The synthesis of Immucillin-H prodrug (Figure 1.22).

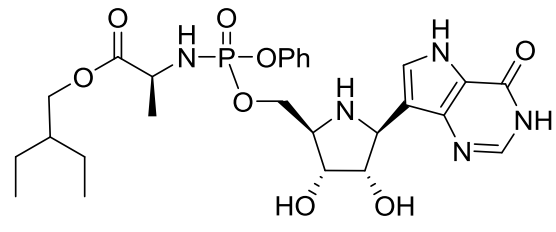

36

Figure 1.22

f) The target molecules will be sent to US NIAID for screening once they have been synthesized. 


\section{Results and discussion}

\subsection{The synthesis of acetonitrile adduct compound 32}

Acetonitrile adduct 32 was synthesized from 2,3 - acetonide L-lyxonolactone 37 following an improved route to iminoribitol 14 given in Scheme 2.1. ${ }^{72}$

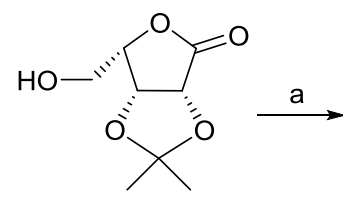

37

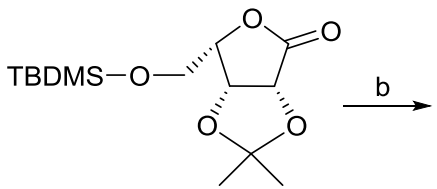

38

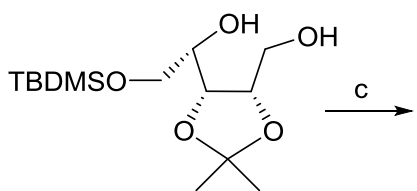

39

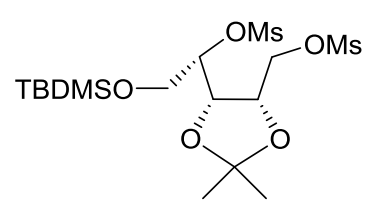

40

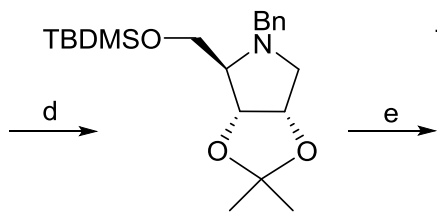

41

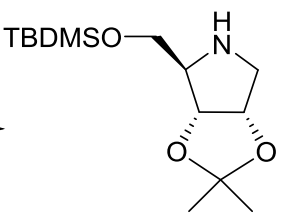

14

Scheme 2.1 Reagents: (a) TBDMSCl, imidazole, DMF, DMAP (b) MeOH, $\mathrm{NaBH}_{4}$, THF (c) $\mathrm{CH}_{3} \mathrm{ClO}_{2} \mathrm{~S}$, DMAP, pyridine (d) Benzylamine (e) Pd/C, EtOH, $\mathrm{H}_{2}$.

Compound $\mathbf{3 7}$ is commercially available, however on inspection of $\mathbf{3 7}$ by TLC and NMR we noted that some of the isopropylidene protecting group had come off or rearranged to the 3,4-acetonide during the storage and so was less than $50 \%$ pure. It was found that $\mathbf{3 7}$ was soluble in ethyl acetate while the solubility of the impurity was limited. Thus, the impurity can be removed by filtration and the filtrate evaporated to afford reasonably pure L-lyxonolactone derivative $\mathbf{3 7}$. The 5 '-hydroxyl group was then protected by silylation using TBDMSCl and imidazole in DMF to afford compound $\mathbf{3 8}$ in excellent yield (92\%). The ester can be completely reduced to the diol compound 39 in the presence of reducing reagent $\mathrm{NaBH}_{4}$ in good yield. To introduce the nitrogen to the five-member ring system, the diol was firstly converted to the bis-mesylate ester 40 wherein the methanesulfonyl moiety provides a good leaving group. Then treatment with benzylamine readily substitutes the primary methanesulfonyl group 
followed by a intramolecular $S_{N} 2$ reaction to displace the second mesylate with concomitant inversion of stereochemistry at C-4 to afford the benzylpyrrolidine derivative $\mathbf{4 1}$ in good yield (68\%). The hydrogenation of $\mathbf{4 1}$ was carried out in the presence of $\mathrm{Pd} / \mathrm{C}$ under an atmosphere of hydrogen gas. The reaction could be carried out at atmospheric pressure affording a moderated yield of the desired product 14, however the progress was slow. Occasionally, the reaction would stall and the catalyst needed to be replaced and the reaction vessel recharged with hydrogen gas for the reaction to proceed to completion.

In the original synthesis of immucillin- $\mathrm{H}$ and the immucillins in general, imine $\mathbf{1 6}$ was a key intermediate however this reaction required low reaction temperatures $\left(<70^{\circ} \mathrm{C}\right)$, long addition times (syringe pump), and the product only had limited stability. Recently Biocryst reported an alternative synthetic method (described in Section 1) involving the use of a phase transfer catalyst and potassium hydroxide in a biphasic mixture to afford excellent yields of imine $\mathbf{1 6}$ at temperatures close to ambient. However, the product could still only be stored for several days at $0^{\circ} \mathrm{C}$ which limited its utility.

A more stable alternative to the imine $\mathbf{1 6}$ and a more reactive electrophile is the nitrone $\mathbf{4 2}$ which is a white crystalline solid that exhibits long-term stability at $-18^{\circ} \mathrm{C} .{ }^{73}$ Ferrier Research Institute originally synthesised $\mathbf{4 2}$ using stoichiometric amounts of $\mathrm{SeO}_{2}$ and $\mathrm{H}_{2} \mathrm{O}_{2}$ in aqueous acetone but they became aware of the ability of this system to form unstable acetone peroxides that could potentially detonate and cause substantial damage. ${ }^{74}$ An alternative method involves the use of what proved to be a substantially improved procedure to our previous preparation of the nitrone $\mathbf{4 2}$ in which we adopted catalytic methylrhenium trioxide (MTO) oxidation of secondary amines to oxidize iminoribitol (Scheme 2.2 $)^{75}$. During the reaction, the hydroxylamine intermediate was firstly formed and then it was converted to two regioisomers of nitrone. They thus obtained an excellent combined yield of nitrone regioisomers $42(72 \%)$ and $42 a(18 \%)$, which were easily separable by a combination of recrystallization and chromatography. They have successfully performed the MTO 
oxidation on $>20 \mathrm{~g}$ scale. The desired nitrone $\mathbf{4 2}$ can be isolated by chromatography. It was found that the nitrone was partially soluble in hexane (cold washing hexane cannot prevent this from happening), thus chromatography was applied to the mother liquor residue to acquire more nitrone.

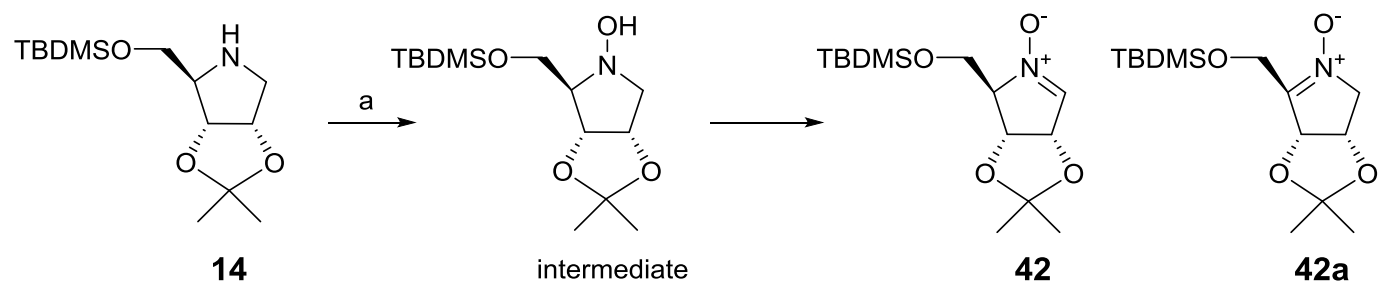

Scheme 2.2 Synthesis of Nitrones via MTO. Reagents and conditions: (a) MTO (0.2 mol \%), $\mathrm{H}_{2} \mathrm{O}_{2}$ $(30 \%)$ in DCM, rt, then $\mathrm{MeOH}, 15$ mins, then dropwise addition of 14 in $\mathrm{DCM}, 0^{\circ} \mathrm{C}, 0.5 \mathrm{~h}, 72 \%$ for 42 and $18 \%$ for $42 a$.

A detailed mechanism for the oxidation of secondary amines to nitrones is illustrated in Scheme 2.3. ${ }^{76}$ The study regarding the mechanism suggested that the reaction proceeded in at least two stages involving the key hydroxylamine intermediate 44. Oxidation of amine $\mathbf{4 3}$ afforded the hydroxylamine $\mathrm{N}$-oxide $\mathbf{4 5}$ which was dehydrated to nitrone $\mathbf{4 6}$. Alternatively, dehydration of intermediate $\mathbf{4 4}$ resulted in the imine $\mathbf{4 7}$ which can be further oxidized to either nitrone $\mathbf{4 6}$ or oxaziridine $\mathbf{4 8}$. However, the formation of imine $\mathbf{4 7}$ was ruled out as a separate experiment demonstrated aldehyde $\mathbf{4 9}$ was the main product if $\mathbf{4 7}$ was the starting material. No $\mathbf{4 6}$ was detected in such case. Therefore, oxidation of $\mathbf{4 3}$ followed by dehydration was believed to be the reaction mechanism. In our case, the observation of the reaction progress was consistent with the proposed mechanism.<smiles>c1ccc2c(c1)CNc1ccccc1C2</smiles>

43<smiles></smiles>

44 Oxidant<smiles>O=[N+]1c2ccccc2Cc2ccccc21</smiles>

45<smiles>COc1ccccc1</smiles><smiles>C1=Nc2ccccc2Cc2ccccc21</smiles><smiles>[Te][Te]</smiles><smiles>CO</smiles><smiles>[O-][N+]1=Cc2ccccc2Cc2ccccc21</smiles>

46

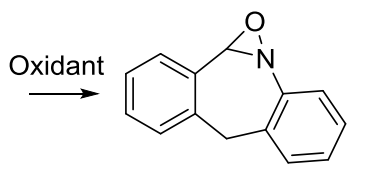

48<smiles>O=CN1c2ccccc2Cc2ccccc21</smiles>

49

Scheme 2.3

Page 35 of 83 
Nitrone 42 underwent a stereoselective addition of lithiated acetonitrile anion to electrophilic nitrone (Scheme 2.4). The temperature was maintained below $-70^{\circ} \mathrm{C}$, which is critical as the reagent may decompose if the temperature rises above $-65^{\circ} \mathrm{C}$. Then the intermediate $\mathrm{N}$-hydroxylamine was reduced to the amine using activated $\mathrm{Zn}$ in acetic acid to afford the amine in good yield. The amine was then protected with ditert-butylcarbonate to provide the carbamate in excellent yield. Multiple batches of this key intermediate were made due to its key role in all our proposed targets and the three-step yield was around 55\% which could potentially be optimised by further study.

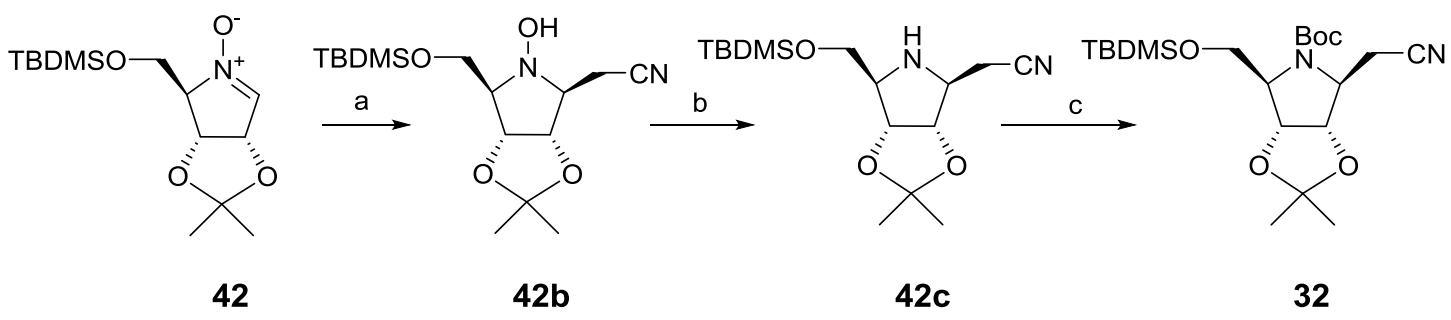

Scheme 2.4 Reagents: (a) ${ }^{n} \mathrm{BuLi}, \mathrm{THF}, \mathrm{CH}_{3} \mathrm{CN}$ (b) $\mathrm{CH}_{3} \mathrm{COOH}, \mathrm{Zn}$ (c) (Boc) ${ }_{2} \mathrm{O}, \mathrm{CHCl}_{3}$.

Compound 32 provides a basic building block for the further synthesis of our proposed nucleoside analogues compounds 33, $\mathbf{3 4}$ as well as Forodesine and Galidesivir. Chromatography using the Grace Reveleris flash chromatography system (this is an advanced and powerful system that allows the chemist to see previously invisible components and impurities, helping to provide maximum purity and recovery of target compounds in minimal time) afforded pure 32 whose ${ }^{1} \mathrm{H}$ and ${ }^{13} \mathrm{C}$ NMR were identical to that reported and could be used in the next step.

\subsection{The attempted synthesis of isothiazole- $C$ - nucleosides 33,34 .}

To prepare compound $\mathbf{5 2}$, oxime $\mathbf{5 0}$ was firstly synthesized from $\mathbf{3 2}$ as illustrated in Scheme 2.5. The oxime was formed in the presence of ${ }^{t} \mathrm{Bu}$-nitrite and $\mathrm{KO}^{\mathrm{t}} \mathrm{Bu}$ in good yield. This reaction was carried out under anhydrous conditions and the ${ }^{t} \mathrm{Bu}$-nitrite was added in excess and $\mathrm{KO}^{t} \mathrm{Bu}$ solution in THF then added dropwise. In one reaction, which was exposed to the air, the yield was very poor $(<30 \%)$. The yield of this reaction 
was around $60-70 \%$, however, when it was scaled up to $3.6 \mathrm{~g}$, the yield plummeted. The reason for this was still under investigation, nevertheless it was believed the heat accumulation from this exothermic reaction could be one of the factors. Meanwhile some unreacted acetonitrile adduct $\mathbf{3 2}$ was recovered from the scale-up reaction which meant the reaction system was either in an undesired equilibrium or less likely the reagents might not be dispersed evenly. The oxime was stable at $r t$, however, it began to decompose after one week. In most cases, it was carried to next step immediately after chromatography. NMR data suggested $\mathbf{5 0}$ was an approximate 1:1 mixture of rotamers.

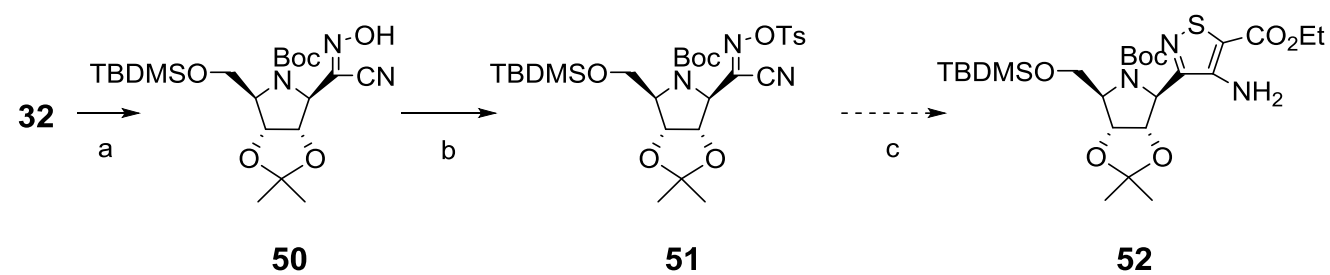

Scheme 2.5 Reagents: (a) KO${ }^{t} \mathrm{Bu},{ }^{t} \mathrm{BuONO}, \mathrm{THF}$ (b) TsCl, DIPEA, DCM (c) $\mathrm{HSCH}_{2} \mathrm{CO}_{2} \mathrm{Et}, \mathrm{Et}_{3} \mathrm{~N}$, EtOH. The tosylation of oxime $\mathbf{5 0}$ afforded the tosylate $\mathbf{5 1}$ in moderate yield. The $p$ toluenesulfonyl chloride ( $\mathrm{TsCl}$ ) was added in 1.5equiv. However, along with the desired product, a by-product (or intermediate) was found by TLC which possessed the same exact mass to starting material. Initially we believed that this by-product might be a rotamer, however the NMR indicated no aromatic protons in the by-product. The Beckman rearrangement could be an explanation for the by-product formed, however the reaction is usually catalyzed by acid (Scheme 2.6). The by-product in some cases was the major product and was unstable decomposing rapidly if left on the bench. NMR data suggested $\mathbf{5 1}$ was an approximate 1:1 mixture of rotamers.

It might prove beneficial in future to monitor the reaction by ${ }^{1} \mathrm{H} N M R$ or MS which can provide useful information on reaction progress. 


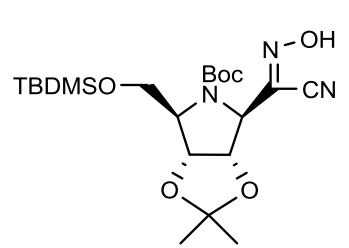

50

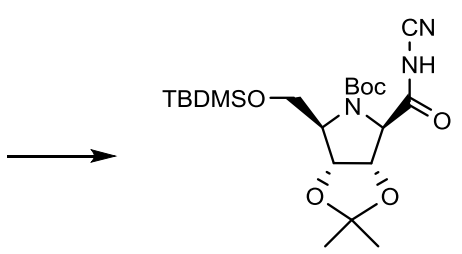

$50 a$

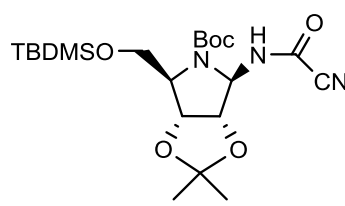

$50 \mathrm{~b}$

Scheme 2.6

Tosylate $\mathbf{5 1}$ was then treated with $\mathrm{HSCH}_{2} \mathrm{CO}_{2} \mathrm{Et}$ and $\mathrm{NEt}_{3}$, however, none of the desired product was observed. The proposed mechanism of this reaction when previously applied to a ribose derivative involved an acyclic intermediate 54 (though not necessary for the reaction to occur) wherein the tosylate group would be ejected to form the imino nitrile $\mathbf{5 5}$ (Scheme 2.7). In the presence of $\mathrm{NEt}_{3}$, it would cyclize to give the isothiazole spontaneously. On the other hand, due to the positive polarization of the oxime $\mathrm{N}$-atom, its reactivity toward nucleophiles was strongly decreased. In such situation, undesired nucleophilic attack on the sulfoxyl S-atom may take place, rolling back to oxime $\mathbf{5 0 . 6 5}$

However, in our case the 1- $\mathrm{N}^{\prime}$ was protected by Boc group meant it was not common to bear any negative charge in the reaction, thus mechanism involving $1-\mathrm{N}^{\prime}$ was not possible. ${ }^{65}$ The reaction should be a straight addition/elimination reaction and does not require ring opening to occur (Scheme 2.7). Isothiazole enamino esters 52 are suitable precursor for the synthesis of purine-like isothiazol pyrimidine iminoribitol $C$ nucleoside. Numerous attempts were made towards this reaction however the desired product was unable to be isolated. 


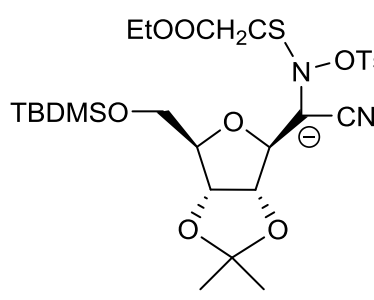

53

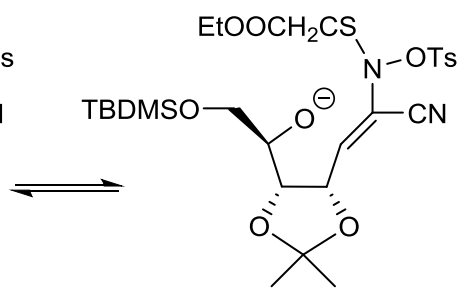

54

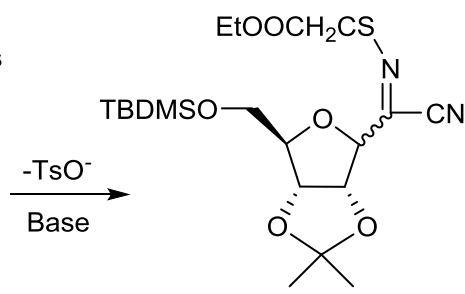

55

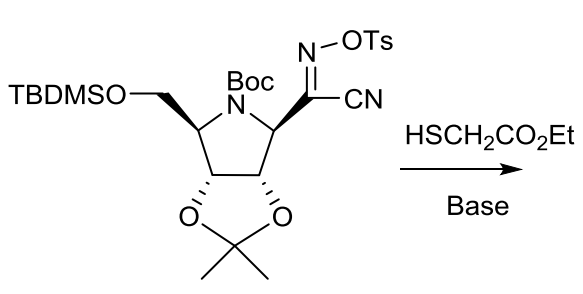

51

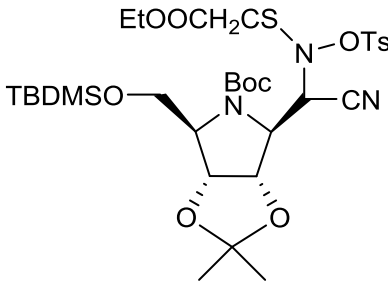

$51 \mathrm{a}$

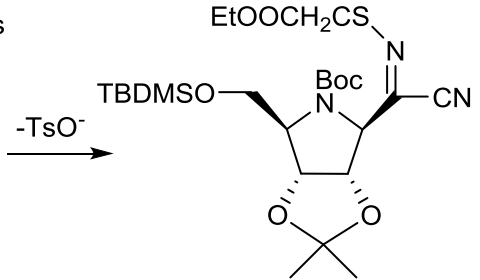

$51 b$

Scheme 2.7

The routes designed for the synthesis of compound 33, $\mathbf{3 4}$ and corresponding prodrugs 60, 61 were all via the precursor compound 52 (Scheme 2.8, Scheme 2.9). However, due to our inability to isolate compound $\mathbf{5 2}$ despite numerous attempts, we could not carry out the next steps in planned sequence of reactions. Consequently, new approaches to molecule $\mathbf{3 3}$ and $\mathbf{3 4}$ are under investigation. 


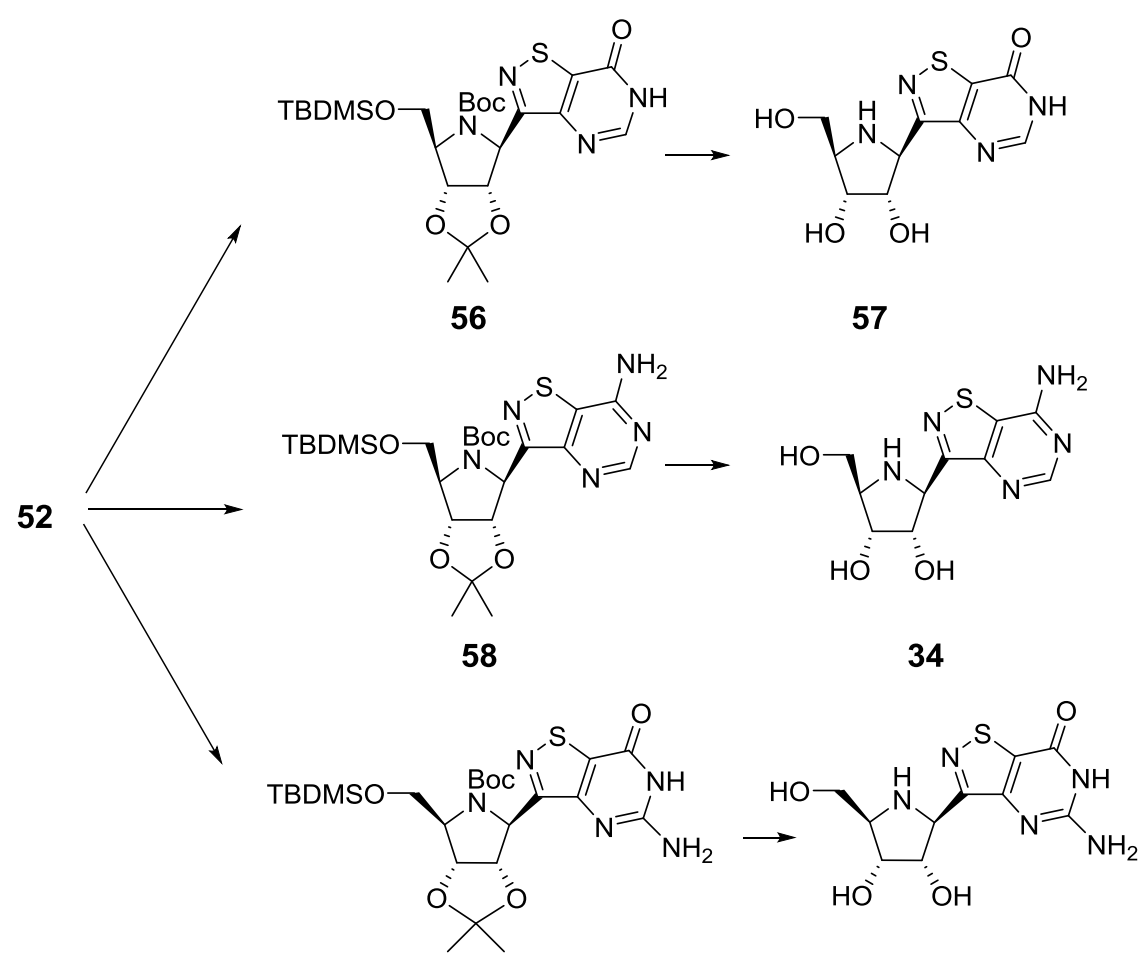

59

33

Scheme 2.8<smiles>CCOC(=O)[C@H](P)NP(=O)(O)OC[C@H]1N[C@@H](c2nsc3c(N)ncnc23)[C@H]1O</smiles>

60<smiles>CCOC(=O)[C@H](C)NP(=O)(O)OC[C@H]1N[C@@H](c2nsc3c(=O)[nH]c(N)nc23)[C@H](O)[C@@H]1O</smiles>

61

Scheme 2.9

\subsection{The synthesis of Immucillin-H compound 24}

The linear synthetic route to Immucillin-H was used instead of the more convenient convergent method developed by the Ferrier as several key synthetic intermediates in this progress were utilized in the attempted synthesis of some of the planned nucleoside analogues of AIA. Thus, acetonitrile adduct $\mathbf{3 2}$ was used as the starting 
material for the synthesis of Immucillin-H 24. It can be prepared via the route illustrated in Scheme $\mathbf{2 . 1 0} .^{53}$ The enol 62 was originally prepared by treating $\mathbf{3 2}$ with Bredereck's reagent to afford enamine, followed by mild acid hydrolysis (72\%). Here, 32 was treated with ethyl formate to afford enol 62 directly in moderate yield. This was a slow exothermic reaction, thus an ice bath was required to maintain the reaction at $0^{\circ} \mathrm{C}$. Meanwhile water could compete in the reaction, therefore the reaction was carried out under anhydrous conditions. A large excess of ethyl formate and $\mathrm{KO}^{\mathrm{t}} \mathrm{Bu}$ can be used and may increase the yield, however when it was carried out at $1 \mathrm{~g}$-scale the yield decreased $(<30 \%)$, probably because of the increased inner temperature. ${ }^{53}$

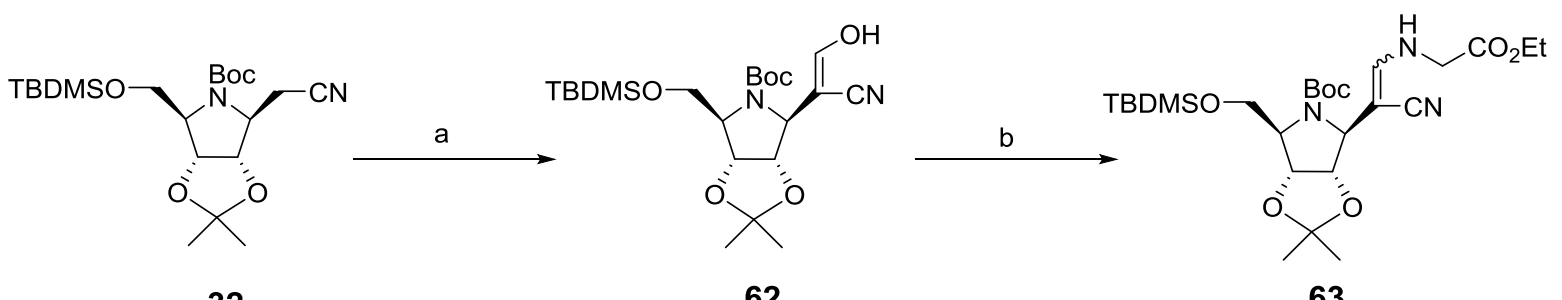

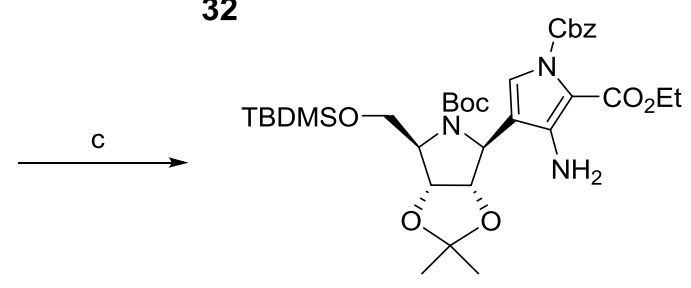

64

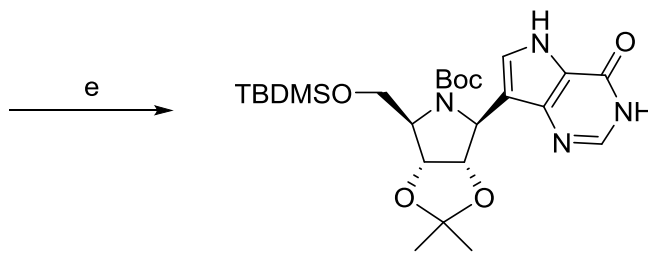

66

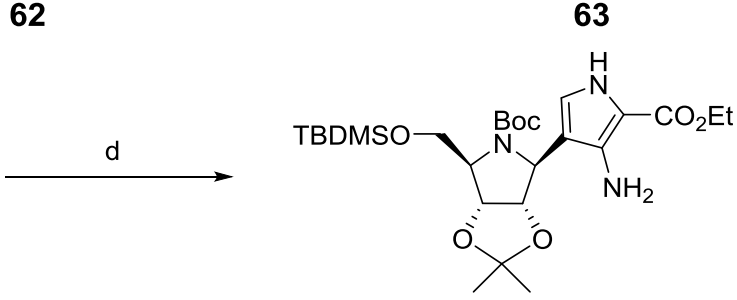

65

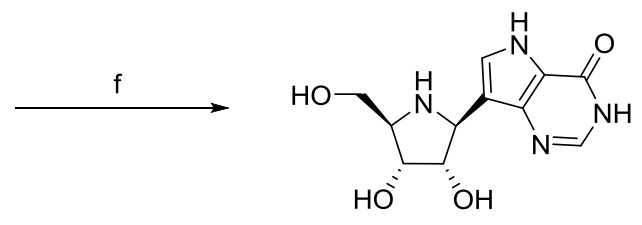

24

Scheme 2.10 Reagents (a) KO ${ }^{t} \mathrm{Bu}, \mathrm{THF}$, EtOCHO (b) $\mathrm{H}_{2} \mathrm{NCH}_{2} \mathrm{CO}_{2} \mathrm{Et} \cdot \mathrm{HCl}$

$\mathrm{NaOAc}, \mathrm{MeOH}$ (c) $\mathrm{ClCO}_{2} \mathrm{Bn}, \mathrm{DBU}, \mathrm{DCM}$ (d) $\mathrm{H}_{2}, \mathrm{Pd} / \mathrm{C}, \mathrm{EtOH}$ (e) $\mathrm{H}_{2} \mathrm{NCH}=\mathrm{NH}, \mathrm{HOAc}, \mathrm{EtOH}$ (f) TFA.

With enol $\mathbf{6 2}$ ready, Immucillin-H 24 can be synthesized as described in Scheme $\mathbf{2 . 1 0}$ via standard methods. ${ }^{53}$ The enol 62 was treated with ethyl glycinate to give enamines 63. Protection of the enamine-nitrogen was required in order to effect a cyclization to afford pyrrole. Thus, the enamines 63 was treated with excess benzyl chloroformate and DBU to furnish 64 as a syrup. Hydrogenolysis of 64 in ethanol under an atmosphere of hydrogen afforded the pyrrole 65 . Treatment of 65 with formamidine 
acetate gave the protected deazapurine aza-C-glycoside 66 which could be deprotected using TFA to afford the Immucillin-H (24).

\subsection{The synthesis of phosphorochloridate compound 35}

(tert-Butoxycarbonyl)-L-alanine (67) was commercially available and can be easily acquired. Esterification was carried out in DCM in the presence of weak base to give ester 68 in good yield. Boc group can be removed using hydrogen chloride (4M in 1,4dioxane). Amino acid ester 69 existed as $\mathrm{HCl}$ salt form with some impurities in it (from TLC). The yellowish solid was used without further purification. To prepare the aminoacyl phosphorochloridate 70, phenyl phosphorodichloridate and amino acid ester 69 were mixed and $\mathrm{Et}_{3} \mathrm{~N}$ was added as a base. This reaction was carried out at ambient temperature overnight $(<8 \mathrm{~h})$. In this case, it gave an acceptable yield under this condition, thus no more work was done toward this. However, prior work suggested the reaction can finish in a couple of hours. Additionally, the product was quite unstable at $\mathrm{rt}^{45}$ Thus ideally, the reaction should be monitored by ${ }^{31} \mathrm{P}$ NMR to increase the yield. Moreover, a proper equivalence (1.1equiv.) of the dichloridate reagent may also help to increase the yield.
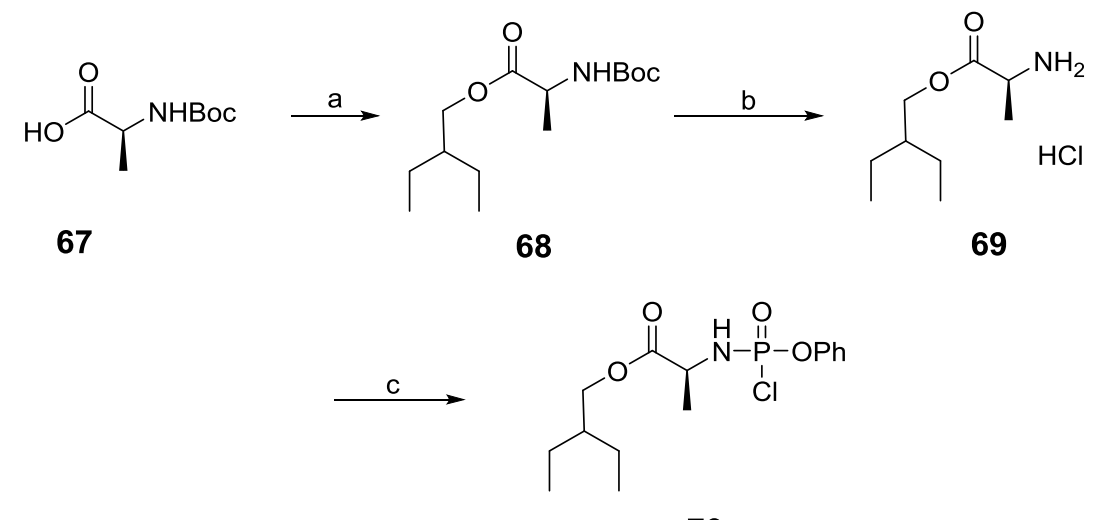

70

Scheme 2.11 Reagents: (a) $\left(\mathrm{CH}_{3} \mathrm{CH}_{2}\right)_{2} \mathrm{CHCH}_{2} \mathrm{OH}$, DMAP, DCM (b) $\mathrm{HCl}$, 1,4-dioxane (c) PhOPOCl2, $\mathrm{Et}_{3} \mathrm{~N}, \mathrm{DCM}$.

Phosphorochloridate $\mathbf{7 0}$ should be used immediately or after a quick flash 
chromatography. If it was stored in the freezer $\left(-20^{\circ} \mathrm{C}\right)$ under argon, it can last for about one month. However, another purification is recommended before use. The ${ }^{1} \mathrm{H} N M R$ and ${ }^{13} \mathrm{C}$ NMR were identical to the reported NMR spectrum.

\subsection{The synthesis of Immucillin-H Prodrug compound 36}

Before treating $\mathbf{2 4}$ with aminoacyl phosphorochloridate reagent, it would be better to protect the amine nitrogen and 2,3-hydroxyl groups thereby leaving the 5-hydroxyl group only exposed to the dichloridate reagent. Immucillin-H was treated with di-tertbutoxycarbonate, followed by acetone to afford the protected Immucillin-H 71. Then the $\mathbf{N}$-2,3-protected Immucillin-H $\mathbf{7 1}$ was reacted with dichloridate reagent to furnish compound 72. The yield of the $N$-methylimidazole (NMI) mediated coupling reaction varied either in this work (8-40\%) or the reported literature $(11-80 \%)$, and it seems is largely dependent on the nucleobase, temperature, ProTide type and stoichiometry. ${ }^{27}$ In this case, a higher equivalents of dichloridate reagent $(>4.5)$ and base $(>5)$ gave a higher yield in general. While the dichloridate reagent was used in slight excess (1.6 equiv.), the yield was less than $10 \%$. Another issue with this reaction was that along with the desired product, a less polar by-product was formed as well. This by-product [MS $\left.\left(\mathrm{MH}^{+}\right), m / z, 603.3\right]$ existed from the outset of the reaction and became dominant after a few hours, especially when the scale of the reaction was $>100 \mathrm{mg}$ scale. Further work will involve the identification of this impurity. 


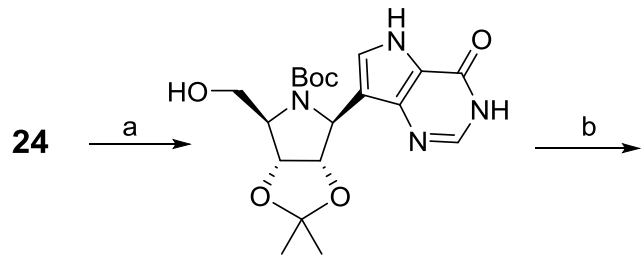

71

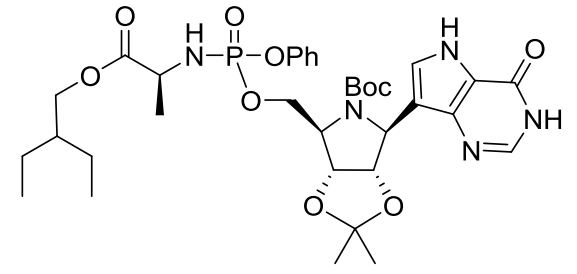

72

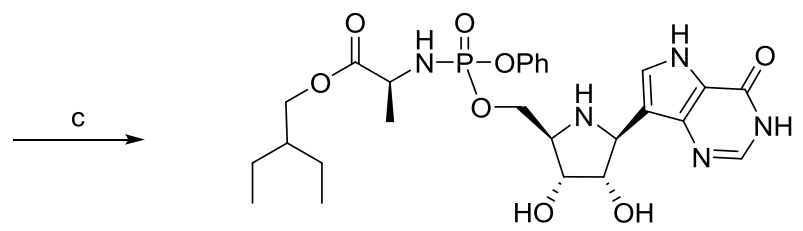

36

Scheme 2.12 Reagents: (a) (Boc) ${ }_{2} \mathrm{O}, \mathrm{Et}{ }_{3} \mathrm{~N}, \mathrm{H}_{2} \mathrm{O}, \mathrm{MeOH}$; then $\left(\mathrm{CH}_{3}\right)_{2} \mathrm{CO}, \mathrm{CSA},\left(\mathrm{CH}_{3}\right)_{2} \mathrm{C}\left(\mathrm{OCH}_{3}\right)_{2}$ (b) NMI, DCM, compound 70 (c) TFA, DCM; after $2 \mathrm{~h}, \mathrm{TFA}, \mathrm{THF}, 60^{\circ} \mathrm{C}$.

Compound $\mathbf{7 2}$ was then selectively deprotected using TFA in DCM to remove the acetonide and Boc protection. Care needed to be taken that all the starting material and intermediate were completely reacted. In some cases, the intermediate can last for a long time, and heating the reaction and replacing DCM with THF in $\mathrm{H}_{2} \mathrm{O}$ may accelerate the reaction. Following the work up procedure, chromatography was applied to the crude product. We were unable to separate the diastereomers by chromatography despite repeated attempts. In the future, we will investigate the use of preparative HPLC to separate these isomers

${ }^{1} \mathrm{H}$ NMR showed 30 protons from molecule 36 in total (Figure 2.1). It was suggested that due to the phosphorous chiral centre, the two protons from 9-deaza-guanine base moiety $(C-9,12)$ appeared as four singlets at $7.86,7.84,7.56$ and $7.52 \mathrm{ppm}$ indicating an approximately 3:1 mixture of diastereomers. Meanwhile the multiplet peaks from 7.15-7.35 ppm were assigned to the phenyl group in the phosphoramidate moiety, accounting for 5 protons. (C-36 40). $\mathrm{H}_{2} \mathrm{O}$ peak appeared at $4.79 \mathrm{ppm}$ and partially overlapped the proton signal from the tertiary carbon next to $\mathrm{N}-19$. From the DEPT spectra, the multiplets at 4.61-4.48 and 4.02-3.90 were the eight protons from the iminoribitol $(C-2,3,4,15)$ and the two secondary carbons $(C-16,24)$. The peaks around $3.34 \mathrm{ppm}$ were from $\mathrm{MeOH}$ and $\mathrm{MeOD}$. The thirteen protons from the pentane moiety 
(C-26 29) and the methyl group (C-30) were located around 0.83-1.35 ppm. The peak at 1.40-1.48 ppm belonged to the tertiary carbon (C-25) of the pentane moiety. Finally, an unknown peak at $1.93 \mathrm{ppm}$ was believed to be the impurity.

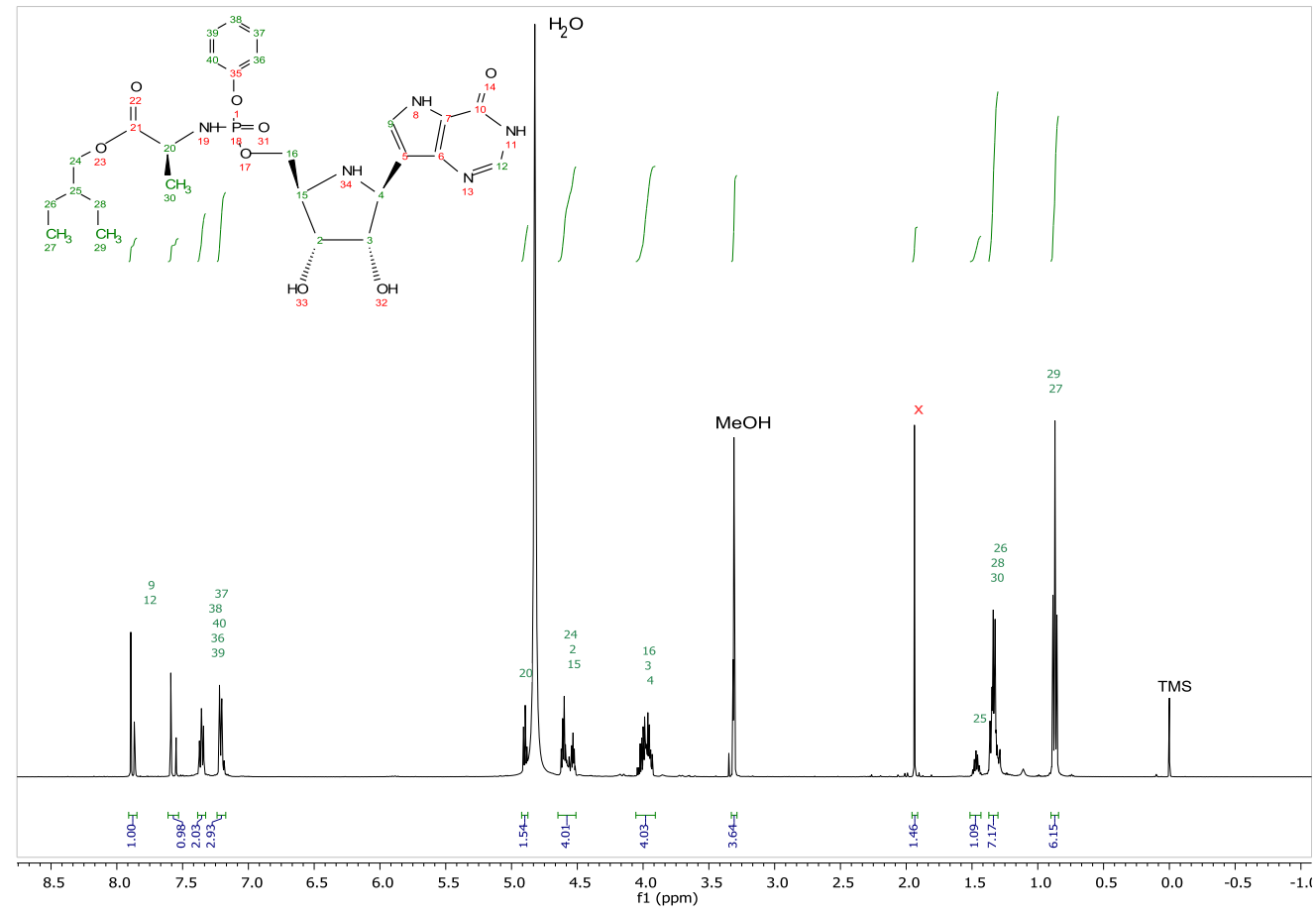

Figure 2.1

${ }^{31} \mathrm{p}$ NMR exhibited two singlets at 4.10 and $3.93 \mathrm{ppm}$ at approximately a 3:1 ratio which was consistent with the relative amounts of diastereomers observed in the ${ }^{1} \mathrm{H}$ NMR (Figure 2.2). 


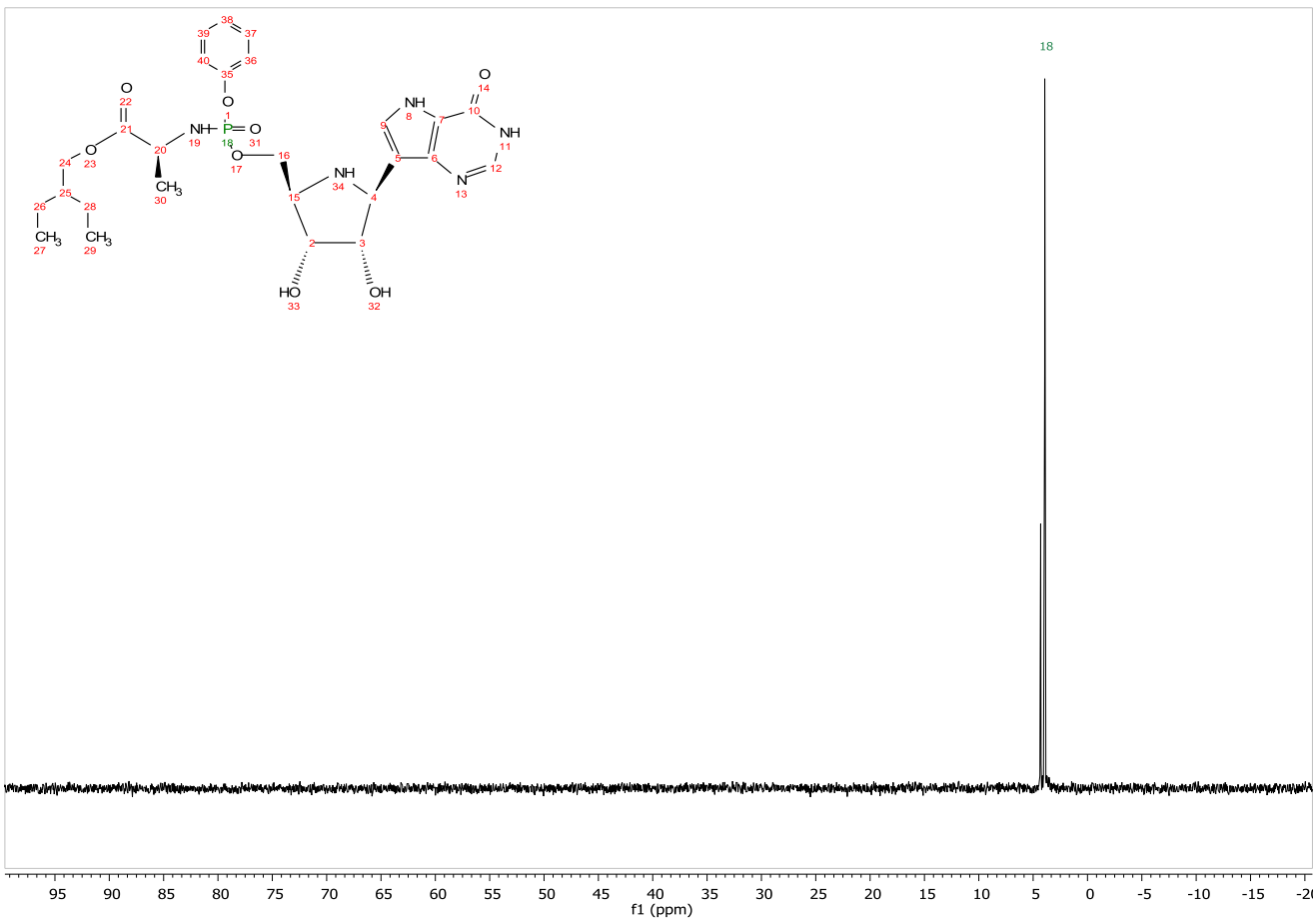

Figure 2.2

Carbon at $143.4,130.9,129.0,126.4,121.40,121.36 \mathrm{ppm}$ correlated to the aromatic carbon bearing one proton in phenyl and de-aza-guanine moiety (C-9,12,36 40). All the quaternary carbon signals in the molecule occurred between 109.9-155.7 ppm (C$5,6,7,10,21,35)$. Methyl groups (C-27, 29, 30) were found at 11.3-20.5 ppm. Peaks at 75.5, $75.5(\mathrm{CH}), 72.3(\mathrm{CH}), 68.3\left(\mathrm{CH}_{2}\right), 65.3,65.2\left(\mathrm{~d}, \mathrm{~J}=5.0 \mathrm{~Hz}, \mathrm{~d}, \mathrm{~J}=3.5 \mathrm{~Hz}, \mathrm{CH}_{2}\right)$, $64.6(\mathrm{~d}, \mathrm{~J}=7.9 \mathrm{~Hz}, \mathrm{CH}), 60.7,60.5(\mathrm{CH}), 51.8,51.7(\mathrm{CH}), 41.7(\mathrm{CH}), 24.3,24.2\left(\mathrm{CH}_{2}\right)$ The coupling observed in the NMR was due to long range ${ }^{13} \mathrm{C}-{ }^{31} \mathrm{P}$ coupling. Peaks marked by red arrows were unknown impurities (Figure 2.3). 


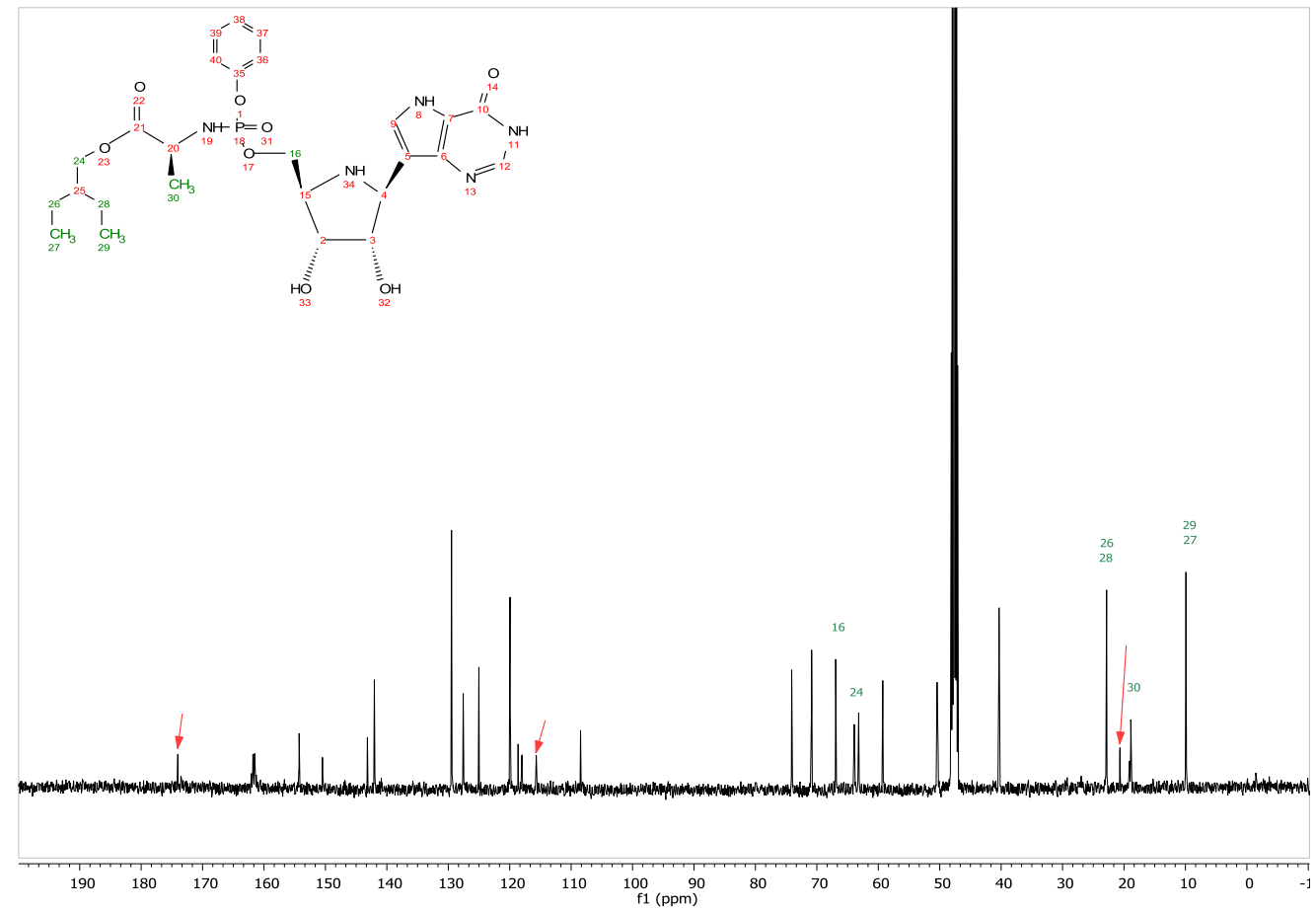

Figure 2.3

HRMS (MS $\left(\mathrm{MH}^{+}\right.$), calculated 577.2301 for $\mathrm{C}_{26} \mathrm{H}_{36} \mathrm{~N}_{5} \mathrm{O}_{8} \mathrm{P}$, found at 578.2386) was consistent with the desired product. HPLC-MS analysis indicated the peak at $3.13 \mathrm{~min}$ was the desired product. While the peak at 4.66 min was supposed to be the impurity $(m / z, 606.2)$.

Data collected from ${ }^{1} \mathrm{H}$ and ${ }^{13} \mathrm{C}$ NMR put forward the idea that the impurity could be acetate or acetic acid, however from the HPLC, another impurity did exist in the product. Nonetheless, the amount is minimal and thus no further purification was required. The product purity was $>96 \%$ from HPLC analysis (Figure 2.4). 


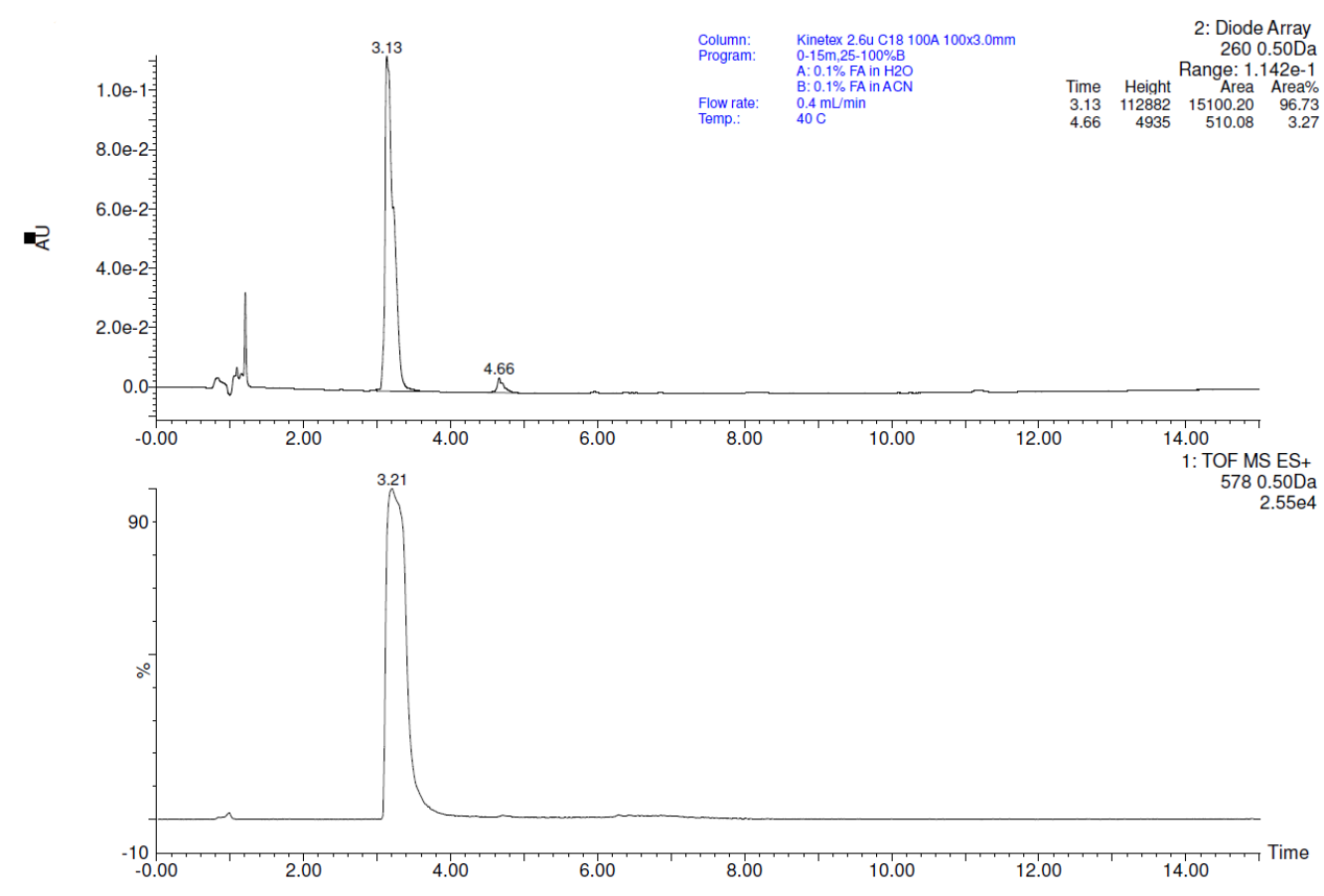

Figure 2.4

The presumed activation pathway of the Immucillin-H ProTides is showed in Scheme 2.13. ${ }^{77}$ Once inside the cell, an enzymatic hydrolysis of the amino acid ester moiety mediated by an esterase or carboxypeptidase type enzyme should occur (36A). Then spontaneous cyclization and subsequent spontaneous expulsion of the aryl group will afford the unstable ring (36B). After the ring opening is mediated by water (36C), hydrolysis of the P-N bond mediated by phosphoramidase-type enzyme releases the monophosphate Immucillin-H (36D). 


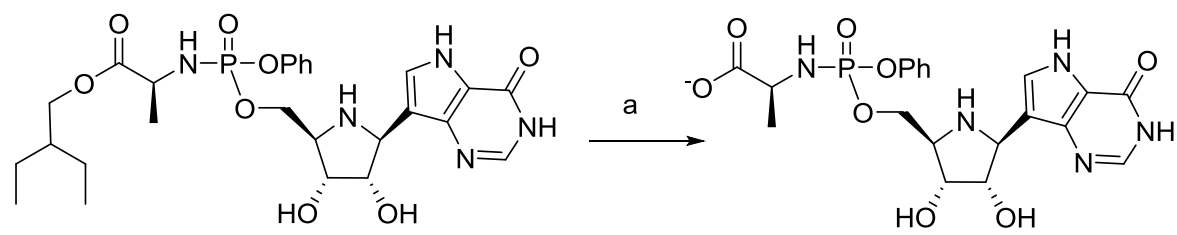

36<smiles>[R]C1NP(=O)(OC[C@H]2N[C@H](c3c[nH]c4c(=O)[nH]cnc34)[C@H](O)[C@@H]2O)OC1=O</smiles>

36B

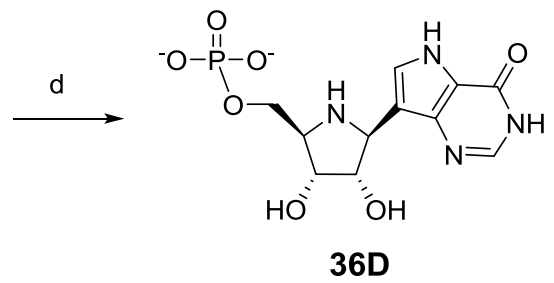

36A

esterase or carboxypeptidase type enzyme

b: spontaneous

c: spontaneous

d: phosphoramidase type enzyme

Scheme 2.13

\subsection{Further work}

We want to identify the by-product formed in the synthesis of $\mathbf{3 6}$. Moreover, apart from Immucillin-H prodrug (36), Immucillin-A and G prodrug are to be made as well. Furthermore, new route for the synthesis of unsuccessful compounds $\mathbf{3 3}$ and $\mathbf{3 4}$ are under investigation. Compound $\mathbf{3 6}$ is to be sent for testing. 


\section{Experimental}

\subsection{General}

NMR spectra were recorded on an instrument at $500 \mathrm{MHz}\left({ }^{1} \mathrm{H}\right), 125 \mathrm{MHz}\left({ }^{13} \mathrm{C}\right)$ or 200 $\mathrm{MHz}\left({ }^{31} \mathrm{P}\right)$. Normally, spectra were measured in $\mathrm{CDCl}_{3}$ with $\mathrm{Me}_{4} \mathrm{Si}$ as internal reference. Low and High resolution exact mass determinations were performed by Water Q-TOF Premier $^{\mathrm{TM}}$ Electrospray Mass Spectrometer. Optical rotations were determined with a

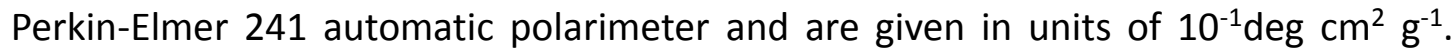
Aluminium backed silica gel sheets (Merck) were used for thin layer chromatography. Column chromatography was performed on silica gel (20-40 $\mu \mathrm{m}$ pore, Reveleris $\left.{ }^{\circledast}\right)$ on Grace $^{\circledR}$. Chromatography solvents were from commercially available products for LC. Unless otherwise stated all the reactions were carried out under an inert atmosphere.

\subsection{HPLC/LCMS sample preparation}

HPLC/LCMS was carried out on a Waters Acquity UPLC H-Class system. Kinetex C18 column $(100 \times 3.0 \mathrm{~mm}, 100 \mathrm{~A})$ was used for chromatographic separation. The mobile phase composed of $0.1 \%$ FA in $\mathrm{H} 2 \mathrm{O}(\mathrm{A})$ and $0.1 \%$ FA in $\mathrm{ACN}(\mathrm{B})$ in a gradient mode (0$15 \mathrm{~min}, 25-100 \% \mathrm{~B})$. The flow rate was set to $0.4 \mathrm{~mL} /$ minute with UV detector wavelength fixed at $210 \mathrm{~nm}$. The sample solution (compound 36, $100 \mathrm{ppm}$ ) was prepared in methanol and $10 \mu \mathrm{l}$ was injected. Mass parameters were set as spray voltage was kept at $1.0-4.0 \mathrm{kV}$ and capillary temperature at $200-320^{\circ} \mathrm{C}$. Nitrogen was used as both sheath and auxiliary gas. Mass range was kept at $m / z$ 100-1000.

\subsection{Compounds synthesis}

\subsubsection{The synthesis of acetonitrile adduct compound 32}

(3aR,6S,6aR)-6-(hydroxymethyl)-2,2-dimethyldihydrofuro[3,4-d] [1,3]dioxol-4(3aH)- 
one (37). Lactone $\mathbf{3 7}$ is commercially available however it had decomposed on storage and was therefore purified before use. The mixture containing compound 37 (100 g) dissolved in EtOAc $(500 \mathrm{ml})$ and stirred for $12 \mathrm{~h}$. The solid was filtered and the filtrate was evaporated under vacuum to give a white solid which was dried under vacuum to furnish reasonably pure lyxonolactone $37(50 \mathrm{~g}) .{ }^{1} \mathrm{H} N M R\left(500 \mathrm{MHz}, \mathrm{D}_{2} \mathrm{O}\right) \delta 5.14(\mathrm{~m}$, 1H), $5.07(\mathrm{~m}, 1 \mathrm{H}), 4.81(\mathrm{~m}, 1 \mathrm{H}), 4.02-3.85(\mathrm{~m}, 2 \mathrm{H}), 1.45(\mathrm{~s}, 3 \mathrm{H}), 1.41(\mathrm{~s}, 3 \mathrm{H}) .{ }^{13} \mathrm{C} N M R$ (126 MHz, $\left.\mathrm{D}_{2} \mathrm{O}\right) \delta 177.26(\mathrm{C}), 114.84(\mathrm{C}), 81.09(\mathrm{CH}), 76.44,76.28(\mathrm{CH}), 59.68(\mathrm{CH} 2)$, $25.81(\mathrm{CH} 3), 24.77(\mathrm{CH} 3)$ that is identical to the NMR data reported in the literature. ${ }^{52}$

\section{(3aR,6S,6aR)-6-(((tert-Butyldimethylsilyl)oxy)methyl)-2,2-dimethyldihydrofuro[3,4-} d][1,3]dioxol-4(3aH)-one (38). Imidazole (8 g, $116.33 \mathrm{mmol}$ ) and 4-dimethylaminopyridine $(500 \mathrm{mg}, 4.05 \mathrm{mmol}$ ) were added to an ice-cooled solution of lyxonolactone 37 (10 g, $53.14 \mathrm{mmol})$ in DMF under an atmosphere of argon and the resulting mixture stirred for $20 \mathrm{~min}$. TBDMSCl (11 g, $70.79 \mathrm{mmol})$ was then added slowly over a period of $20 \mathrm{~min}$ and the reaction mixture allowed to warm to $\mathrm{rt}$ and left stirring for 22 h. Reaction completion was indicated by TLC (7:3, EtOAc:hexane) and was quenched by pouring into ice water $(50 \mathrm{ml})$ and the aqueous layer then extracted with EtOAc (100 $\mathrm{ml} \times 2)$, the organic layers combined and washed with (satd.) $\mathrm{NaCl}(80$ $\mathrm{ml})$. The organic layer was dried $\left(\mathrm{MgSO}_{4}\right)$, filtered and concentrated under vacuum to give an oily residue. The oily residue was placed in an ice bath and triturated with hexane $(100 \mathrm{ml})$. The solid was collected by filtration and washed with hexane $(10 \mathrm{ml})$ to afford the product. More product was obtained by purifying the mother liquor by. Chromatography (gradient, $0-70 \%$ EtOAc in hexane) to afford a white solid that was combined with the solid from the trituration to give lactone 38 (14.5 g, 90\%) as white needles. ${ }^{1} \mathrm{H}$ NMR $\left(500 \mathrm{MHz}, \mathrm{CDCl}_{3}\right) 4.78-4.60(\mathrm{~m}, 2 \mathrm{H}), 4.42(\mathrm{~m}, 1 \mathrm{H}), 3.99-3.74(\mathrm{~m}$, $2 \mathrm{H}), 1.36(\mathrm{~s}, 3 \mathrm{H}), 1.29(\mathrm{~s}, 3 \mathrm{H}), 0.81(\mathrm{~s}, 9 \mathrm{H}), 0.00(\mathrm{~s}, 6 \mathrm{H}) .{ }^{13} \mathrm{C} \mathrm{NMR}\left(126 \mathrm{MHz}, \mathrm{CDCl}_{3}\right) \delta$ 173.69 (C), 114.04 (C), $79.38(\mathrm{CH}), 76.03(\mathrm{CH}), 75.74(\mathrm{CH}), 60.87(\mathrm{CH} 2), 26.76(\mathrm{CH} 3)$, $25.82(\mathrm{CH} 3), 18.29(\mathrm{C}),-5.37,-5.53(\mathrm{CH} 2)$. The NMR data was identical to that previously reported in the literature. ${ }^{52}$ 
(S)-2-((tert-Butyldimethylsilyl)oxy)-1-((4R,5S)-5-(hydroxymethyl)-2,2-dimethyl-1,3dioxolan-4-yl)ethan-1-ol (39). Lactone 38 (14 g, 48.54mmol) was added to a well stirred mixture of THF (135 ml) and methanol $(15 \mathrm{ml}, \mathrm{v} / \mathrm{v}, 9: 1)$ and stirred for $10 \mathrm{~min}$ until complete dissolution. The internal temperature of the flask was lowered to $0^{\circ} \mathrm{C}$ and sodium borohydride $(3.5 \mathrm{~g}, 91 \mathrm{~mol})$ was added at such a rate that the reaction temperature was maintained below $10^{\circ} \mathrm{C}$. On complete addition the reaction mixture was warmed to $\mathrm{rt}$ and the mixture left stirring for $22 \mathrm{~h}$. TLC (EtOAc:Hexane, 3:7) indicated the reaction was complete and so the mixture was diluted with EtOAc (150 $\mathrm{ml})$ and washed with $10 \% \mathrm{HCl}(80 \mathrm{ml})$, water $(80 \mathrm{ml})$, dried and evaporated under reduced pressure to give an oily residue. The residue was triturated with hexane (50 $\mathrm{ml}$ ) and cooled in an ice bath for $30 \mathrm{~min}$ to afford a white crystalline solid. The crystals were collected by filtration washing with hexane $(20 \mathrm{ml})$ to afford diol 39 (9.99 g, 70\%) as a white solid. ${ }^{1} \mathrm{H}$ NMR $\left(500 \mathrm{MHz}, \mathrm{CDCl}_{3}\right) \delta 4.18-4.13(\mathrm{~m}, 2 \mathrm{H}), 3.55(\mathrm{~m}, 5 \mathrm{H}), 1.43(\mathrm{~s}$, $3 \mathrm{H}), 1.29(\mathrm{~s}, 3 \mathrm{H}), 0.82(\mathrm{~s}, 9 \mathrm{H}), 0.00(\mathrm{~s}, 6 \mathrm{H}) .{ }^{13} \mathrm{C} \mathrm{NMR}\left(126 \mathrm{MHz}, \mathrm{CDCl}_{3}\right) \delta 108.24$ (C), $77.36(\mathrm{CH}), 75.77(\mathrm{CH}), 69.22(\mathrm{CH}), 64.59(\mathrm{CH} 2), 61.41(\mathrm{CH} 2), 27.14(\mathrm{CH} 3), 25.04(\mathrm{CH} 3)$, $18.28(\mathrm{C}),-5.40,-5.45(\mathrm{CH} 2)$. The NMR data was identical to that previously reported in the literature. ${ }^{52}$

\section{(S)-2-((tert-Butyldimethylsilyl)oxy)-1-((4S,5S)-2,2-dimethyl-5-(((methylsulfonyl)oxy)} methyl)-1,3-dioxolan-4-yl)ethyl methanesulfonate (40). Dry pyridine (20 mL), 4dimethylaminopyridine (30 mg, $0.24 \mathrm{mmol}$ ) and methanesulfonyl chloride ( $5 \mathrm{~mL}, 64.0$ mmol) were added into a $500 \mathrm{ml}$ flask charged with argon. The diol 39 (4.9 g, $16 \mathrm{mmol})$ was dissolved in dry pyridine $(20 \mathrm{~mL})$ and slowly added to the reaction mixture with stirring and the resulting mixture left stirring for $3 \mathrm{~h}$ at $\mathrm{rt}$. The reaction was monitored by TLC (EtOAc:hexane, 1:9) and upon the completion quenched with water (1 $\mathrm{ml})$, followed by the addition of EtOAc $(100 \mathrm{ml})$ and the mixture stirred for 2 min before being washed with water $(80 \mathrm{ml})$, dried and concentrated in vacuo to afford dimesylate $\mathbf{4 0}(7.5 \mathrm{~g}, \mathbf{7 8 \%})$ as a syrup. The crude product was committed to the next step 
without purification. ${ }^{1} \mathrm{H} N M R\left(500 \mathrm{MHz}, \mathrm{CDCl}_{3}\right) \delta 4.64(\mathrm{~m}, 1 \mathrm{H}), 4.36-4.27(\mathrm{~m}, 4 \mathrm{H})$, $3.71-3.89(\mathrm{~m}, 2 \mathrm{H}), 3.01(\mathrm{~s}, 3 \mathrm{H}), 2.97(\mathrm{~s}, 3 \mathrm{H}), 1.41(\mathrm{~s}, 3 \mathrm{H}), 1.28(\mathrm{~s}, 3 \mathrm{H}), 0.80(\mathrm{~s}, 9 \mathrm{H}), 0.00$ (d, $J=3.1 \mathrm{~Hz}, 6 \mathrm{H}) .{ }^{13} \mathrm{C} \mathrm{NMR}\left(126 \mathrm{MHz}, \mathrm{CDCl}_{3}\right) \delta 109.59$ (C), 78.95, (CH), 75.39 (CH), $74.49(\mathrm{CH}), 67.88(\mathrm{CH} 2), 63.11(\mathrm{CH} 2), 38.92(\mathrm{CH} 3), 37.65(\mathrm{CH} 3), 27.23,25.82(\mathrm{CH} 3)$, $25.40(\mathrm{CH} 3), 18.28(\mathrm{C}),-5.54(\mathrm{CH} 3)$. The NMR data was identical to that previously reported in the literature. ${ }^{52}$

(3aR,4R,6aS)-5-Benzyl-4-(((tert-butyldimethylsilyl)oxy)methyl)-2,2-di-methyl-tetrahydro-4H-[1,3]dioxolo[4,5-c]pyrrole (41). Mesylate 40 (10 g, $21.6 \mathrm{mmol}$ ) was added to neat benzylamine $(10 \mathrm{~mL}, 90 \mathrm{mmol})$ and the reaction mixture was heated up to $70^{\circ} \mathrm{C}$ for $48 \mathrm{~h}$ and monitored for complete reaction by $\operatorname{TLC}(4: 1$, hexane: EtOAC). The reaction mixture was then cooled to $\mathrm{rt}$ and brine $(10 \mathrm{ml})$ was added to the reaction mixture, followed by extraction with DCM $(10 \mathrm{ml})$, and the organic layer was then washed with water $(50 \mathrm{ml})$, dried and evaporated under reduced pressure to furnish a syrup which contained considerable amounts of benzylamine. The residue was taken up in toluene $(50 \mathrm{ml})$ and dry ice was added to it to precipitate out the salts which were removed by filtration and the solids washed with cold toluene, and the filtrate was then evaporated under vacuum to afford a crude residue which was purified by chromatography (gradient, 0-20\% EtOAc in hexane) to afford 41 (6.5 g, 91\%) as a syrup. ${ }^{1} \mathrm{H}$ NMR (500 $\left.\mathrm{MHz} \mathrm{CDCl}_{3}\right) \delta 7.84-7.31(\mathrm{~m}, 5 \mathrm{H}), 4.58(\mathrm{~m}, 1 \mathrm{H}), 4.49(\mathrm{dd}, \mathrm{J}=6.5,2.2 \mathrm{~Hz}, 1 \mathrm{H}), 3.95(\mathrm{~d}$, $J=13.4 \mathrm{~Hz}, 1 \mathrm{H}), 3.75-3.53(\mathrm{~m}, 3 \mathrm{H}), 3.04(\mathrm{dd}, \mathrm{J}=10.4,5.6 \mathrm{~Hz}, 1 \mathrm{H}), 2.94(\mathrm{~m}, 1 \mathrm{H}), 2.65$ (dd, J = 10.4, 2.9 Hz, 1H), $1.49(\mathrm{~s}, 3 \mathrm{H}), 1.26(\mathrm{~s}, 3 \mathrm{H}), 0.83(\mathrm{~s}, 9 \mathrm{H}),-0.01$ (d, J = 8.0 Hz, 6H). The NMR data was identical to that previously reported in the literature. ${ }^{52}$

\section{(3aR,4R,6aS)-4-(((tert-Butyldimethylsilyl)oxy)methyl)-2,2-dimethyltetrahydro-4H-}

[1,3]dioxolo[4,5-c]pyrrole (14). Amine 41 (5.6 g, $15 \mathrm{mmol}$ ) was added to ethanol (25 $\mathrm{mL}, 385 \mathrm{mmol}$ ) and stirred for $10 \mathrm{~min}$. Pearlman's catalyst $(200 \mathrm{mg}, 1.40 \mathrm{mmol}$, $20 \% \mathrm{w} / \mathrm{w} \mathrm{Pd}$ on carbon) was added to the reaction mixture and the resulting suspension stirred under 1 atmosphere of hydrogen. After $72 \mathrm{~h}$ the reaction stalled 
and the catalyst was removed and replaced with fresh Pearlman's catalyst (200 mg), recharged with hydrogen and the reaction mixture stirred for a further $24 \mathrm{~h}$. This process was repeated until the starting material had been consumed as monitored by TLC (4:1, hexane:EtOAC). The reaction mixture was filtered through Celite ${ }^{\circledR}$ pad and washed with ethanol $(30 \mathrm{ml})$. The filtrate was evaporated under vacuum to afford a syrup. The crude residue was purified by chromatography (gradient, 0-20\% EtOAc in hexane) to furnish iminoribitol $14(3.8 \mathrm{~g}, 88 \%)$ as a syrup. ${ }^{1} \mathrm{H} \mathrm{NMR}\left(500 \mathrm{MHz}, \mathrm{CDCl}_{3}\right) \delta$ $4.72-4.52(\mathrm{~m}, 2 \mathrm{H}), 3.67-3.40(\mathrm{~m}, 2 \mathrm{H}), 3.15(\mathrm{ddd}, J=6.1,5.1,1.2 \mathrm{~Hz}, 1 \mathrm{H}), 2.94(\mathrm{~d}, J=$ $2.7 \mathrm{~Hz}, 2 \mathrm{H}), 1.42(\mathrm{~s}, 3 \mathrm{H}), 1.27(\mathrm{~s}, 3 \mathrm{H}), 0.84(\mathrm{~s}, 9 \mathrm{H}),-0.00$ (d, J = $1.9 \mathrm{~Hz}, 6 \mathrm{H}) .{ }^{13} \mathrm{C} \mathrm{NMR}$ (126 MHz, $\left.\mathrm{CDCl}_{3}\right) \delta 110.95(\mathrm{C}), 83.42(\mathrm{CH}), 82.28(\mathrm{CH}), 66.33(\mathrm{CH}), 63.85(\mathrm{CH} 2), 53.43$ (CH2), $26.47(\mathrm{CH} 3), 25.88(\mathrm{CH} 3), 18.19(\mathrm{C}),-5.51(\mathrm{CH} 2)$. The NMR data was identical to that previously reported in the literature..$^{52}$

\section{(3aR,4R,6aS)-4-(((tert-butyldimethylsilyl)oxy)methyl)-2,2-dimethyl-3a,6a-dihydro-}

4H-[1,3]dioxolo[4,5-c]pyrrole 5-oxide (42). Methanol $(5 \mathrm{~mL})$ was added to a stirred suspension of hydrogen peroxide $(6 \mathrm{ml}, 52.1 \mathrm{mmol})$, methyltrioxorhenium(VII) $(8.8 \mathrm{mg}$, $0.04 \mathrm{mmol})$ and $\mathrm{DCM}(40 \mathrm{~mL})$ and the resulting mixture left to stir at $\mathrm{rt}$ for $10 \mathrm{~min}$ at which point, the suspension turned a canary yellow and was cooled to $0^{\circ} \mathrm{C}$. Neat amine $14(5 \mathrm{~g}, 17.39 \mathrm{mmol})$ was then added to the suspension dropwise and the resulting suspension left to stir. The reaction was monitored by $\operatorname{TLC}$ (3:7, EtOAc:hexane) and after $20 \mathrm{~min}$, indicated the reaction was complete. The mixture was warmed to rt and diluted with hexane $(100 \mathrm{ml})$ and washed with water $(30 \mathrm{ml})$, dried and concentrated in vacuo to afford a crude residue that was co-distilled with hexane $(10 \mathrm{ml} \times 2)$ to remove residual $\mathrm{DCM}$ and $\mathrm{MeOH}$, affording a white solid 42. Crude nitrone 42 was triturated in hexane $(100 \mathrm{ml})$ and cooled in an ice bath and then filtered and washed with cold hexane to afford the nitrone 42 as a white solid (2.61 g, 49\%). ${ }^{1} \mathrm{H}$ NMR (500 $\left.\mathrm{MHz}_{\mathrm{CDCl}}\right) \delta 6.81(\mathrm{~s}, 1 \mathrm{H}), 5.07(\mathrm{dt}, \mathrm{J}=6.2,1.5 \mathrm{~Hz}, 1 \mathrm{H}), 4.77(\mathrm{~d}, \mathrm{~J}=6.2 \mathrm{~Hz}, 1 \mathrm{H}), 4.31-$ $3.67(\mathrm{~m}, 2 \mathrm{H}), 1.38(\mathrm{~d}, \mathrm{~J}=0.7 \mathrm{~Hz}, 3 \mathrm{H}), 1.31(\mathrm{~d}, \mathrm{~J}=0.7 \mathrm{~Hz}, 3 \mathrm{H}), 0.79(\mathrm{~s}, 9 \mathrm{H}), 0.00(\mathrm{~s}, 3 \mathrm{H})$, $-0.02(\mathrm{~s}, 3 \mathrm{H}) .{ }^{13} \mathrm{C}$ NMR (126 MHz, $\left.\mathrm{CDCl}_{3}\right) \delta 133.06(\mathrm{CH}), 111.59$ (C), $80.73(\mathrm{CH}), 79.11$ 
$(\mathrm{CH}), 77.10(\mathrm{CH}), 59.83(\mathrm{CH} 2), 25.91(\mathrm{CH} 3), 25.68(\mathrm{CH} 3), 18.11(\mathrm{C}),-5.64(\mathrm{CH} 2),-5.73$

(CH2). The NMR data was identical to that previously reported in the literature. ${ }^{52}$

tert-Butyl(3aR,4R,6S,6aS)-4-(((tert-butyldimethylsilyl)oxy)methyl)-6-(cyanomethyl)2,2-dimethyltetrahydro-5H-[1,3]dioxolo[4,5-c]pyrrole-5-carboxylate (32). $n$-Butyllithium (5.11 ml, $9.61 \mathrm{mmol}, 2.5 \mathrm{~mol} / \mathrm{L}$ in hexane) was added to dry THF (40 mL) and the resulting solution cooled to $-70^{\circ} \mathrm{C}$ under an atmosphere of argon. Acetonitrile $(0.54$ $\mathrm{ml}, 10.2 \mathrm{mmol}$,) was added slowly keeping the reaction temperature below $-60^{\circ} \mathrm{C}$ and the resulting white suspension left stirring for $30 \mathrm{~min}$. A solution of nitrone $\mathbf{4 2}$ (5.1 g, $16.9 \mathrm{mmol})$ in dry THF $(24 \mathrm{ml})$ was added to the reaction flask over a period of $10 \mathrm{~min}$, maintaining the reaction temperature below $-70^{\circ} \mathrm{C}$. TLC (EtOAc/hexane, 1:2) indicated that the reaction was complete reacting to a less polar, non-UV absorbing product. The reaction was quenched with water $(5 \mathrm{ml})$, allowed it to warm to rt and then partitioned between hexane $(50 \mathrm{ml})$ and water $(20 \mathrm{ml})$, the organic layer was dried and then concentrated to afford a crude syrup (6.1 g) presumably the hydroxylamine which was committed to the next step without purification or characterization. Zinc (1.23 g, 18.8 mmol) was added to a solution of crude (42b) in acetic acid $(25 \mathrm{ml})$ and the resulting suspension stirred. The reaction had a long slow exotherm, and the reaction temperature was maintained below $30^{\circ} \mathrm{C}$. After $12 \mathrm{~h}$ TLC (EtOAc/hexane, 1:2) indicated that none of the starting material remained. The reaction mixture was filtered and washed with $\mathrm{CHCl}_{3}(10 \mathrm{ml})$ and then concentrated in vacuo. The residue was dissolved in $\mathrm{CHCl}_{3}$ and washed with saturated $\mathrm{NaHCO}_{3}(20 \mathrm{ml})$, dried and concentrated in vacuo to give a crude residue $(6.1 \mathrm{~g})$ presumably the amine $(42 \mathrm{c})$ which was committed to the next step without further purification or characterization. The residue was dissolved in $\mathrm{CHCl}_{3}(20 \mathrm{ml})$ and di-tert-butyl dicarbonate $(6.1 \mathrm{~g}, 27.9 \mathrm{mmol})$ added and resulting mixture stirred at $\mathrm{rt}$ for $2 \mathrm{~h}$. TLC (EtOAc/hexane, 3:7) indicated that the reaction was complete and was quenched with water $(10 \mathrm{ml})$ and washed with (satd.) $\mathrm{NaHCO}_{3}(10 \mathrm{ml})$, and concentrated in vacuo to afford a syrup. Chromatography (gradient, 0-30\% EtOAc in hexane) of the syrup gave acetonitrile adduct 32 (3.19 g, 
overall yield $53 \%$ for three steps) as a clear colorless syrup. ${ }^{1} \mathrm{H} \mathrm{NMR}\left(500 \mathrm{MHz}, \mathrm{CDCl}_{3}\right)$ $\delta 4.68$ - $4.51(\mathrm{~m}, 2 \mathrm{H}), 4.16-3.71(\mathrm{~m}, 4 \mathrm{H}), 2.95-2.66(\mathrm{~m}, 2 \mathrm{H}), 1.48(\mathrm{~s}, 9 \mathrm{H}), 1.46,1.34$ (2s, 6H), 0.91 (s, 9H), 0.09, 0.08 (2s, 6H). ${ }^{13} \mathrm{C} \mathrm{NMR} \mathrm{(126} \mathrm{MHz,} \mathrm{CDCl} 3$ ) $\delta 117.2$ (C), 112.1 (C), 84.0, 82.9 (CH), 81.8, 81.1 (CH2), 66.2 65.9, (CH) 61.7, 61.4 (C), 63.2, 62.9 (C), 28.2 (CH3), 27.1, 25.1 (CH3, 25.9 (CH3), 21.3, 20.5 (C), 18.3 (CH3), $25.5(\mathrm{CH} 3)$. The NMR data was identical to that previously reported in the literature. ${ }^{52}$

\subsubsection{The attempted synthesis of isothiazole- $N$ - nucleosides 33,34 .}

tert-Butyl(3aR,4R,6S,6aS)-4-(((tert-butyldimethylsilyl)oxy)methyl)-6-((Z)-cyano(hydroxyimino)methyl)-2,2-dimethyltetrahydro-5H-[1,3]dioxolo[4,5-c]pyrrole-5carboxylate (50). A solution of acetonitrile adduct $32(1.01 \mathrm{~g}, 2.34 \mathrm{mmol})$ in dry THF $(20 \mathrm{ml})$ was cooled to $0^{\circ} \mathrm{C}$ and tert-butyl nitrite $(0.87 \mathrm{~mL}, 7.03 \mathrm{mmol})$ and potassium tert-butoxide ( $3.52 \mathrm{~mL}, 3.52 \mathrm{mmol}, 1 \mathrm{~mol} / \mathrm{L}$ in tetraydrofuran ) were added to the reaction mixture and a slight exotherm was noted. After $1 \mathrm{~h}$, TLC (EtOAc/Hexane 1:2) showed all starting material was consumed, affording a more polar product. EtOAc (10 $\mathrm{ml}$ ) was added and washed with water $(5 \mathrm{ml})$ and brine $(5 \mathrm{ml})$, dried and concentrated under reduced pressure to give a yellowish syrup. The syrup was purified by chromatography (gradient, $0-70 \%$ EtOAc in hexane) to furnish the desired product oxime 50 (756 mg, 70\%). ${ }^{1} \mathrm{H}$ NMR (500 MHz, $\mathrm{CDCl}_{3}$, approximately 1:1 mixture of rotamers) $\delta 10.2(\mathrm{~s}, 0.5 \mathrm{H}), 10.0(\mathrm{~s}, 0.5 \mathrm{H}), 4.8-3.5(\mathrm{~m}, 6 \mathrm{H}), 1.78(\mathrm{~s}, 1 \mathrm{H}), 1.42(\mathrm{~s}, 9 \mathrm{H})$, $1.27(\mathrm{~s}, 3 \mathrm{H}), 1.25-0.81(\mathrm{~m}, 12 \mathrm{H}), 0.0(\mathrm{~d}, 6 \mathrm{H}) .{ }^{13} \mathrm{C} \mathrm{NMR}\left(126 \mathrm{MHz}, \mathrm{CDCl}_{3}\right.$, approximately 1:1 mixture of rotamers) $\delta 154.55,153.82$ (C), 134.79, 134.16 (C), 112.52 (C) 108.82 (C), $84.21(\mathrm{CH}), 83.13(\mathrm{CH}), 82.19(\mathrm{C}, \mathrm{CH}), 65.49,65.20(\mathrm{CH}), 63.24(\mathrm{CH} 2), 28.33,28.17$ (CH3), 26.03 (CH3), 25.33 (CH3), 18.45 (C), -5.29, -5.51 (CH2). HRMS $\left(\mathrm{MH}^{+}\right)$calculated for $\mathrm{C}_{21} \mathrm{H}_{37} \mathrm{~N}_{3} \mathrm{O}_{6} \mathrm{Si}: 455.2452$; found:456.2547.

tert-Butyl(3aR,4R,6S,6aS)-4-(((tert-butyldimethylsilyl)oxy)methyl)-6-((Z)-cyano- 
((tosyloxy)imino)methyl)-2,2-dimethyltetrahydro-5H-[1,3]dioxolo[4,5-c]pyrrole-5carboxylate (51). p-Toluenesulfonyl chloride $(0.16 \mathrm{~g}, 0.82 \mathrm{mmol}$,$) was added to a$ stirred solution of oxime 50 (250 mg, $0.55 \mathrm{mmol})$ and $\mathrm{N}, \mathrm{N}$-diisopropylethylamine $(0.38$ $\mathrm{mL}, 2.19 \mathrm{mmol}$ ) in dry DCM $(7.5 \mathrm{~mL}$ ) and left for $1 \mathrm{~h}$. TLC (EtOAc/Hex, 1:4) indicated the reaction was complete and was quenched by adding water $(5 \mathrm{ml})$ Diluted with DCM $(10 \mathrm{ml})$ and then washed $10 \% \mathrm{HCl}(5 \mathrm{ml})$ (satd.) $\mathrm{NaHCO}_{3}(5 \mathrm{ml})$, filtered and concentrated in vacuo. The crude residue was purified by chromatography (gradient, 0-20\% EtOAc in hexane) to afford 51 as a clear syrup (171 mg, 51\%). ${ }^{1} \mathrm{H}$ NMR (500 MHz, $\left.\mathrm{CDCl}_{3}\right) \delta 7.88(\mathrm{~d}, \mathrm{~J}=8.4 \mathrm{~Hz}, 2 \mathrm{H}), 7.37(\mathrm{~d}, \mathrm{~J}=7.8 \mathrm{~Hz}, 2 \mathrm{H}), 4.86-3.68(\mathrm{~m}, 6 \mathrm{H}), 2.46(\mathrm{~s}, 3 \mathrm{H})$, $1.52-1.33(\mathrm{~m}, 15 \mathrm{H}), 0.9-0.8(\mathrm{~m}, 9 \mathrm{H}), 0.08-0.00(\mathrm{~m}, 4 \mathrm{H}) .{ }^{13} \mathrm{C} \mathrm{NMR}\left(126 \mathrm{MHz}, \mathrm{CDCl}_{3}\right)$ $\delta$ 153.95, 153.06 (C), 146.34 (C), 142.86 (C), 131.25 (C), 129.97 (CH), $129.24(\mathrm{CH})$, $112.49(\mathrm{C}), 107.17(\mathrm{C}), 84.54(\mathrm{CH}), 82.84(\mathrm{C}, \mathrm{CH}), 81.82(\mathrm{CH}), 65.64(\mathrm{CH}), 63.77,63.43$ $(\mathrm{CH} 2), 53.40,28.25(\mathrm{CH} 3), 28.02(\mathrm{CH} 3), 26.06(\mathrm{CH} 3), 25.22(\mathrm{CH} 3), 18.55(\mathrm{C}),-5.28,-$ $5.66(\mathrm{CH} 2)$. HRMS $\left(\mathrm{MH}^{+}\right)$calculated for $\mathrm{C}_{28} \mathrm{H}_{43} \mathrm{~N}_{3} \mathrm{O}_{8} \mathrm{SSi}: 609.2540$; found:610.2626.

tert-Butyl(3aS,4S,6R,6aR)-4-(4-amino-5-(ethoxycarbonyl)isothiazol-3-yl)-6-(((tertbutyldimethylsilyl)oxy)methyl)-2,2-dimethyltetrahydro-5 $\mathrm{H}$-[1,3]dioxolo[4,5-c] pyrrole-5-carboxylate (52). Ethyl thioglycolate $(0.04 \mathrm{ml}, 0.42 \mathrm{mmol})$ was added to a stirred solution of tosylate 51 (171 mg, $0.28 \mathrm{mmol})$ in EtOH (5 ml). Triethylamine (0.12 $\mathrm{ml}, 1.12 \mathrm{mmol}$ ) was added and the resulting mixture stirred for $48 \mathrm{~h}$ until the reaction was complete by TLC (EtOAc/Hexane, 1:2). TLC showed no starting material but several major products (not characterized). Chromatography cannot isolate isothiazol $\mathbf{5 2}$ from other impurities.

\subsubsection{The synthesis of Immucillin-H compound 24}

tert-Butyl (3aR,4R,6S,6aS)-4-(((tert-butyldimethylsilyl)oxy)methyl)-6-((Z)-1-cyano-2hydroxyvinyl)-2,2-dimethyltetrahydro-5H-[1,3]dioxolo[4,5-c]pyrrole-5-carboxylate (62). Ethyl formate $(1.4 \mathrm{ml}, 19 \mathrm{mmol})$ was added to an ice-cooled solution of acetonitrile adduct $32(1.6 \mathrm{~g}, 3.8 \mathrm{mmol})$ in dry THF $(30 \mathrm{~mL})$. Potassium tert-butoxide 
(7.5 $\mathrm{mL}, 7.5 \mathrm{mmol}, 1 \mathrm{~mol} / \mathrm{L}$ in THF) was added to the resulting mixture and the reaction mixture monitored for reaction by TLC (EtOAc/hexane, 3:7). After $1 \mathrm{~h}$ nearly all the starting material had been consumed therefore the mixture was warmed to $\mathrm{rt}$, diluted with EtOAc $(5 \mathrm{ml})$, washed with water $(5 \mathrm{ml})$, brine $(5 \mathrm{ml})$, dried and concentrated in vacuo to afford a clear orange syrup crude. The crude residue was purified by chromatography (gradient, 0-30\% EtOAc in hexane) on silica gel to afford 62 (650 mg, 47\%) and unreacted starting material 32 (300 mg). ${ }^{1} \mathrm{H}$ NMR $\left(500 \mathrm{MHz}, \mathrm{CDCl}_{3}\right.$ ) d 10.10 (d, $1 \mathrm{H}), 4.92,4.83-4.77(\mathrm{~m}, 3 \mathrm{H}), 4.02(\mathrm{~m}, 1 \mathrm{H}), 3.73-3.51(\mathrm{~m}, 1 \mathrm{H}), 1.52(\mathrm{~s}, 9 \mathrm{H}), 1.49(\mathrm{~s}$, $6 \mathrm{H}), 0.91(\mathrm{~s}, 9 \mathrm{H}), 0.10(\mathrm{~d}, J=5.01 \mathrm{~Hz} 6 \mathrm{H})$. The NMR data was identical to that previously reported in the literature..$^{53}$

tert-Butyl (3aR,4R,6S,6aS)-4-(((tert-butyldimethylsilyl)oxy)methyl)-6-(1-cyano-2-((2ethoxy-2-oxoethyl)amino)vinyl)-2,2-dimethyltetrahydro-5 $\mathrm{H}$-[1,3]dioxolo[4,5-c] pyrrole-5-carboxylate (63). Glycine ethyl ester hydrochloride $(0.22 \mathrm{~g}, 1.6 \mathrm{mmol})$ and sodium acetate $(300 \mathrm{mg}, 3.65 \mathrm{mmol}$ ) were added to a stirred solution of enol 62 (160 $\mathrm{mg}, 0.35 \mathrm{mmol})$ in methanol $(4 \mathrm{~mL})$. The resulting mixture was stirred at $\mathrm{rt}$ for $16 \mathrm{~h}$ at which point no starting material remained by TLC (EtOAc/hexane, 3:7). The solvent was removed and chromatography (gradient, 0-30\% EtOAc in hexane) of the resulting residue gave enamine $63(110 \mathrm{mg}, 70 \%)$ as a mixture of isomers with the presence of some impurities. The NMR of the product was identical to that previously reported in the literature and was committed to the next step without further purification. ${ }^{53}$

\section{Benzyl-2-ethyl-3-amino-4-((3aS,4S,6R,6aR)-5-(tert-butoxycarbonyl)-6-(((tert-} butyldimethylsilyl)oxy)methyl)-2,2-dimethyltetrahydro-4H-[1,3]dioxolo[4,5-c] pyrrol-4-yl)-1H-pyrrole-1,2-dicarboxylate (64). A solution of enamine 63 (3.46 g, 6.42 $\mathrm{mmol})$ in dry DCM $(80 \mathrm{~mL})$ containing $\mathrm{DBU}(18 \mathrm{~mL}, 116 \mathrm{mmol})$ and benzyl chloroformate $(8.8 \mathrm{~mL}, 43 \mathrm{mmol})$ was heated under reflux for $4 \mathrm{~h}$. The resulting mixture was cooled and washed with dilute $10 \% \mathrm{HCl}(20 \mathrm{ml})$, (satd.) (aq.) $\mathrm{NaHCO}_{3}(20$ $\mathrm{ml}$ ), dried and concentrated in vacuo. Chromatography of the crude residue afforded 
pyrrole 64 (3.68 g, 90\%). The NMR data was identical to that previously reported in the literature..$^{53}$

tert-Butyl(3aS,4S,6R,6aR)-4-(4-amino-5-(ethoxycarbonyl)-1H-pyrrol-3-yl)-6-(((tertbutyldimethylsilyl)oxy)methyl)-2,2-dimethyltetrahydro-5H-[1,3]dioxolo[4,5-c] pyrrole-5-carboxylate (66). A solution of pyrrole 64 (1.84 g, $2.73 \mathrm{mmol})$ in ethanol (30 $\mathrm{mL}$ ) was stirred with $\mathrm{Pd} / \mathrm{C}(0.1 \mathrm{~g}, 10 \% \mathrm{w} / \mathrm{w})$ under an atmosphere of hydrogen for $3 \mathrm{~h}$. The resulting suspension was filtered through Celite ${ }^{\circledR}$ and the filtrate concentrated in vacuo. The crude residue was committed to the next step without characterization or purification. Crude compound 65 was dissolved in ethanol $(40 \mathrm{~mL})$ containing formamidine acetate $(1.40 \mathrm{~g}, 13.4 \mathrm{mmol})$ and the solution was heated at reflux temperature for $16 \mathrm{~h}$. The mixture was concentrated in vacuo and the crude residue purified by chromatography to afford the deazahypoxanthine derivative 66 (1.3 g, 91\%) as a syrup. The NMR data was identical to that previously reported in the literature. ${ }^{53}$

\section{7-((2S,3S,4R,5R)-3,4-Dihydroxy-5-(hydroxymethyl)pyrrolidin-2-yl)-3,5-dihydro-4H-}

pyrrolo[3,2-d]pyrimidin-4-one (24). Deazahypoxanthine derivative 66 (475 mg, 0.91 $\mathrm{mmol})$ in trifluoroacetic acid $(20 \mathrm{~mL})$ was allowed to stand at $\mathrm{rt}$ for $16 \mathrm{~h}$. The crude solution was concentrated in vacuo, and the residue, dissolved in water and washed with chloroform ( $5 \mathrm{ml} \times 2$ ) and the aqueous layer concentrated in vacuo. The residue was dissolved in aqueous methanol $(5 \mathrm{ml}, 50 \% \mathrm{v} / \mathrm{v})$ and treated with Amberlyst A21 base resin until the solution was neutral. The resin was removed by filtration and the solvent concentrated in vacuo to afford a residue. The crude residue was dissolved in water, treated with excess aqueous $\mathrm{HCl}$ and then lyophilised. Trituration of the residue with ethanol furnished Immucillin-H 24 as a white crystalline $\mathrm{HCl}$ salt $(0.225 \mathrm{~g}, 81 \%)$. The NMR data was identical to that previously reported in the literature..$^{53}$ 


\subsubsection{The synthesis of phosphorochloridate compound}

35

2-Ethylbutyl (tert-butoxycarbonyl)-L-alaninate (68). To a solution of (tertbutoxycarbonyl)-L-alanine $(67,3.00 \mathrm{~g}, 15.9 \mathrm{mmol})$ in DCM $(75 \mathrm{ml})$ was added 2ethylbutan-1-ol (3.9 ml, $32 \mathrm{mmol})$, 1-(3-dimethylaminopropyl)-3-ethylcarbodiimide hydrochloride (3.41 g, $17.4 \mathrm{mmol}$ ) and 4-dimethylaminopyridine (196 mg, $1.59 \mathrm{mmol}$ ) and the resulting mixture was stirred for $16 \mathrm{~h}$. The reaction mixture was concentrated in vacuo and the residue dissolved in EtOAc $(120 \mathrm{ml})$ and washed with (satd.) (aq.) $\mathrm{NaHCO}_{3}(75 \mathrm{ml} \times 2)$ and brine $(30 \mathrm{ml})$, dried and concentrated in vacuo. The crude residue was purified by chromatography (gradient, 0-50\% EtOAc in hexane) to afford the protected L-alaninate $68(3.4 \mathrm{~g}, 80 \%)$ as a colourless oil. ${ }^{1} \mathrm{H} \mathrm{NMR}\left(500 \mathrm{MHz}, \mathrm{CDCl}_{3}\right)$ $\delta 5.04(\mathrm{~s}, 1 \mathrm{H}), 4.31(\mathrm{~s}, 1 \mathrm{H}), 4.13-4.00(\mathrm{~m}, 2 \mathrm{H}), 1.59-1.48(\mathrm{~m}, 1 \mathrm{H}), 1.45(\mathrm{~s}, 9 \mathrm{H}), 1.48$ $-1.30(\mathrm{~m}, 7 \mathrm{H}), 0.90(\mathrm{t}, \mathrm{J}=7.2, \mathrm{~J}=7.9,6 \mathrm{H}) .[\alpha]\left(20^{\circ} \mathrm{C}\right)=-42$ (sample concentration, 1.59 $\mathrm{g} / 100 \mathrm{ml}, \mathrm{MeOH})$. The NMR data and $[\alpha]$ was identical to that previously reported in the literature. ${ }^{45}$

2-Ethylbutyl L-alaninate (69). Protected L-alaninate $68(3.4 \mathrm{~g}, 12.4 \mathrm{mmol})$ was dissolved in hydrogen chloride in dioxane $(70 \mathrm{~mL}, 4 \mathrm{M})$ and left to stand for $2 \mathrm{~h}$. TLC $\left(\mathrm{CHCl}_{3} / 1 \mathrm{M} \mathrm{NH} \mathrm{NH}_{3}\right.$ in $\left.\mathrm{MeOH}, \mathrm{v} / \mathrm{v}, 9: 1\right)$ indicated the reaction was complete and the reaction mixture was concentrated in vacuo and the residue co-distilled with $\mathrm{MeOH}$ (5 $\mathrm{ml}$ ) to afford 2-ethylbutyl L-alaninate $69(2.9 \mathrm{~g}, 110 \%)$ as a yellow solid which was used in the next step without further purification. ${ }^{1} \mathrm{H}$ NMR $(500 \mathrm{MHz}, \mathrm{MeOD}) \delta 4.27-4.06$ $(\mathrm{m}, 3 \mathrm{H}), 3.66(\mathrm{~m}, 1 \mathrm{H}), 3.35(\mathrm{~s}, 2 \mathrm{H}), 1.64-1.50(\mathrm{~m}, 4 \mathrm{H}), 1.47-1.34(\mathrm{~m}, 4 \mathrm{H}), 0.93(\mathrm{t}, \mathrm{J}=$ $7.5 \mathrm{~Hz}, 6 \mathrm{H})$. The NMR data was identical to that previously reported in the literature. ${ }^{45}$

2-Ethylbutyl (chloro(phenoxy)phosphoryl)-L-alaninate (70). Dichlorophosphoryloxybenzene $(0.40 \mathrm{~mL}, 2.68 \mathrm{mmol})$ was added to a solution of 2-ethylbutyl L-alaninate 69 $(0.500 \mathrm{~g}, 2.38 \mathrm{mmol})$ in $\mathrm{DCM}(6 \mathrm{~mL})$ and the stirred mixture cooled to $0^{\circ} \mathrm{C}$ in an ice- 
bath. Triethylamine $(0.60 \mathrm{~mL}, 4.26 \mathrm{mmol})$ was then added dropwise and a white precipitate formed and on complete addition the reaction mixture was allowed to warm to rt and stirred for an additional $12 \mathrm{~h}$. The reaction mixture was diluted with $\mathrm{Et}_{2} \mathrm{O}(5 \mathrm{~mL})$, the solid removed by filtration, and filtrate concentrated in vacuo. The residue was purified by chromatography (gradient, $0-100 \%$ EtOAc in hexane) to afford $70(0.4 \mathrm{~g}, 43 \%)$ as a colorless oil. ${ }^{1} \mathrm{H}$ and ${ }^{31} \mathrm{P}$ NMR indicated a $1: 1 \mathrm{mix}$ of diastereomers with the presence of some impurities. It was carried to next step without further purification. ${ }^{1} \mathrm{H}$ NMR $\left(500 \mathrm{MHz}, \mathrm{CDCl}_{3}\right) \delta 7.37(\mathrm{~m}, 3 \mathrm{H}), 7.30-7.21(\mathrm{~m}, 2 \mathrm{H}), 4.32-4.06$ (m, 4H), $1.62-1.47(\mathrm{~m}, 3 \mathrm{H}), 1.43-1.30(\mathrm{~m}, 4 \mathrm{H}), 0.94-0.85(\mathrm{~m}, 6 \mathrm{H}) .{ }^{31} \mathrm{P}$ NMR $(202$ $\mathrm{MHz}, \mathrm{CDCl} 3, \sim 1: 1$ mixture of diastereomers) $\delta 7.94,7.58$. The NMR data was identical to that previously reported in the literature. ${ }^{47}$

\subsubsection{The synthesis of Immucillin-H Prodrug compound} 36

tert-Butyl(3aR,4R,6S,6aS)-4-(hydroxymethyl)-2,2-dimethyl-6-(4-oxo-4,5-dihydro-3Hpyrrolo[3,2-d]pyrimidin-7-yl)tetrahydro-5 $\mathrm{H}$-[1,3]dioxolo[4,5-c]pyrrole-5-

carboxylate (71). Immucillin-H 24 (100 mg, $0.37 \mathrm{mmol}$ ) was dissolved in water $(2 \mathrm{~mL})$ and methanol $(4 \mathrm{~mL})$ and the resulting suspension was heated to $70^{\circ} \mathrm{C}$ and with stirring until the solid was completely solved. The reaction was then cooled to rt and triethylamine $(0.08 \mathrm{ml}, 0.75 \mathrm{mmol})$ added followed by di-tert-butyl dicarbonate (120 $\mathrm{mg}, 0.74 \mathrm{mmol}$ ) and the resulting mixture stirred for $1 \mathrm{~h}$. TLC (DCM/MeOH/ (aq.) (conc.) ammonia, 5:4:1) showed the starting material had fully reacted to a less polar product and so the reaction was quenched with $\mathrm{Et}_{3} \mathrm{~N}(0.1 \mathrm{ml})$ concentrated in vacuo and the residue co-distilled with $\mathrm{EtOH} / \mathrm{MeOH}(5 \mathrm{ml}, \mathrm{v} / \mathrm{v}, 1: 1)$ twice to afford a crude residue. The crude was committed to the next step immediately without further purification or characterization. (1s) - (+)-10-Camphorsulfonic acid (85 mg, $0.36 \mathrm{mmol}$ ) was added to a mixture of the crude $(133 \mathrm{mg})$ in acetone $(3 \mathrm{~mL})$ and dimethoxypropane $(1 \mathrm{~mL}, 8.16$ mmol). After $2 \mathrm{~h}, \mathrm{TLC}\left(\mathrm{CHCl}_{3} / \mathrm{EtOAc} /\right.$ Methanol, 5:2:2) indicated that the reaction was 
complete and was quenched with $\mathrm{Et}_{3} \mathrm{~N}(0.5 \mathrm{ml})$. The reaction mixture was concentrated in vacuo to afford a crude residue which was purified by chromatography (gradient, $0-10 \% \mathrm{MeOH}$ in EtOAc) to afford a mixture of compound 71 (201 mg) and $\mathrm{Et}_{3} \mathrm{~N} . \mathrm{HCl}$ salt. To remove the $\mathrm{HCl}$ salt, the mixture was treated with $\mathrm{NaOMe}(0.2 \mathrm{~g})$ in $\mathrm{MeOH}(2 \mathrm{ml})$, neutralized using amberlite 50 . Chromatography (gradient, $0-5 \% \mathrm{MeOH}$ in EtOAc) again gave the protected Immucillin-H 71 (85 mg, two step yield 57\%) as pale yellow solid which was committed to the next step without further purification. HRMS $\left(\mathrm{MH}^{+}\right)$calculated for $\mathrm{C}_{34} \mathrm{H}_{48} \mathrm{~N}_{5} \mathrm{O}_{10} \mathrm{P}: 717.3139$; found:718.3219.

tert-butyl(3aR,4R,6S,6aS)-4-(((((S)-1-(2-ethylbutoxy)-1-oxopropan-2-yl)amino) (phenoxy)phosphoryl)oxy)methyl)-2,2-dimethyl-6-(4-oxo-4,5-dihydro-3H-pyrrolo [3,2-d]pyrimidin-7-yl)tetrahydro-5H-[1,3]dioxolo[4,5-c]pyrrole-5-carboxylate (72). Phosphorochloridate 70 (415 mg, $1.11 \mathrm{mmol})$ in dry DCM (3 mL) was added in one lot to a well-stirred mixture of $71(100 \mathrm{mg}, 0.25 \mathrm{mmol})$ and 1-methylimidazole $(0.8 \mathrm{ml}$, $1.23 \mathrm{mmol})$ in dry DCM $(3 \mathrm{~mL})$ at $\mathrm{rt}$. The reaction mixture was monitored by TLC ( $\mathrm{MeOH} / \mathrm{EtOAc}, \mathrm{v} / \mathrm{v}, 0.5: 9.5$ ) and after $12 \mathrm{~h}$, showed that no starting materials remained. The reaction mixture was concentrated in vacuo and the crude residue dissolved in EtOAc $(5 \mathrm{ml})$, washed with dilute $10 \% \mathrm{HCl}(3 \mathrm{ml} \times 2)$, water $(2 \mathrm{ml} \times 2)$ and brine $(2 \mathrm{ml} \times$ 2 ), dried and evaporated under reduced pressure. The resulting residue was purified by chromatography (gradient, $0-5 \% \mathrm{MeOH}$ in EtOAc) to yield compound 72 (30 mg, $17 \%)$ as a gum. Carried to next step without further purification. ${ }^{31} \mathrm{P}$ NMR (202 MHz, $\left.\mathrm{CDCl}_{3}\right) \delta 2.56(\mathrm{~s})$.

\section{2-Ethylbutyl $\quad(((2 R, 3 R, 4 S, 5 S)-3,4-d i h y d r o x y-5-(4-0 x o-4,5-d i h y d r o-3 H$-pyrrolo[3,2-} d]pyrimidin-7-yl)pyrrolidin-2-yl)methoxy)(phenoxy)phosphoryl)-L-alaninate (36). Trifluoroacetic acid ( $2 \mathrm{~mL}, 25.8 \mathrm{mmol}$ ) was added to a mixture of compound 72 (30 mg, $0.04 \mathrm{mmol})$ and THF $(2 \mathrm{~mL})$, and water $(0.5 \mathrm{ml})$ and the resulting mixture, stirred for 12 h. TLC (MeOH/EtOAc/ (aq.) NH3 $(25 \% \mathrm{w} / \mathrm{w}), \mathrm{v} / \mathrm{v}, 1: 8: 1)$ showed all the starting material was consumed resulting in two main products, one of which was presumed 
to be an intermediate. The reaction was concentrated in vacuo and co-distilled with toluene $(3 \mathrm{ml})$ and chloroform $(3 \mathrm{ml})$ to remove residual TFA. The resulting residue was dissolved in methanol and treated with Amberlyst A21 base resin until neutral, filtered and concentrated in vacuo. Purification of the crude residue by chromatography (gradient, 0-100\% w/w, 2.5\% (v/v, 1:1, (aq.) $\mathrm{NH}_{3} / \mathrm{MeOH}$ )/EtOAc in EtOAc) afforded 36 (14 mg, 66\%) and intermediate compound (12 mg). The intermediate was submitted to the TFA deprotection step again to afford more of compound $\mathbf{3 6}(8 \mathrm{mg})$. Totally 22 $\mathrm{mg}$, with an overall yield of $90 \%$. ${ }^{1} \mathrm{H}$ NMR $\left(500 \mathrm{MHz}, \mathrm{CD}_{3} \mathrm{OD}, \sim 3: 1\right.$ mixture of diastereomers, HOD, $\delta 4.79): \delta 7.86(\mathrm{~s}, 0.75 \mathrm{H}), 7.84(\mathrm{~s}, 0.25 \mathrm{H}), 7.56(\mathrm{~s}, 0.75 \mathrm{H}), 7.52(\mathrm{~s}$, 0.25H), 7.35-7.30 (m, 2H), 7.20-7.15 (m, 3H), $4.87(\mathrm{t}, J=6.6 \mathrm{~Hz}, 1 \mathrm{H}), 4.61-4.48(\mathrm{~m}, 4 \mathrm{H})$, 4.02-3.90 (m, 4H), 1.48-1.40 (m, 1H), 1.35-1.24 (m, 7H), 0.840, $0.837(2 \mathrm{t}, J=7.5,7.5$ $\mathrm{Hz}, 6 \mathrm{H}) .{ }^{13} \mathrm{C}$ NMR $\left(125.7 \mathrm{MHz}, \mathrm{CD}_{3} \mathrm{OD}, \sim 3: 1\right.$ mixture of diastereomers, centre line $\delta$ 49.0): $\delta 163.35,163.82$ (2d, J = 33.9 Hz, 35.0 Hz, C), 155.7 (C), 151.95, 151.89 (C), 144.6 (C), $143.4(\mathrm{CH}), 130.9(\mathrm{CH}), 129.0(\mathrm{CH}), 126.4(\mathrm{CH}), 121.40,121.36(\mathrm{CH}), 120.0,119.4$ (C), 109.9 (C), 75.50, 75.47 (CH), $72.3(\mathrm{CH}), 68.3(\mathrm{CH} 2), 65.3,65.2(\mathrm{~d}, J=5.0 \mathrm{~Hz}, \mathrm{~d}, J=$ 3.5 Hz, CH2), 64.6 (d, J = 7.9 Hz, CH), 60.7, $60.5(\mathrm{CH}), 51.8,51.7(\mathrm{CH}), 41.7(\mathrm{CH}), 24.3$, $24.2(\mathrm{CH} 2), 20.5,20.3(2 \mathrm{~d}, J=7.5,6.8 \mathrm{~Hz}, \mathrm{CH} 3), 20.2,11.31,11.28(\mathrm{CH} 3) .{ }^{31} \mathrm{P} N M R$ (202.4 MHz, CD $\mathrm{CD}_{3} \mathrm{OD} \sim 3: 1$ mixture of diastereomers): $\delta 4.10$ (s), 3.93 (s). HRMS (MS $\left(\mathrm{MH}^{+}\right)$, calculated 577.2301 for $\mathrm{C}_{26} \mathrm{H}_{36} \mathrm{~N}_{5} \mathrm{O}_{8} \mathrm{P}$, found at 578.2386 ) 


\section{Abbreviations and Acronyms}

$[\alpha]$

Ac

$\mathrm{ACN}$

aq.

$\mathrm{Ar}$

atm.

Biocryst

$\mathrm{Bn}$

$\mathrm{BOC}, \mathrm{BoC}$

$(\mathrm{BOC})_{2} \mathrm{O}(\mathrm{Boc})_{2} \mathrm{O}$

$\mathrm{Bu}, n$-Bu, ${ }^{n} \mathrm{Bu}$

$t$-Bu, ${ }^{t} \mathrm{Bu}$

${ }^{\circ} \mathrm{C}$

cat.

$\mathrm{CBZ}, \mathrm{Cbz}$

COSY

$\delta$

DBU

DCM

DEPT

DMAP

DMF

DMSO

equiv.

et al

FA

Et

FDA

$\mathrm{h}$

HPLC

$\mathrm{Hz}$

in vacuo

$J$

$\mu$

Me

$\min$

Ms

MS

MtBE

MTO observed optical rotation in degrees

acetyl

acetonitrile

aqueous

aryl

atmosphere(s)

Biocryst Pharmaceuticals

benzyl

tert-butoxycarbonyl

di-tert-butoxycarbonate

normal (primary) butyl

tert-butyl

degrees Celsius

catalyst

benzyloxycarbonyl (preferred over the abbreviation Z) correlation spectroscopy (NMR)

chemical shift in parts per million downfield from tetramethylsilane

1,8-diazabicyclo[5.4.0]undec-7-ene

dichloromethane

Distortionless Enhancement by Polarization Transfer (NMR)

4-( $N, N$-dimethylamino)pyridine

dimethylformamide

dimethyl sulfoxide

equivalent

and others

formic acid

ethyl

US Federal Drug Administration

hours

high-performance liquid chromatography

hertz

in vacuum

coupling constant in NMR

micro

methyl

minutes

methylsulfonyl (mesyl)

mass spectrometry

Methyl $t$-butyl ether

methylrhenium trioxide 


$\begin{array}{ll}m / z & \text { mass-to-charge ratio (not } m / e \text { ) } \\ \text { NCS } & N \text {-Chlorosuccinimide } \\ \text { NIAID } & \text { US National Institute for Allergy and Infectious Diseases } \\ \text { NMR } & \text { nuclear magnetic resonance } \\ \mathrm{Ph} & \text { phenyl } \\ \mathrm{ppm} & \text { part(s) per million } \\ \mathrm{Pr} & \text { propyl } \\ \mathrm{iPr} & \text { isopropyl } \\ \mathrm{Rf} & \text { retention factor (in chromatography) } \\ \mathrm{rt} & \text { room temperature } \\ \text { satd. } & \text { saturated } \\ \text { TBDMSO } & t \text {-butyldimethylsiloxy protecting group } \\ \text { TFA } & \text { trifluoroacetic acid } \\ \text { THF } & \text { tetrahydrofuran } \\ \text { TLC } & \text { thin-layer chromatography } \\ \text { Ts } & \text { para-toluenesulfonyl (tosyl) } \\ \text { TS } & \text { transition state } \\ \text { UV } & \text { ultraviolet } \\ \text { V/v } & \text { volume per unit volume } \\ \text { WHO } & \text { World Health Organization } \\ \text { W/w } & \text { weight per unit weight }\end{array}$




\section{Appendix A New compound NMR data}

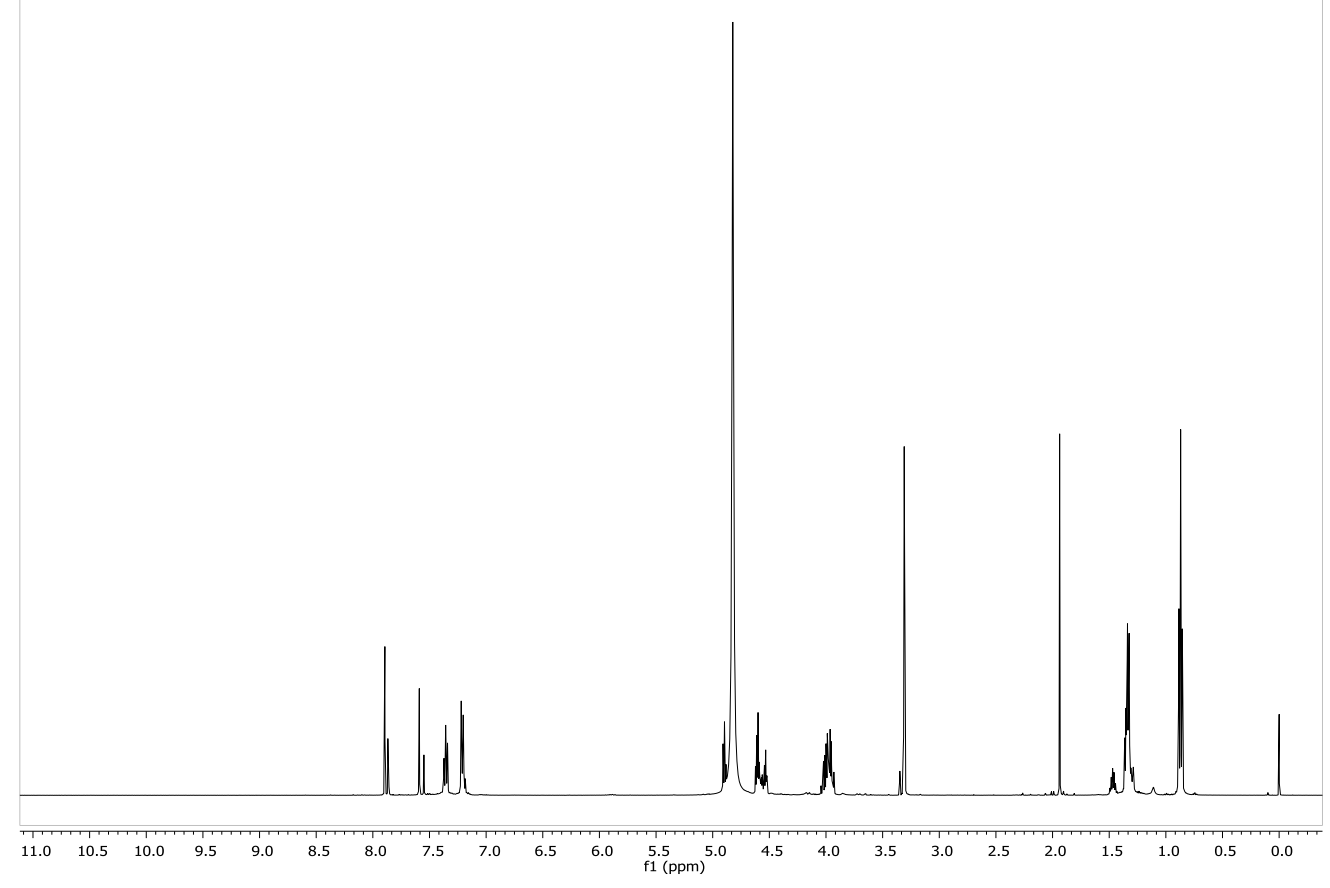

Figure $5.1^{1} \mathrm{H}$ NMR of Compound 36

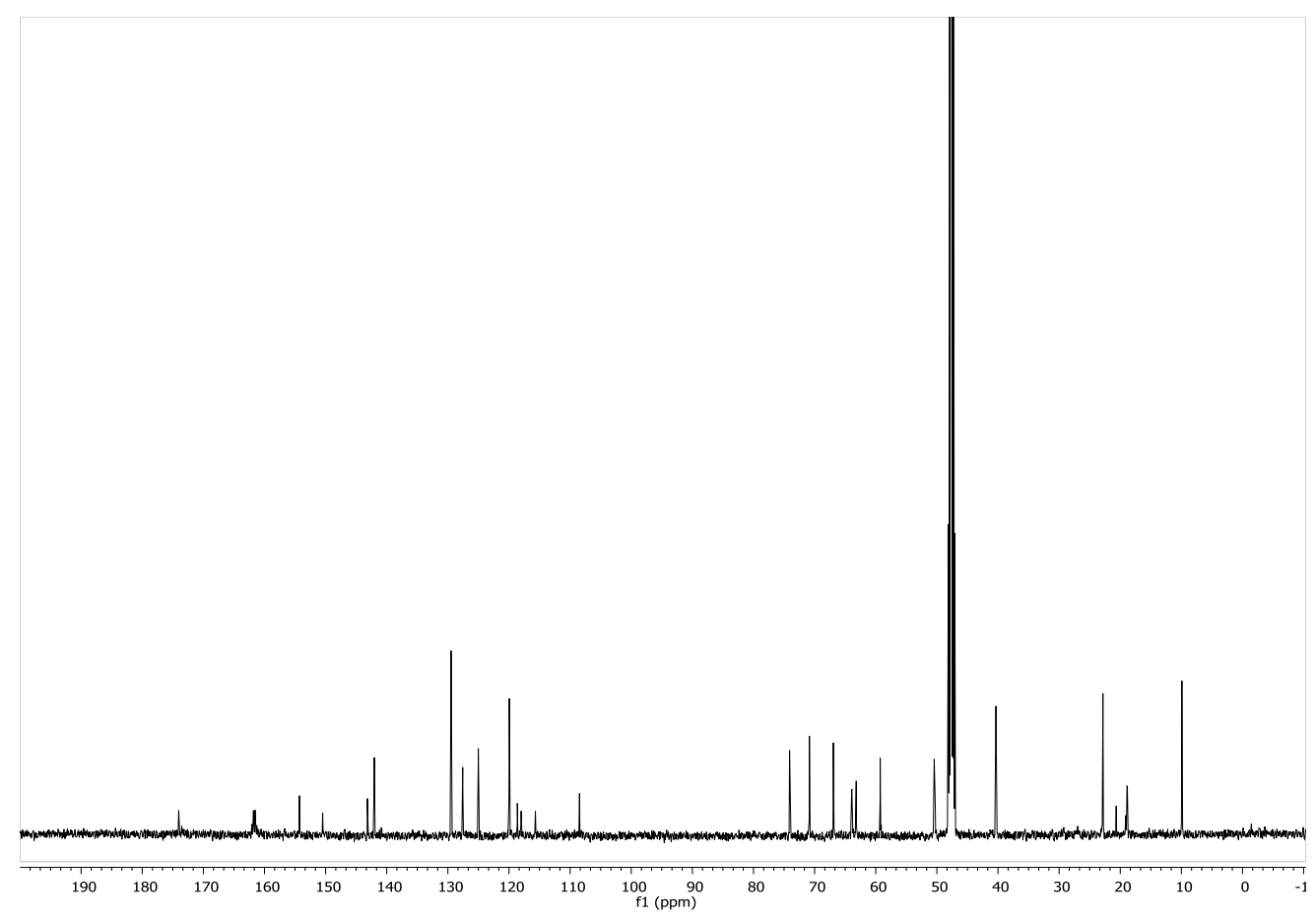

Figure $5.2{ }^{13} \mathrm{C}$ NMR of Compound 36 


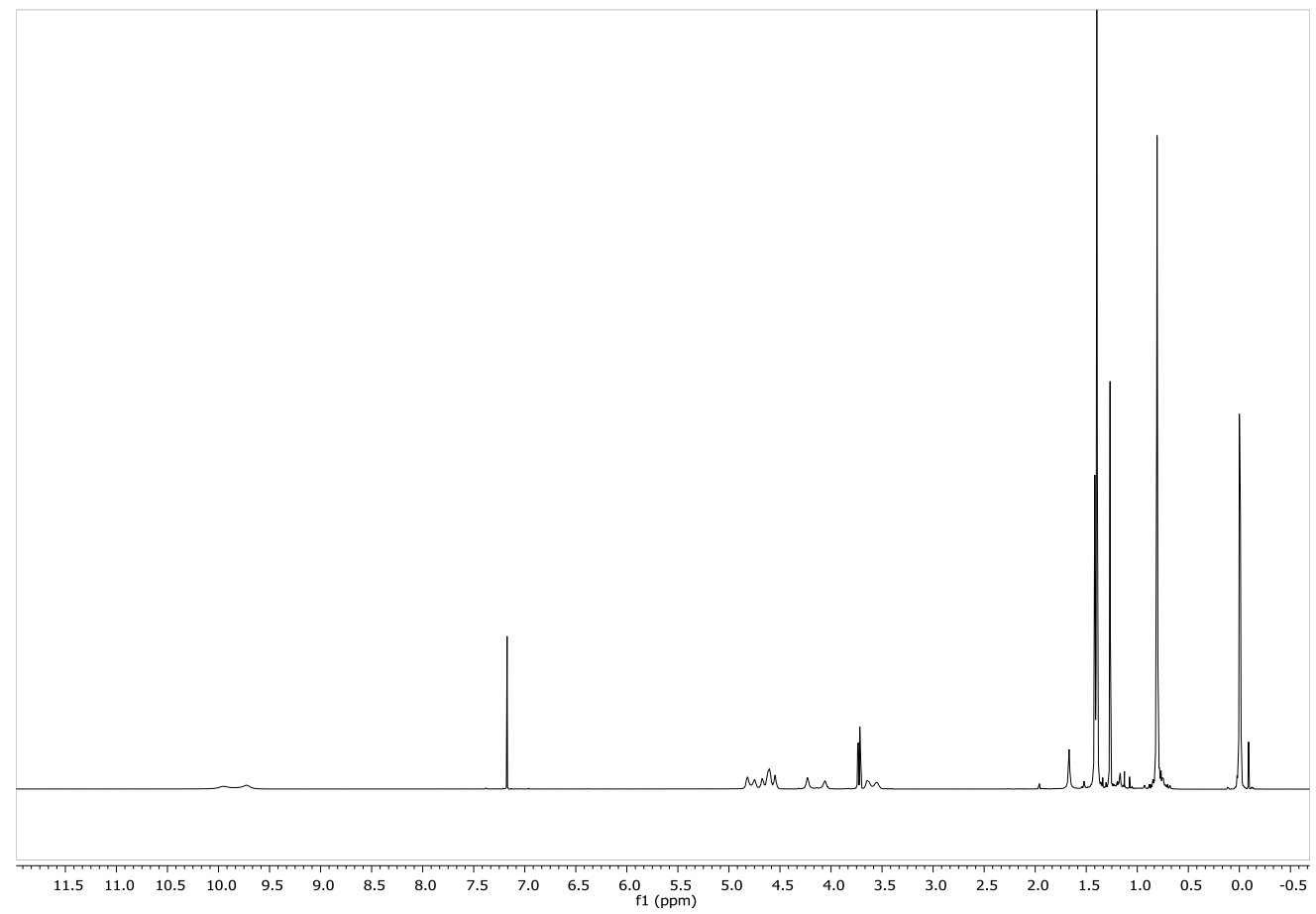

Figure $5.3^{1} \mathrm{H}$ NMR of Compound $\mathbf{5 0}$

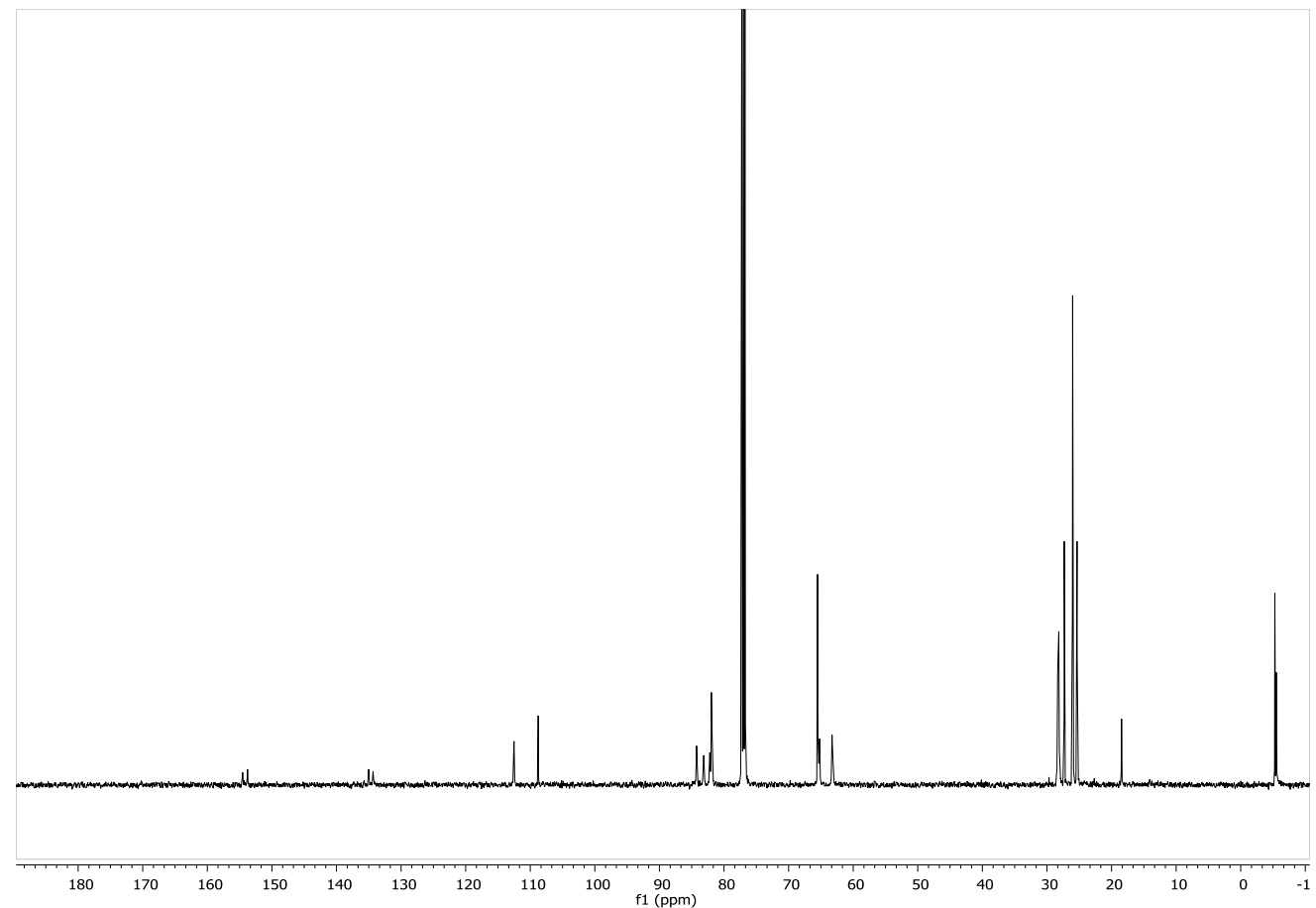

Figure $5.4{ }^{13} \mathrm{C}$ NMR of Compound $\mathbf{5 0}$ 


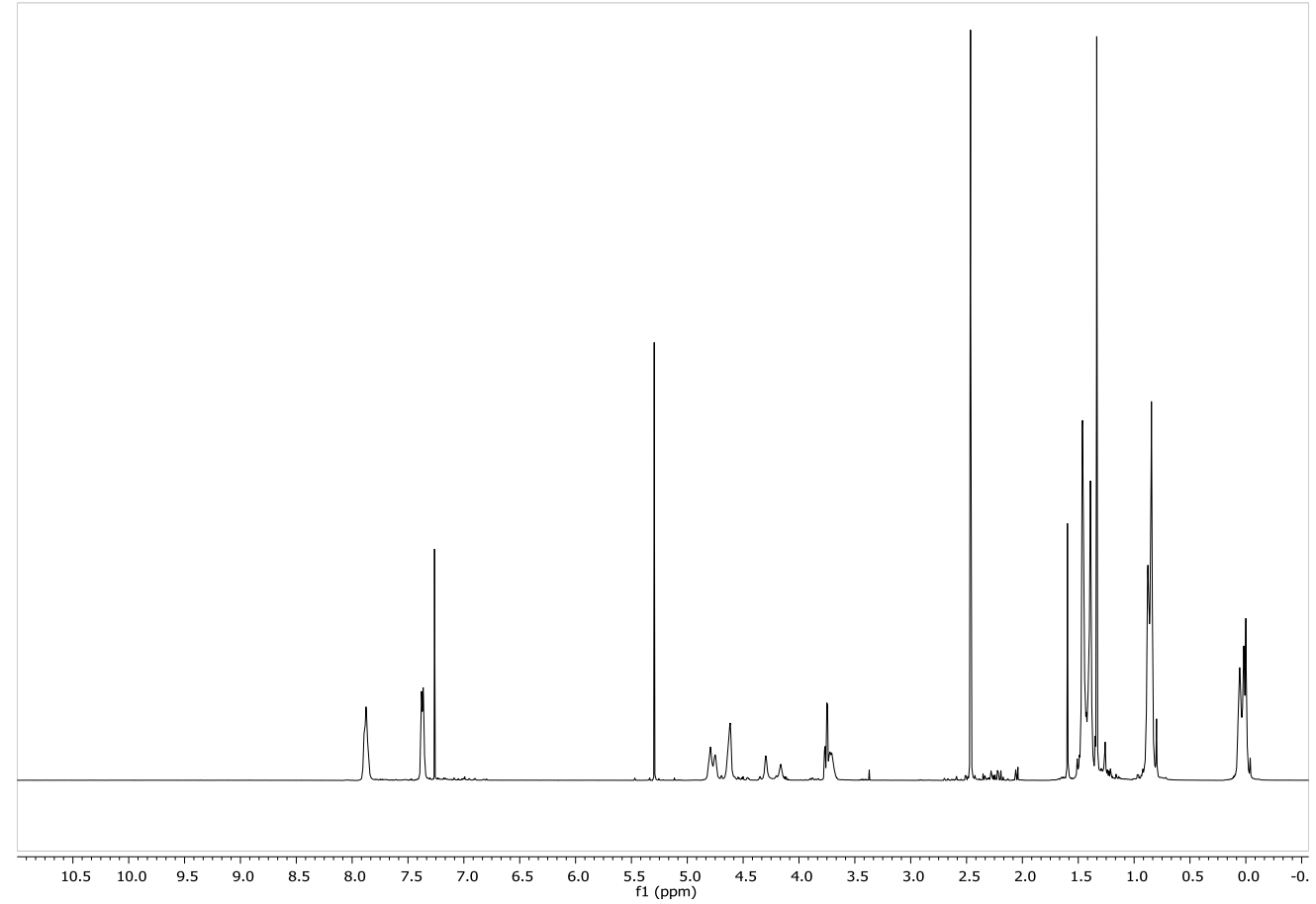

Figure $5.5^{1} \mathrm{H}$ NMR of Compound 51

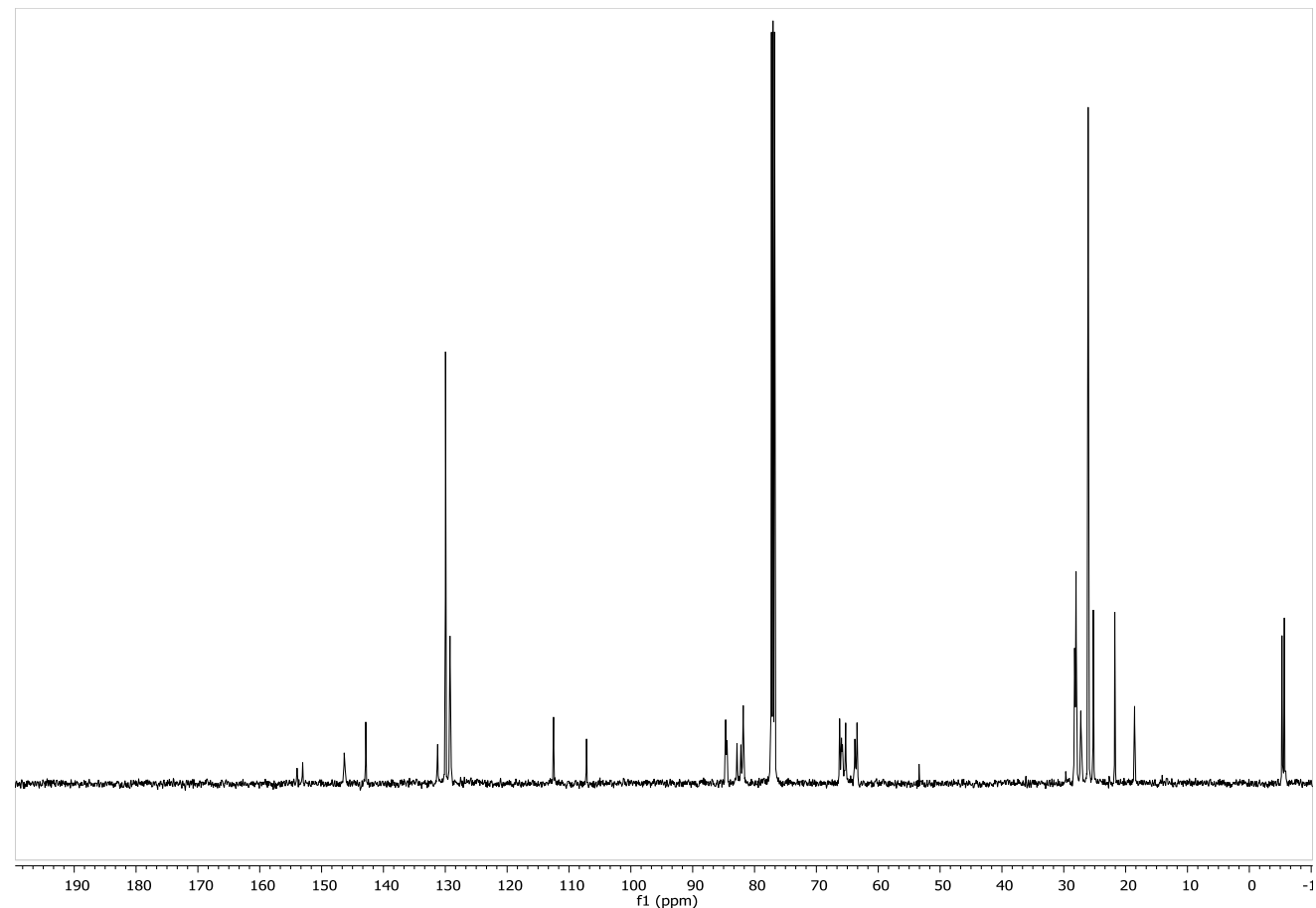

Figure 5.6 ${ }^{1} \mathrm{C}$ NMR of Compound 51 


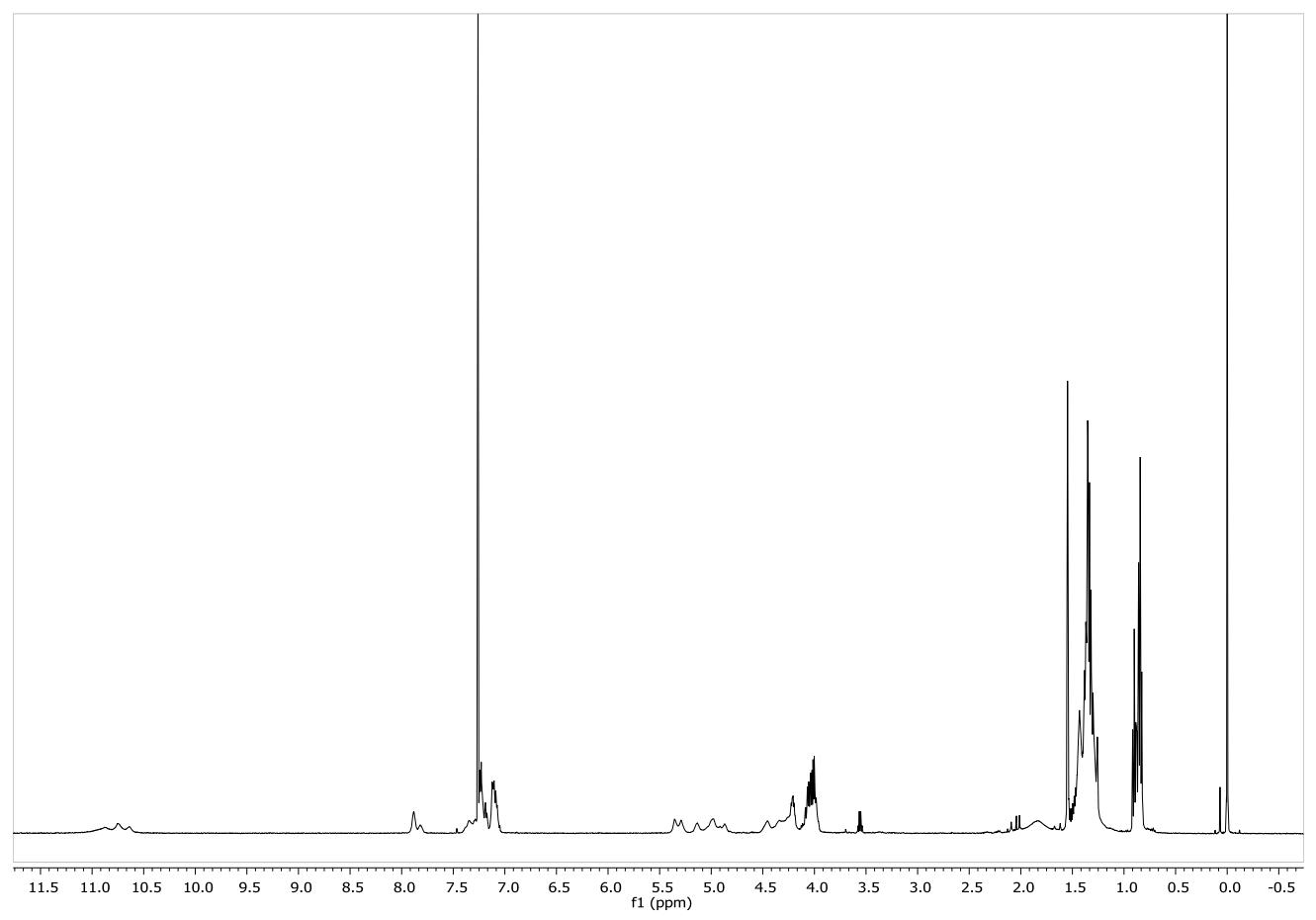

Figure $5.7^{1} \mathrm{H}$ NMR of Compound 72

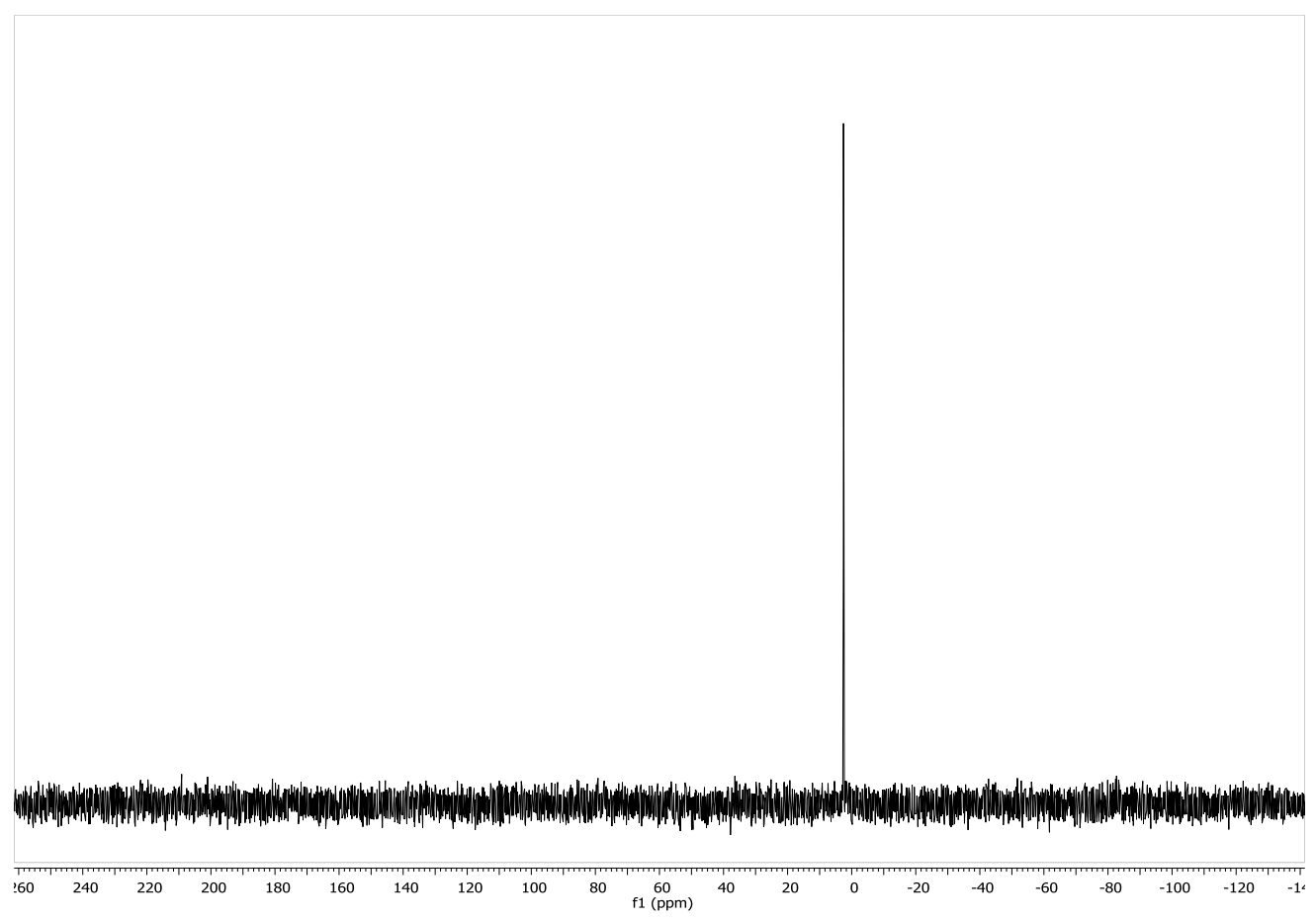

Figure $5.8^{13} \mathrm{P}$ NMR of Compound 72

Page 69 of 83 


\section{Appendix B New compound MS data}

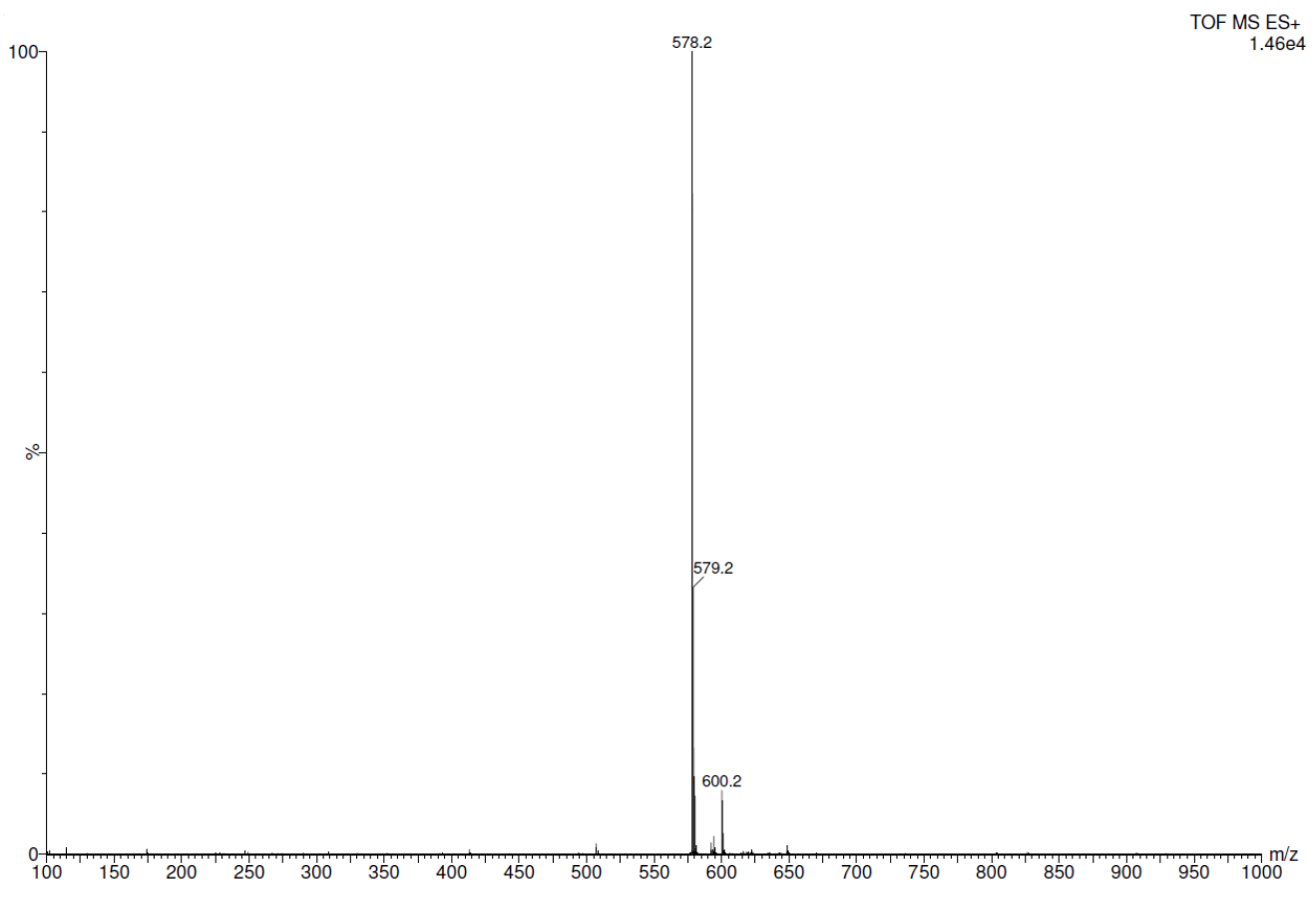

Figure 6.1 LRMS compound 36

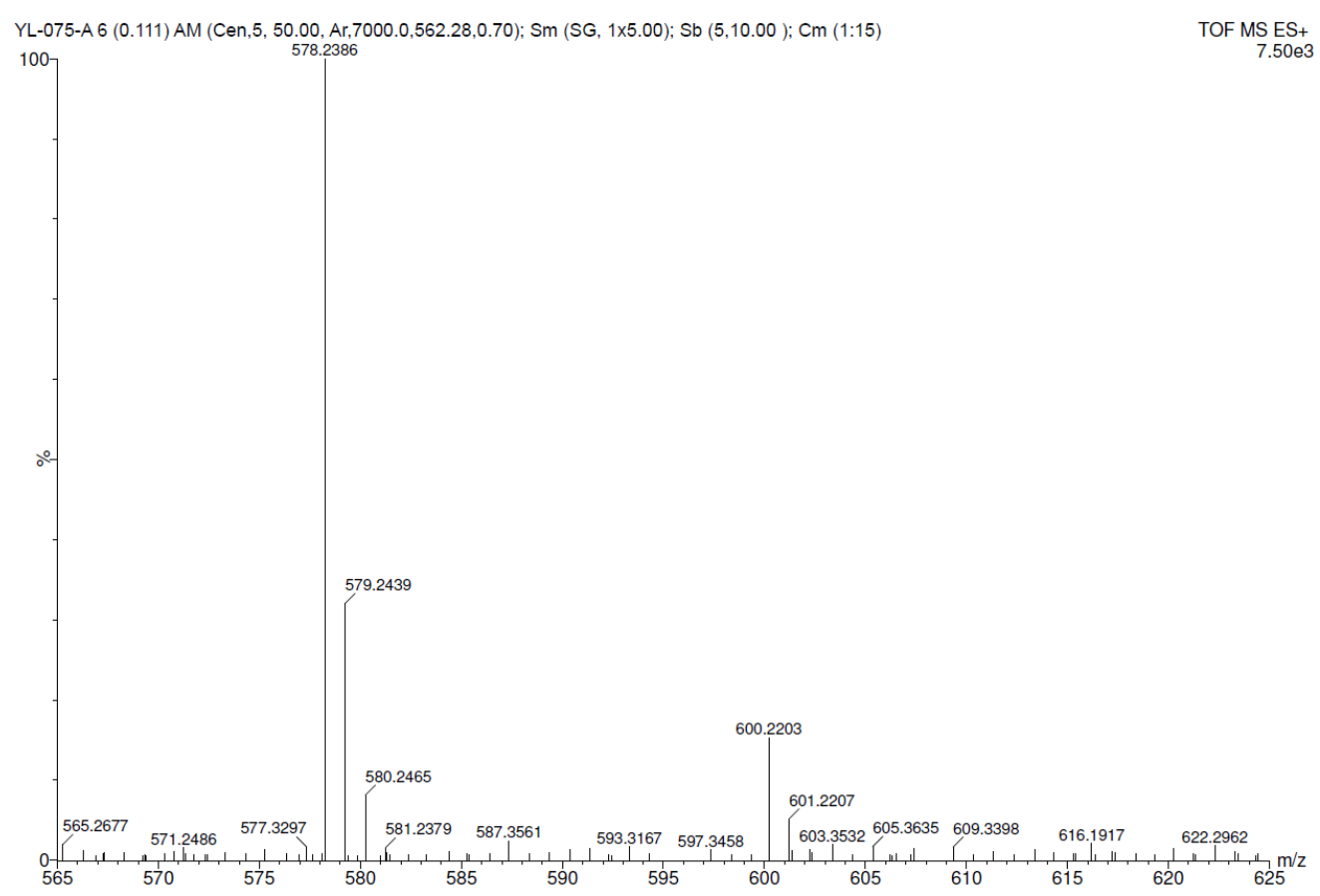

Figure 6.2 HRMS compound 36 


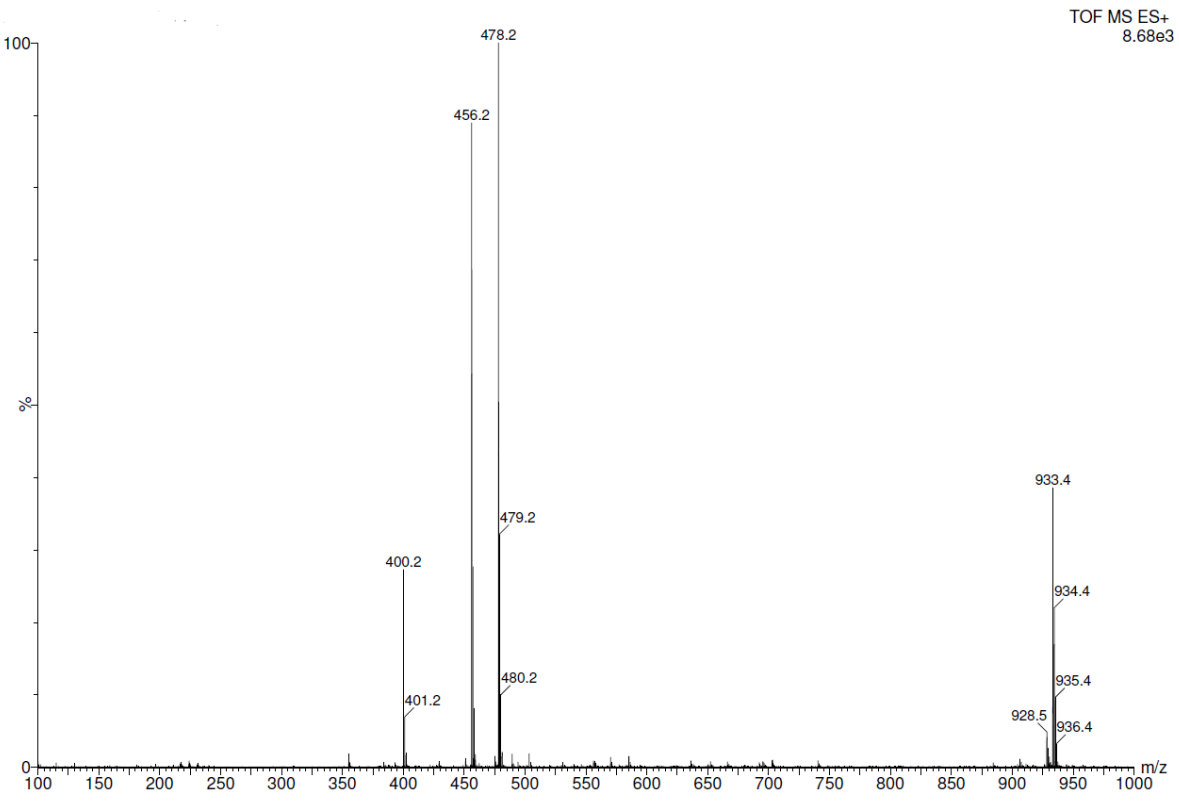

Figure 6.3 LRMS compound 50

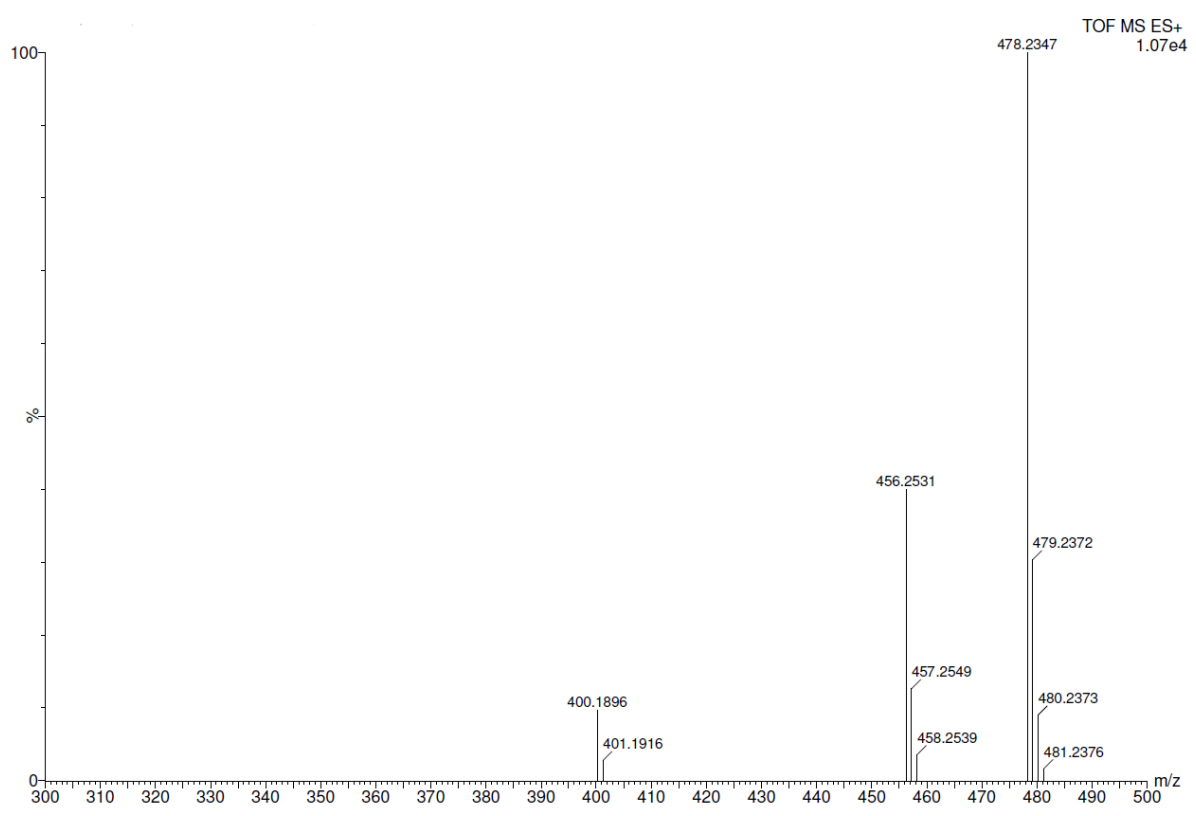

Figure 6.4 HRMS compound $\mathbf{5 0}$ 


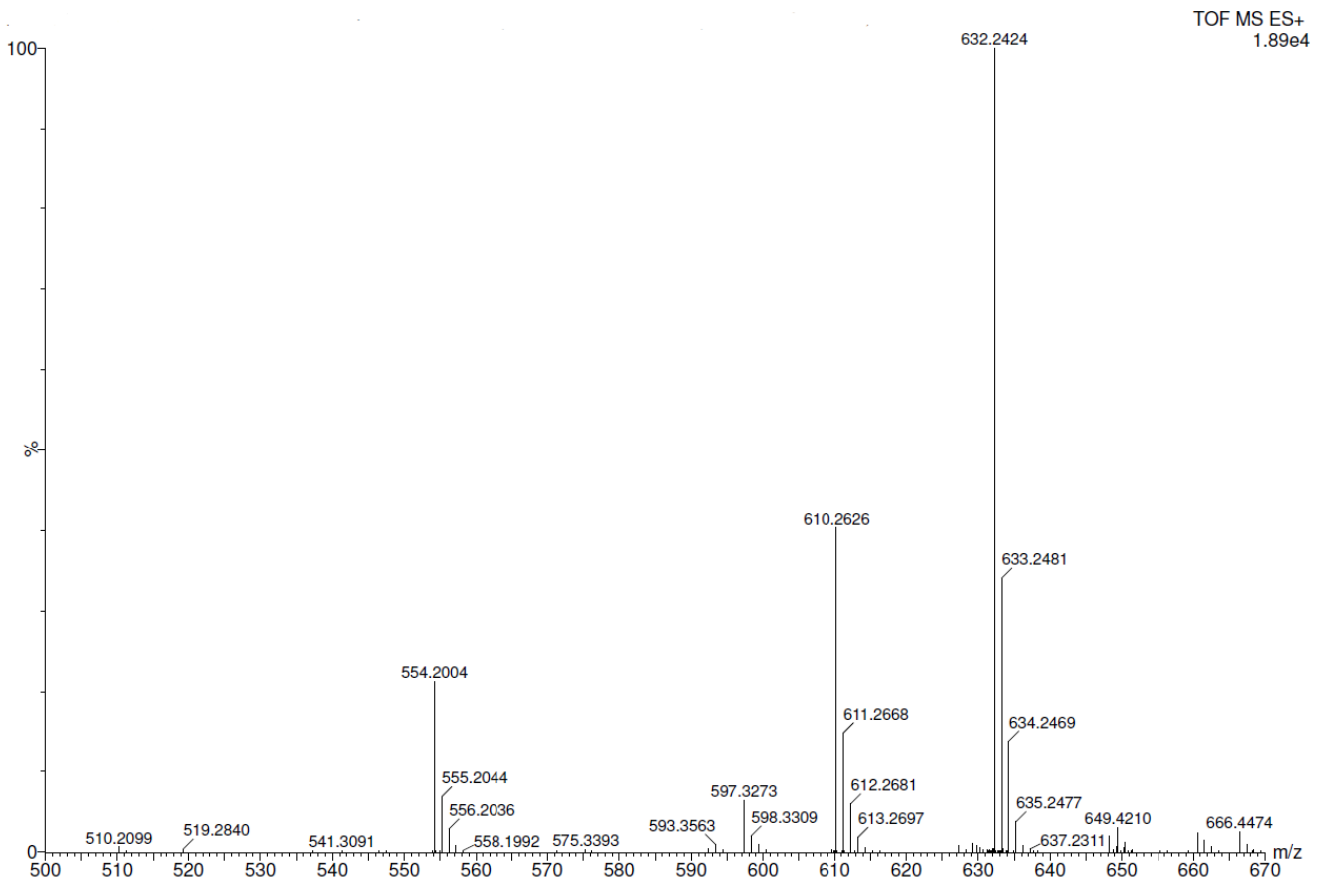

Figure 6.5 HRMS compound 51

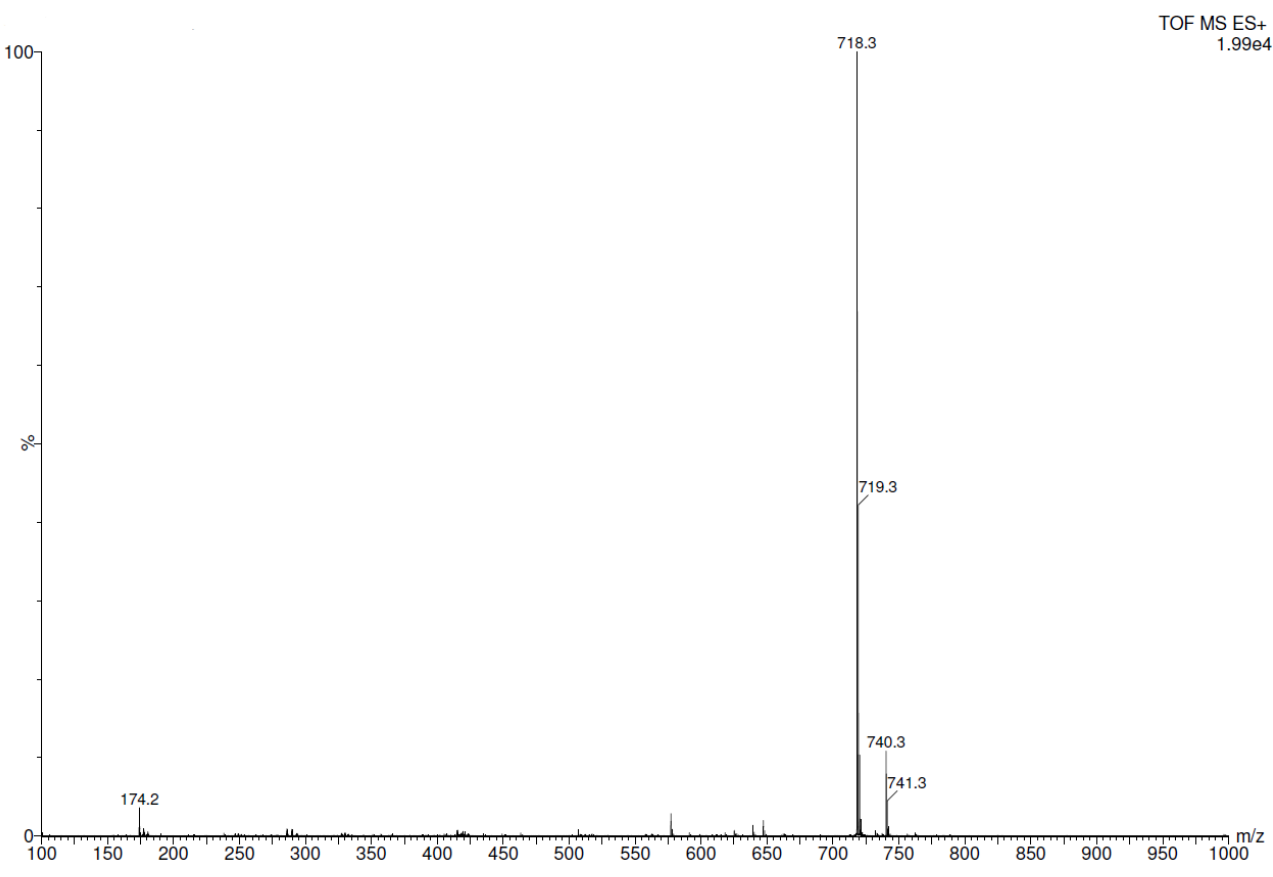

Figure 6.6 LRMS compound 72 


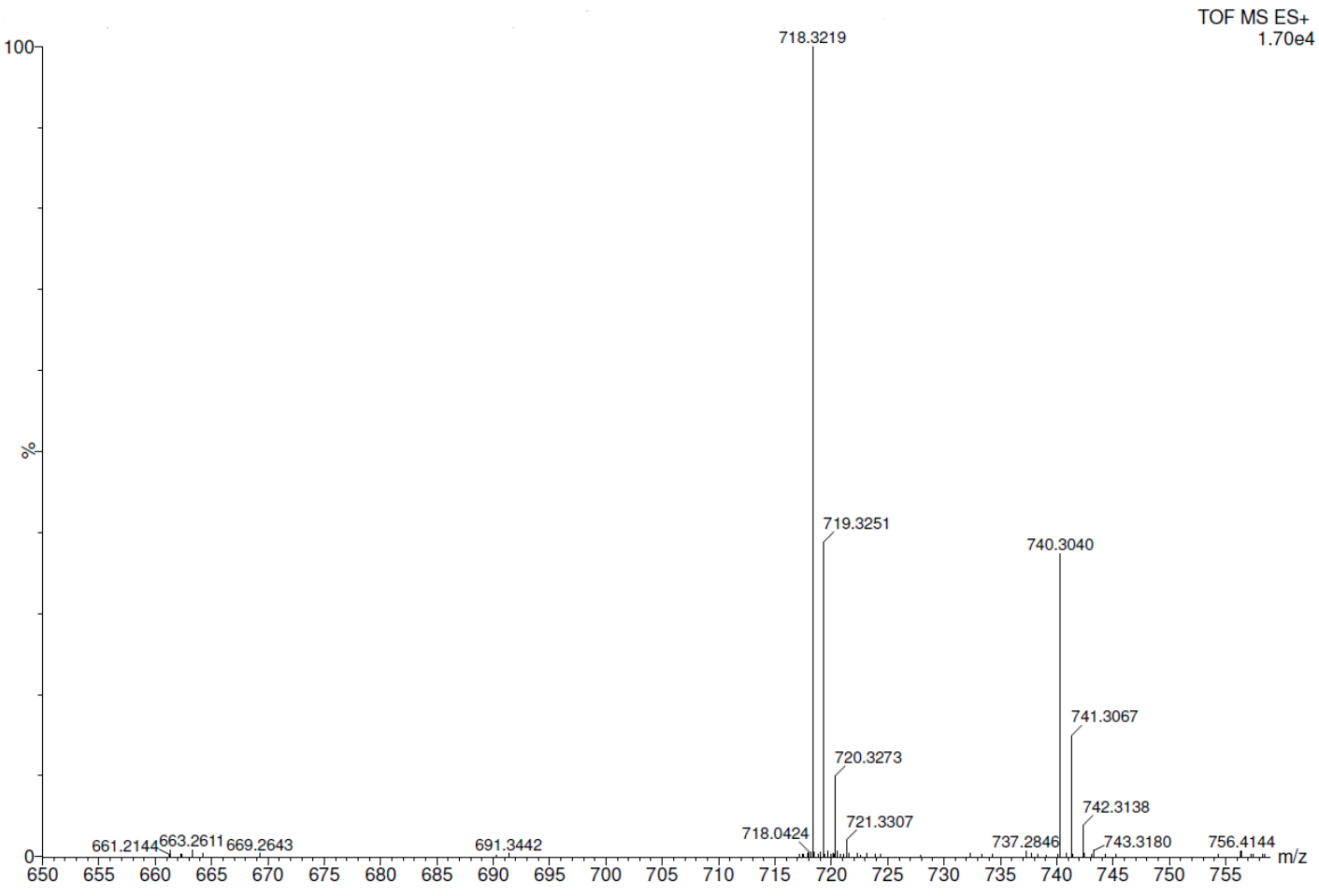

Figure 6.7 HRMS compound 72 


\section{Appendix C New compound HPLC data}
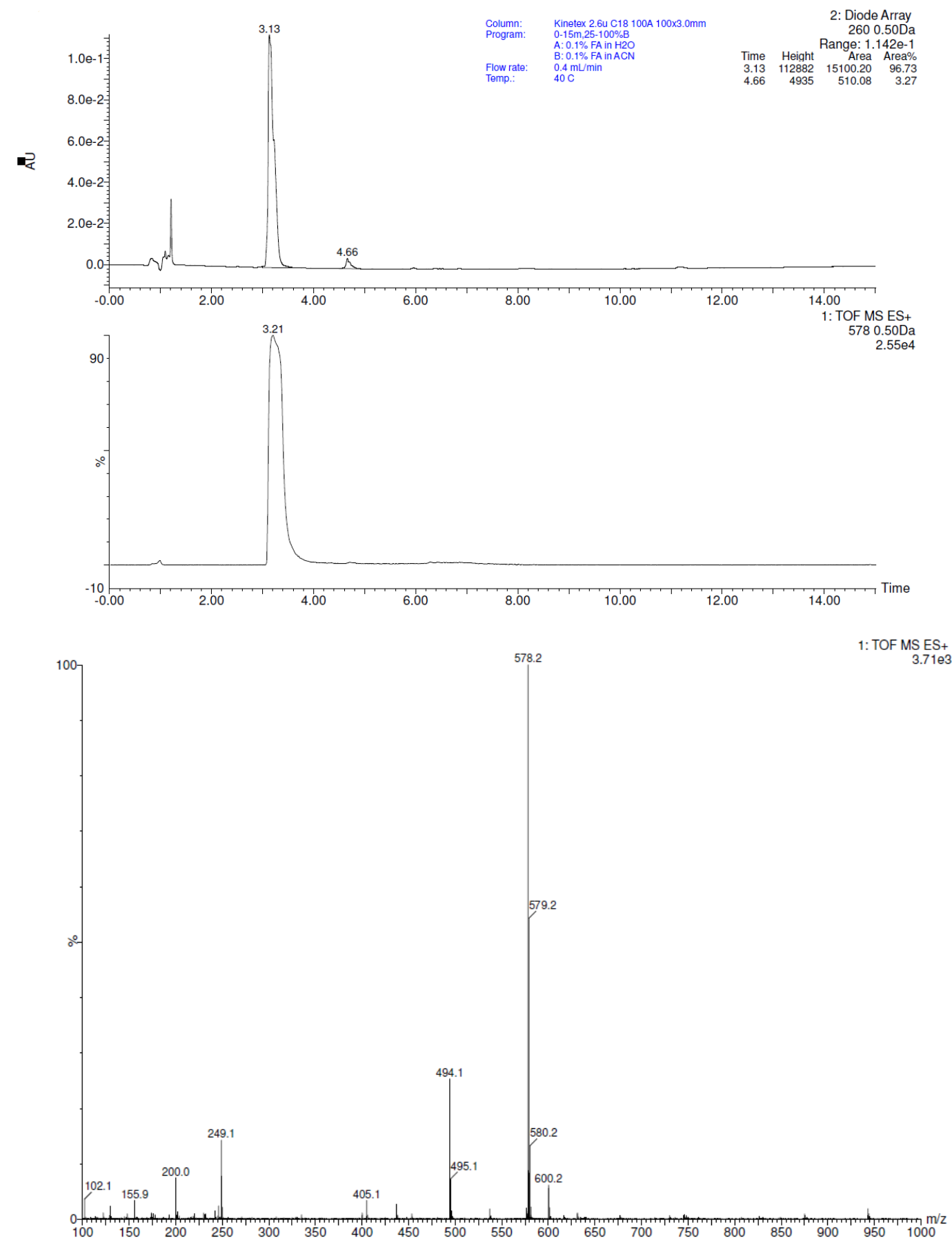


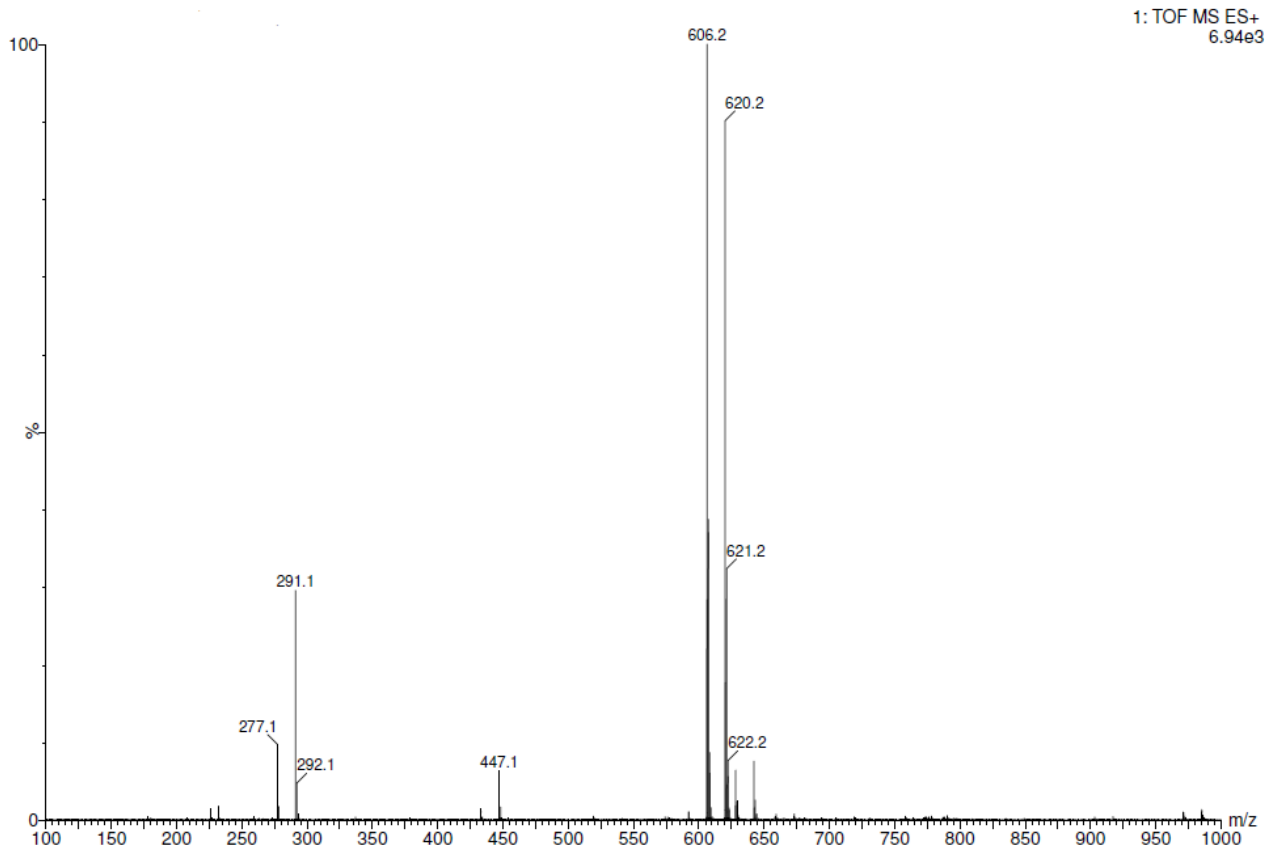

Figure 7.1 LCMS compound 36, LRMS at $3.13 \mathrm{~min}, 4.66 \mathrm{~min}$. 


\section{References}

1. Compain, P.; Martin, O. R., Iminosugars: from synthesis to therapeutic applications. John Wiley \& Sons: 2007.

2. Inouye, S.; Tsuruoka, T.; Ito, T.; Niida, T., Structure and synthesis of nojirimycin. Tetrahedron 1968, 24 (5), 2125-2144.

3. Ishida, N., et al., Nojirimycin, a new antibiotic. II. Isolation, characterization and biological activity. The Journal of antibiotics 1967, 20 (2), 66-71.

4. Paulsen, H.; Sangster, I.; Heyns, K., Monosaccharide mit stickstoffhaltigem Ring, XIII. Synthese und Reaktionen von Keto-piperidinosen. Chemische Berichte 1967, 100 (3), 802-815.

5. Paulsen, H.; Todt, K., Cyclic Monosaccharides having nitrogen or sulfur in the ring. Advances in Carbohydrate Chemistry 1968, 23, 115-232.

6. Stütz, A. E., Iminosugars as glycosidase inhibitors. Wiley-VCH: 1999.

7. Cipolla, L.; La Ferla, B.; Gregori, M., Combinatorial approaches to iminosugars as glycosidase and glycosyltransferase inhibitors. Combinatorial chemistry \& high throughput screening 2006, 9 (8), 571-582.

8. Compain, P.; Martin, O. R., Design, synthesis and biological evaluation of iminosugar-based glycosyltransferase inhibitors. Current topics in medicinal chemistry 2003, 3 (5), 541-560.

9. Fan, J.-Q., A contradictory treatment for lysosomal storage disorders: inhibitors enhance mutant enzyme activity. Trends in pharmacological sciences 2003, 24 (7), 355-360.

10. Fan, J.; Asano, N.; Suzuki, Y.; Ishii, S., Chemical chaperone therapy for Fabry disease, a genetic disorder. Glycoconjugate J 1999, 16, S156.

11. Singh, V., et al., Femtomolar transition state analogue inhibitors of $5^{\prime}$ methylthioadenosine/S-adenosylhomocysteine nucleosidase from Escherichia coli. Journal of Biological Chemistry 2005, 280 (18), 1826518273. 
12. Schramm, V. L., Transition States, Analogues, and Drug Development. ACS Chemical Biology 2013, 8 (1), 71-81.

13. Martin, O.; Compain, P., Iminosugars: Recent insights into their bioactivity and potential as therapeutic agents-Preface. Bentham Science, netherlands: 2003.

14. De Clercq, E., An Odyssey in antiviral drug development-50 years at the Rega Institute: 1964-2014. Acta Pharmaceutica Sinica B 2015, 5 (6), 520 543.

15. Cameron, C. E.; Götte, M.; Raney, K. D., Viral genome replication. Springer: 2009.

16. Jordheim, L. P.; Durantel, D.; Zoulim, F.; Dumontet, C., Advances in the development of nucleoside and nucleotide analogues for cancer and viral diseases. Nat Rev Drug Discov 2013, 12 (6), 447-464.

17. Carroll, S. S.; Olsen, D. B., Nucleoside Analog Inhibitors of Hepatitis C Virus Replication. Infectious Disorders - Drug TargetsDisorders) 2006, 6 (1), 17-29.

18. Chemical synthesis of nucleoside analogues. Merino, P., Ebrary, I., Eds. Hoboken, N.J. : Wiley: Hoboken, N.J., 2013.

19. Romeo, G.; Chiacchio, U.; Corsaro, A.; Merino, P., Chemical Synthesis of Heterocyclic- Sugar Nucleoside Analogues. Chemical reviews 2010, 110 (6), 3337-3370.

20. Martinez, J. P., et al., Antiviral drug discovery: broad-spectrum drugs from nature. Natural Product Reports 2015, 32 (1), 29-48.

21. Simmons, C. P., et al., Therapeutics for Dengue: Recommendations for Design and Conduct of Early-Phase Clinical Trials. PLoS Negl Trop Dis 2012, 6 (9), e1752.

22. World Health Organization. End of Ebola transmission in Guinea and Liberia. $\quad$ http://www.who.int/csr/disease/ebola/top-stories-2016/en/, accessed in Feb. 2017. 
23. Izawa, K., et al., Small-Molecule Therapeutics for Ebola Virus (EBOV) Disease Treatment. European Journal of Organic Chemistry 2016, 2016 (1), 8-16.

24. Richman, D. D., HIV Chemotherapy. Nature 2001, 410 (6831), 995-1001.

25. Stella, V. J.; Charman, W. N. A.; Naringrekar, V. H., Prodrugs. Drugs 1985, 29 (5), 455-473.

26. Van Rompay, A. R.; Johansson, M.; Karlsson, A., Phosphorylation of nucleosides and nucleoside analogs by mammalian nucleoside monophosphate kinases. Pharmacology \& therapeutics 2000, 87 (2), 189198.

27. Pradere, U., et al., Synthesis of Nucleoside Phosphate and Phosphonate Prodrugs. Chemical Reviews 2014, 114 (18), 9154-9218.

28. Mehellou, Y., The ProTides Boom. ChemMedChem 2016, 11 (11), 11141116.

29. Ora, M.; Ojanperä, J.; Lönnberg, H., Hydrolytic Reactions of Thymidine 5' - O - Phenyl - N - Alkylphosphoramidates, Models of Nucleoside 5' Monophosphate Prodrugs. Chemistry - A European Journal 2007, 13 (30), 8591-8599.

30. Van Boom, J., et al., Phosphorylation of nucleoside derivatives with aryl phosphoramidochloridates. Tetrahedron 1975, 31 (23), 2953-2959.

31. Uchiyama, M.; Aso, Y.; Noyori, R.; Hayakawa, Y., O-Selective phosphorylation of nucleosides without $\mathrm{N}$-protection. The Journal of Organic Chemistry 1993, 58 (2), 373-379.

32. Donghi, M., et al., Synthesis and evaluation of novel phosphoramidate prodrugs of $2^{\prime}$-methyl cytidine as inhibitors of hepatitis C virus NS5B polymerase. Bioorganic \& medicinal chemistry letters 2009, 19 (5), 13921395.

33. Nillroth, U., et al., Specific interaction between HIV-1 proteinase and 5'phosphate peptidomimetic derivatives of nucleoside analogues. Drug 
design and discovery 1995, 13 (1), 43-54.

34. Cihlar, T.; Ray, A. S., Nucleoside and nucleotide HIV reverse transcriptase inhibitors: 25 years after zidovudine. Antiviral Research 2010, 85 (1), 3958.

35. Wilson, R. H., Novel Therapeutic Developments Other Than EGFR and VEGF Inhibition in Colorectal Cancer. The Oncologist 2006, 11 (9), 10181024.

36. Mehellou, Y.; Balzarini, J.; McGuigan, C., Aryloxy phosphoramidate triesters: a technology for delivering monophosphorylated nucleosides and sugars into cells. ChemMedChem 2009, 4 (11), 1779-1791.

37. Roman, C. A.; Balzarini, J.; Meier, C., Diastereoselective synthesis of aryloxy phosphoramidate prodrugs of $3^{\prime}-\operatorname{deoxy}-2^{\prime}, 3^{\prime}-$ didehydrothymidine monophosphate. J. Med. Chem 2010, 53 (21), 76757681.

38. McGuigan, C., et al., Design, synthesis and evaluation of a novel double pro-drug: INX-08189. A new clinical candidate for hepatitis C virus. Bioorganic \& Medicinal Chemistry Letters 2010, 20 (16), 4850-4854.

39. Gentile, I.; Buonomo, A. R.; Zappulo, E.; Borgia, G., Interferon-free therapies for chronic hepatitis $\mathrm{C}$ : toward a hepatitis $\mathrm{C}$ virus-free world? Expert Review of Anti-infective Therapy 2014, 12 (7), 763-773.

40. De Clercq, E., Current race in the development of DAAs (direct-acting antivirals) against HCV. Biochemical Pharmacology 2014, 89 (4), 441-452.

41. Cada, D. J.; Cong, J.; Baker, D. E., Formulary drug reviews: Sofosbuvir. Hospital Pharmacy 2014, 49 (5), 466-478.

42. Kapczynski, A.; Kesselheim, A. S., 'Government Patent Use': A Legal Approach To Reducing Drug Spending. Health Affairs 2016, 35 (5), 791797.

43. Warren, T. K., et al., Therapeutic efficacy of the small molecule GS-5734 against Ebola virus in rhesus monkeys. Nature 2016, 531 (7594), 381-385. 
44. Lee, W. A., et al., Selective Intracellular Activation of a Novel Prodrug of the Human Immunodeficiency Virus Reverse Transcriptase Inhibitor Tenofovir Leads to Preferential Distribution and Accumulation in Lymphatic Tissue. Antimicrobial Agents and Chemotherapy 2005, 49 (5), 1898-1906.

45. Slusarczyk, M., et al., Application of ProTide Technology to Gemcitabine: A Successful Approach to Overcome the Key Cancer Resistance Mechanisms Leads to a New Agent (NUC-1031) in Clinical Development. Journal of Medicinal Chemistry 2014, 57 (4), 1531-1542.

46. Wuts, P. G.; Greene, T. W., Greene's protective groups in organic synthesis. John Wiley \& Sons: 2006.

47. Sofia, M. J., et al., Discovery of a $\beta-d-2^{\prime}$-Deoxy-2' - $\alpha$-fluoro-2' $-\beta-C-$ methyluridine Nucleotide Prodrug (PSI-7977) for the Treatment of Hepatitis C Virus. Journal of Medicinal Chemistry 2010, 53 (19), 7202-7218.

48. Evans, G. B., et al., Synthesis of second-generation transition state analogues of human purine nucleoside phosphorylase. Journal of medicinal chemistry 2003, 46 (24), 5271-5276.

49. Evans, G. B., et al., 8-Aza-immucillins as Transition-State Analogue Inhibitors of Purine Nucleoside Phosphorylase and Nucleoside Hydrolases. Journal of Medicinal Chemistry 2003, 46 (1), 155-160.

50. Bantia, S.; Kotian, P. L.; Babu, Y. S., Methods and compositions for inhibition of polymerase. Google Patents: 2012.

51. Kotian, P. L.; Babu, Y. S., Compositions and methods for inhibiting viral polymerase. Google Patents: 2013.

52. Sheridan, W. P.; Bantia, S.; Kotian, P. L.; Babu, Y. S., Anti-influenza compositions and methods. Google Patents: 2014.

53. Evans, G. B., et al., Synthesis of Transition State Analogue Inhibitors for Purine Nucleoside Phosphorylase and N-Riboside Hydrolases. Tetrahedron 2000, 56 (19), 3053-3062.

54. Schramm, V. L., Development of transition state analogues of purine 
nucleoside phosphorylase as anti-T-cell agents. Biochimica et Biophysica Acta (BBA)-Molecular Basis of Disease 2002, 1587 (2), 107-117.

55. Miles, R. W., et al., One-third-the-sites transition-state inhibitors for purine nucleoside phosphorylase. Biochemistry 1998, 37 (24), 8615-8621.

56. Hernández, D.; Boto, A., Nucleoside analogues: Synthesis and biological properties of azanucleoside derivatives. European Journal of Organic Chemistry 2014, 2014 (11), 2201-2220.

57. Shelton, J., et al., Metabolism, Biochemical Actions, and Chemical Synthesis of Anticancer Nucleosides, Nucleotides, and Base Analogs. Chemical Reviews 2016, 116 (23), 14379-14455.

58. World Health Organization. Potential Ebola therapies and vaccines. http://www.who.int/csr/resources/publications/ebola/potential-therapiesvaccines/en, accessed in Feb. 2017.

59. Warren, T. K., et al., Protection against filovirus diseases by a novel broadspectrum nucleoside analogue BCX4430. Nature 2014, 508 (7496), 4025.

60. Julander, J. G., et al., BCX4430, a Novel Nucleoside Analog, Effectively Treats Yellow Fever in a Hamster Model. Antimicrobial Agents and Chemotherapy 2014, 58 (11), 6607-6614.

61. B Evans, G.; L Schramm, V.; C Tyler, P., The Immucillins: Design, Synthesis and Application of Transition-State Analogues. Current Medicinal Chemistry 2015, 22 (34), 3897-3909.

62. Taylor, R., et al., BCX4430 - A broad-spectrum antiviral adenosine nucleoside analog under development for the treatment of Ebola virus disease. Journal of Infection and Public Health 2016, 9 (3), 220-226.

63. Julander, J. G., et al., Efficacy of the broad-spectrum antiviral compound BCX4430 against Zika virus in cell culture and in a mouse model. Antiviral Research 2017, 137, 14-22.

64. Fleet, G. W. J.; Son, J. C., Polyhydroxylated pyrrolidines from sugar Page 81 of 83 
lactomes: Synthesis of 1,4-dideoxy-1,4-imino-d-glucitol from dgalactonolactone and syntheses of 1,4-dideoxy-1,4-imino-d-allitol, 1,4dideoxy-1,4-imino- $d$-ribitol, and $(2 s, 3 r, 4 s)$-3,4-dihydroxyproline from $d$ gulonolactone. Tetrahedron 1988, 44 (9), 2637-2647.

65. Wamhoff, H.; Berressem, R.; Nieger, M., Efficient synthesis of fused isothiazole C-nucleosides. 1. Synthesis of a 3-. beta.-Dribofuranosylisothiazolo [4, 5-d] pyrimidin-7 $(6 \mathrm{H})$-one isostere of inosine. The Journal of Organic Chemistry 1993, 58 (19), 5181-5185.

66. Horenstein, B. A.; Zabinski, R. F.; Schramm, V. L., A new class of Cnucleoside analogues. 1-(S)-aryl-1,4-dideoxy-1,4-imino-D-ribitols, transition state analogue inhibitors of nucleoside hydrolase. Tetrahedron Letters 1993, 34 (45), 7213-7216.

67. Evans, G. B., et al., Addition of Lithiated 9-Deazapurine Derivatives to a Carbohydrate Cyclic Imine: Convergent Synthesis of the Aza-Cnucleoside Immucillins. The Journal of Organic Chemistry 2001, 66 (17), 5723-5730.

68. Process for manufacture of forodesine, http://www.google.com/patents/WO2016110527A1?cl=en. Google Patents: 2016.

69. Kini, G. D.; Hennen, W. J.; Robins, R. K., Synthesis of 2-(4-amino-4-deoxy-. beta.-D-ribofuranosyl) thiazole-4-carboxamide, a carbon-linked nucleoside with a free pyrrolidine sugar. The Journal of Organic Chemistry 1986, 51 (23), 4436-4439.

70. Wamhoff, H.; Berressem, R.; Nieger, M., Efficient Synthesis of Fused Isothiazole C-Nucleosides. 2. Synthesis of 8-Aza-7, 9-deaza-7thiaguanosine and 8-Aza-7, 9-deaza-7-thiaadenosine. The Journal of Organic Chemistry 1994, 59 (7), 1912-1917.

71. Just, G.; Donnini, G. P., C-Nucleosides and related compounds. XIV. The synthesis of a nitrogen analogue of showdomycin. Canadian Journal of 
Chemistry 1977, 55 (16), 2998-3006.

72. Babu, Y. S., et al., Antiviral azasugar-containing nucleosides. Google Patents: 2014.

73. Evans, G. B., et al., Imino-C-nucleoside Synthesis: Heteroaryl Lithium Carbanion Additions to a Carbohydrate Cyclic Imine and Nitrone. The Journal of Organic Chemistry 2004, 69 (6), 2217-2220.

74. Oxley, J. C.; Brady, J.; Wilson, S. A.; Smith, J. L., The risk of mixing dilute hydrogen peroxide and acetone solutions. Journal of Chemical Health and Safety 2012, 19 (2), 27-33.

75. Murray, R. W.; Iyanar, K.; Chen, J.; Wearing, J. T., Synthesis of Nitrones Using the Methyltrioxorhenium/Hydrogen Peroxide System. The Journal of Organic Chemistry 1996, 61 (23), 8099-8102.

76. Stappers, F., et al., Development of a Safe and Scalable Amine-to-Nitrone Oxidation: A Key Step in the Synthesis of R107500. Organic Process Research \& Development 2002, 6 (6), 911-914.

77. Derudas, M., et al., The Application of Phosphoramidate Protide Technology to Acyclovir Confers Anti-HIV Inhibition. Journal of Medicinal Chemistry 2009, 52 (17), 5520-5530. 